\title{
Die Entwicklung isolierter dorsaler und lateraler Gastrula- hiilften von Triton taeniatus und alpestris, ihre Regulation und Postgeneration.
}

\author{
Von \\ Gudrun Ruud und Hans Spemann \\ (Kristiania) (Freiburg i. B.). \\ Mitgeteilt von H. Spemann. \\ Mit 76 Textabbildungen.. \\ (Eingegangen am 17. März 1922.)
}

Inhaltsiibersicht.

I. Einleitung. Material und Methode . . . . . . . . . . 95-102

II. Die Regulation der dorsalen Keimhalfte nach frontaler Durchtrennung während der Gastrulation . . . . . . . . . . 102-114

a) Durchtrennung zu Beginn der Gastrulation ....... 104

b) Durchtrennung zu Ende der Gastrulation . . . . . . . . 107

c) Nähere Bestimmung des Zeitpunkts der Determination . . 110

III. Die Postgeneration der seitlichen Keimhälften nach medianer Durchtrennung zu Beginn der Gastrulation . . . . . . . . 114-158

a) Die typische Entwicklung der Keimhälften bis zum Neurulastadium .................. . 115-128

b) Diskussion der Ergebnisse im Vergleich mit älteren Versuchen an Amphibien und Echinodermen . . . . . . 129-142 (Rouxs Hemiembryonen mit Postgeneration der fehlenden Seite, S. 129, der sekundäre Medullarwulst der Halbembryonen nach unvollkommenem Urmundschluß und das sekun. däre Medullarrohr bei janusartigen Doppelbildungen, S. 132 die Symmetrieverhältnisse der $Z$ willinge und Doppelbildungen yon Echinodermenlarven, S. 138.)

c) Die spätere Entwicklung der Zwillingslarven . . . . . . . 142-154

1. Bildung eines sekundären Schwänzchens bei verspätetem

Urmundschluß . . . . . . . . . . . . . . 143

2. Das Verhalten der Flossensäume ........... 150

d) Die Postgeneration der innenständigen Seite . . . . . 155-158

IV. Der Situs inversics des rechten Zwillings . . . . . . . . . 159-162

V. Zusammenfassung der Ergebnisse. . . . . . . . . 162-165

VI. Literaturverzeichnis . . . . . . . . . . . 165

\section{Einleitung. Material und Methode.}

Die Eier von Triton taeniatus gehöron bekanntlich zu den ersten, an welchen die Fähigkeit der beiden ersten Blastomeren, voneinander getrennt einen vollständigen Embryo zu bilden, genauer studiert wurde. Dabei zeigte sich eine merkwürdige Verschiedenheit im Ergebnis. Entweder liefern die Zellen, innerhalb der Eihüllen mittels einer Haar- 
schlinge auseinandergeschnürt, beide einen Embryo von halber Größe und anscheinend normalen Proportionen, oder aber tut das nur die eine von ihnen, während die andere zu einem rundlichen, teilweise ausgehöhlten Keimstück wird, in welchein wohl die drei Keimblätter voneinander gesondert, Organe aber nicht angelegt sind. Die Erklärung für dieses verschiedene Verhalten liefert ein anderer Versuch, bei dem die Eier längs der ersten Furchungsebene nur eingeschnürt, nicht durchgeschnürt werden. Wenn dann mit Auftreten des Urmundes die Medianebeno des Keimes erkennbar wird, so zeigt sich, daß sie, von selteneren Unregelmäßigkeiten abgesehen, entweder mit der Schnürungsebene zusammenfällt oder senkrecht auf ihr steht (Abb. 1 und 2); und wenn später die Medullarplatte scharf umgrenzt ist, so liegt sie entweder symmetrisch unter der Ligatur oder aber senkrecht zu ihr auf der einen

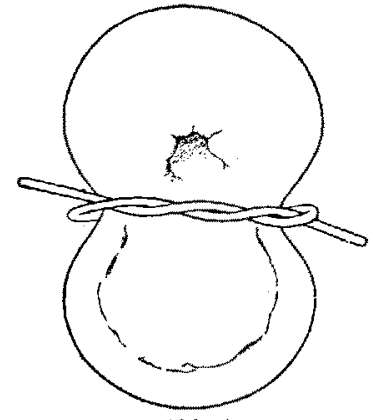

Abb. 1.

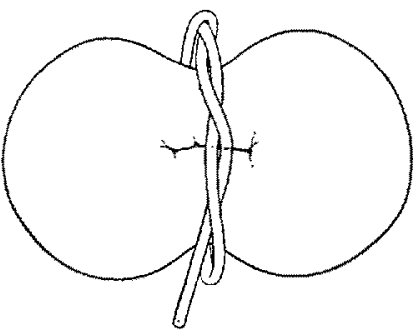

Abb. 2.

Abb. 1 und 2. Keime ron Triton taenialus zu Beginn der Gastrulation; im Zweizellenstadium eingeschnürt, längs der ersten Furche, welche der Medianebene (Abb. 2) oder einer transversalen Ebene $(\mathrm{Abb}, 1)$ entspricht. Vergr. $\times 20$.

Keimhälfte. Bei schwacher Einschnürung können in beiden Fällen normale Embryonen entstehen; bei stärkerer medianer Einschnürung wird das Vorderende verdoppelt, versehieden weit je nach dem Grade der Schnürung, bei stärkerer frontaler Einschnürung entsteht ein Embryo mit großem anhängendem "Dottersack "; bei stärkster medianer oder frontaler Einschnürung endlich trennen sich die beiden Keimhälften während der Gastrulation vollständig voneinander, indem der sie zuerst verbindende Dotterstiel von den zusammenrückenden Urmundlippen abgezwiokt wird, und es entstehen zwei vollständige Embryonen, bzw. ein solcher und ein rundliches Bauchstück. Danach kann es nicht zweifelhaft sein, daß die verschiedenartigen Potenzen der beiden ersten Furchungszellen, wie der Durchschnürungsversuch sie kennen lehrt, auf die verschiedene Bedeutung der ersten Furchungsebene zurückzuführen sind; diese entspricht entweder der späteren Medianebene des Keimes oder aber einer frontalen Ebene, welche im wesentlichen dorsale und ventrale Keimhälfte voneinander trennt (Spemann 1901-1903). 
und lateraler Gastrulahälften von Triton taeniatus und alpestris usw. 97

Die Unfähigkeit der ventralen Blastomere, einen vollständigen Embryo mit Achsenorganen zu bilden, muls auf einem Defekt nicht im Kern, sondern im Protoplasma beruhen. Das folgt aus Schnürversuchen, wo der Furchungskern und seine Abkömmlinge in der einen Eihïlfte zurückgehalten wurden, bis dann einer jener Ablömmlinge durch den dünnen Protoplasmastiel in dis andere Eihälfte hinüberwanderte und sie zur Entwicklung brachtc. Dabei zeigten sich dieselben Versehiedenheiten in der Potenz der beiden sich vollends trennenden Keimhälften wie nach Durchschnürung im Zweizellenstadium; es entstanden entweder Zwillinge oder Embryo und Bauchstück, offenbar je nach der Richtung, in welcher das Ei eingeschnürt worden war. Es konnte sich nun so treffen, daß die ventrale Hälfte den Furchungskern bekam, die dorsale nur einen Abkömmling der 3. oder 4. Kerngeneration; trotzdem entwickelte sich diese mit ihrem $1 / 16$ Furchungskern zu einem normalen Embryo, während jene in Kernmaterial scheinbar bevorzugte nur ein Bauchstück lieferte (Spemann 1914).

Das führt zu einer weiteren Erwägung. Es ist schon öfters der Versuch gemacht worden, festzustellen, welche Teile des Embryos aus den einzelnen Teilen des Eies hervorgehen, oder umgekehrt, den Embryo auf das Ei zurück zu projizieren. Dieser "virtuelle Embryo im Ei « (Roux) hat nun eine lediglich ideelle Bedeutung, wenn die Entwicklung der einzelnen Eiregionen durch die Beschaffenheit der Kerne bestimmt wird, die rein oder vorwiegend aus inneren Gründen different geworden durch den Furchungsprozeß jenen Eiregionen zugeteilt werden. Wenn hingegen das Protoplasma solbst dabei wesentlich mitwirkt oder gar die Führung hat, so könnte dem virtuellen Embryo eine reellere Bedeutung zukommen; es könnte z. B. der Bereich der späteren Medullarplatte schon im Ei abgegrenzt sein. Es liegen nun allerdings Versuche vor, welche dagegen zu sprechen und zu zeigen scheinen, daß die präsumptive Medullarplatte noch in späterem Stadium nach vorn gewissermaßen offen ist und sich von einem Stammbczirk aus durch Angliederung vorher indifferenten Materiales vergrößert. Das könnte man daraus schließen, daß zu Beginn der Gastrulation Ektoderm vom Vorderende der präsumptiven Medullarplatte durch solches der präsumptiven Epidermis ersetzt werden kann (Spemann 1918). Doch beweist jener Versuch, wie mehrfach hervorgehoben, zunächst nur die Umbildungsfähigkeit jenes ektodermalen Zellmateriales unter einem Einfluß, der auf Bildung von Medullarplatte hinwirkt, nicht aber seine völlige Indifferenz; wie es sich ohne jenen $\operatorname{Einflu} \beta$, in indifferenter Umgebung, entwickeln würde, das bleibt noch zu prüfen.

Angenommen nun, zu Beginn der Gastrulation wäre die Medullarplatte nach vorne hin scharf begrenzt, ja schon im Zweizellenstadium wäre ihre Größe schon irgendwie vorbereitet, sei es auch nur durch die 
Menge irgendcines Stoffes, der bei ihrer Bildung aufgebraucht wird, so ergibt sich eine wesentliche Verschiedenheit zwischen seitlicher und dorsaler Blastomere. Die seitliche Blastomere enthält dann sämtliche Anlagen in halber Menge, also in den normalen Proportionen; nou zu bewirken ist die symmetrische Verteilung dieser Anlagen. In der dorsalen Blastomere dagegen ist die Symmetrie nicht gestört, wohl aber das normale Mengenverhältnis der Anlagen; sie enthält zuviel Material für die Medullarplatte und dic übrigen Achsenorgane. Wenn beidemal bilateral-symmetrische, normal proportionierte Embryonen entstehen, so haben ganz versehiedenartige Regulationen stattgefunden, im ersteren. Fall mehr eine Regulation der Form, im zweiten mehr eine solche der relativen Größe der Anlagen. Daher werden Unvollkommenheiten der Regulation verschiedene Folgen haben; im ersteren Fall eine Asymmetrie, im zweiten eine abnorme Größe der Medullarplatte und der übrigen Achsenorgane.

Es wäre von theoretischer Bedeutung, wenn sich solche Abweichungen von der Norm nachweisen ließen; denn wenn die Regulation vollkommen zu Ende geführt ist im Augenblick, wo die Organanlagen unterscheidbar werden, so läßt sich der Weg, den sie genommen hat, nicht mehr feststellen und ihr Ausgangspunkt nicht mehr erschließen. Leicht wird der Nachweis nicht sein. Es ist von vornherein zu erwarten, daß es sich bei jenen Abweichungen nur um kleine Beträge handeln wird, um so kleinere, je früher die Regulation begonnen hat, in je jüngerem Stadium also die Durchtrennung vorgenommen worden ist. Doch scheint mediane Durchschnürung selbst zu Beginn der Furchung gelegentlich eine schwächere Ausbildung der innenständigen Keimhälfte zur Folge zu haben. So habe ich Zwillinge von Triton cristatus beschrieben (1919, Taf. 14, Abb. 19 und 20), entstanden nach stärkster Einschnürung im Zwei- oder Vierzellenstadium mit nachfolgender spontaner Trennung, bei denen die Vorderbeinchen entgegengesetzter Seiten. kleiner und weniger weit entwickelt waren. Der Unterschied war sehr gering, aber er war deutlich und traf zusammen mit Situs inversus des einen Embryos, der als rechter anzusprechen ist, wenn die verkümmerte Seite die innenständige war, so daß die Asymmetrie wahrseheinlich keine zufällige ist. Wenn der Nachweis schon hier schwierig ist, wo. man die beiden einander entsprechenden Hälften direkt miteinander vergleichen kann, so wird es voraussichtlich noch viel schwerer, wo nicht unmöglich sein, an einem Embryo aus einer dorsalen Hälfte festzustellen, ob seine Medullarplatte die normalen Größenverhältnisse einhält oder überschreitet. Immerhin wollte ich es nicht unterlassen, auf die hier vorliegenden Möglichkeiten hinzuweisen.

Dieselben Unterschiede in der Weiterentwicklung wie die isolierten ersten Blastomeren zeigen die beiden Keimhälften auch in späteren. 
Stadien. Auch von der Morula und Blastula entwickeln sich nach medianer Durchtrennung die beiden seitlichen Hälften zu verkleinerten Ganzembryonen, nach fronlaler Durchtrennung die dorsale zu einem Embryo, die ventrale zu einem Bauchstück. Die Embryonen aus dorsalen Hälften sind bisher auf die Proportionen ihrer Organe nicht untersucht; bei den Embryonen aus seitlichen Hälften hat sich in zahlreichen Fällen gezeigt, daß die Regulation zur Symmetrie unvollkommen bleibt, indem die Organe der innenständigen Seite schwächer entwickelt sind oder ganz fehlen ( $\$$ pemann und Falkenberg 1919), Einigemal wurden sogar Neurulae beobachtet, an denen zunächst nur der äußere Medullarwulst deutlich war und erst spüter der schwächere innere Medullarwulst sichtbar wurde (S.385), also seitliche Halbembryonen mit Postgeneration der fehlenden Seite, wic Roux sie beim Froschei aus einer seitlichen Blastomere nach Anstich der anderen erhalten hat.

Daß hier die Regulation unvollkommen bleibt, hängt mit ihrem späteren Beginn zusammen. Wahrscheinlich findet sie dabei eine fester determinierte Anlage vor; jedenfalls aber bleibt ihr weniger Zeit zur Auswirkung. Denn es scheint ja nicht so zu sein, daß die im Gang befindliche Entwicklung unterbrochen und stillgelegt wird, bis die Regulation vollendet ist; vielmehr scheinen die Entwicklungsprozesse weiter zu laufen und dabei durch regulative Vorgänge abgeändert zu werden. Wir kennen einen einfachen Fall, nach dem wir uns eine allgemeine Vorstellung hiervon machen können. Wenn man Froscheier im Zweizellenstadium in Zwangslage umdreht, wie das bekanntlich zuerst von $O$. Schultze (1894) ausgeführt worden ist, so findet eine Umordnung der Eisubstanzen nach ihrem spezifisehen Gewicht statt, durch welche sehließlich eine der normalen nahe kommende Neuordnung erreicht werden kann, die zum Ausgangspunkt einer normalen Weiterentwicklung dienen könnte. Wahrend dessen geht aber die Entwicklung, d. h. hier die Furchung, weiter und macht schließlich der Umordnung der Eisubstanzen, also dem Regulationsprozeß, ein gewaltsames Ende, ehe er seinen natürlichen Abschluß erreicht hat. Die beiden Faktoren, Regulation und Entwicklung, werden hier dadurch noch deutlicher unterscheidbar, daß man sie getrennt beeinflussen kann. Durch Abkühlung wird die Zellteilung stärker verlangsamt als die Umordnung der Eisubstanzen, also für die Regulation Zeit gewonnen, so daß sie zu Ende geführt werden kann, ehe sie von der Entwicklung überholt wird (Moszkowski 1902). In analoger Weise mögen wir uns auch sonst das Verhältnis zwischen Regulation und Entwicklung denken; zu genaueren Vorstellungen fehlen uns vorläufig die tatsiichlichen Grundlagen.

Jedenfalls ist zu erwarten, daß, die Regulation um so unvollkommener bleibt, je später sie einsetzt, und da das hier gerade erwünscht ist, so wurde versucht, die Durchtrennung in medianer und frontaler Richtung 


\section{Gudrun Ruud und Hans Spemann: Die Entwieklung isolierter dorsaler}

in noch späterem Stadium, zu Beginn der Gastrulation, vorzunehmen. Das versprach, falls es ausführbar und erfolgreich war, den weiteren Vorteil, daß mit Auftreten des Urmunds die Orientierung des Embryos erkennbar und damit die Art der Durchtrennung genau bestimmbar wird. Es zeigte sich, daß seitliche Keimhälften noch in diesem Stadium regulationsfähig sind, dorsale Keimhälften sogar noch in so vollkommenem Maße, daß die Versuche auf noch spätere Stadien, bis zum Ablauf der Gastrulation, ausgedehnt werden mußten, sollten die Folgen unvollkommener Regulation d zutl ch in Erscheinung treten.

Die Durchtrennungen in beiderlei Richtung, medianer wie frontaler, wurden nach zwei verschiedenen Methoden vorgenommen: die Keime wurden entweder innerhalb ihrer Hüllen mit einer Haarschlinge zerschnürt, oder aber von allen Hüllen befreit mit einer Glasnadel zerschnitten. Die letztere Methode ist bei weitem exakter und gestattet eine ungestörte Beobachtung der Keimhälften während ihrer Weiterentwicklung; sie wäre unbedingt vorzuziehen, wenn die Sterblichkeit der hüllenlosen Stücke nicht gerade bei diesem Experiment eine ganz enorme wäre. Die Einleitung der Regulation zwar verläuft ganz typisch und kann am besten an zerschnittenen Halbkeimen studiert werden; zur Feststellung des erreichbaren Endergebnisses aber muB die Methode der Zerschnürung herangezogen werden. Im einzelnen verfährt man dabei folgendermaßen.

Da es sehr schwer, oft unmöglich ist, den Keim zu Beginn der Gastrulation genau median oder frontal in die Haarschlinge zu bekommen, so legt man diese schon im Zweizellenstadium an, längs der ersten Furche, aber so locker, daß das Ei möglichst wenig eingeschnürt, vielmehr nur eben festgehalten wird. Wenn dann der Urmund auftritt, entweder auf der einen. Seite der Haarschlinge und parallel zu ihr, oder quer unter der Haarschlinge und symmetrisch zu ihr, so wird der Keim vollends durchgeschnürt. Voraussetzung für das Gelingen ist, daß die äußere Eikapsel genau in ihrer Mitte von der Schlinge gefaßt worden war, sonst weicht der Keim beim Nachschnüren nach ihrer größeren Hälfte hin aus. Die Methode ist insofern etwas roh, als die Einschnürung nicht längs einer Linie, sondern einer ziemlich breiten Zone erfolgt, da ja nicht das Haar selbst, sondern die Eikapsel dem Keim anliegt. Ein Extraovat ist deshalb fast unvermeidlich, und wenn dieses auch die Entwicklung nicht vereitelt, so stört es doch die Beobachtung, die schon durch die allmählich trüb werdende Hülle erschwert wird. Immerhin läßt sich so viel erkennen, daß die Regulation in derselben Weise erfolgt wie bei den Durchschneidungsversuchen, wo sie genau beobachtet werden kann. Die weitere Entwicklung ist eine überraschend gute. Das ist sicher in der Hauptsache darauf zurückzuführen, daß die Hülle einen wirksamen Schutz gegen Infektion gewährt; zum Teil 
mag es aber auch daher kommen, daß der Keim durch die Einschnürung in der Ebene der späteren Durchschnürung schon etwas eingeengt ist, so daß die Wundflächen von Anfang an kleiner sind als bei einem Keim, der nach ganz normaler Entwicklung zu Anfang der Gastrulation median oder frontal durchtrennt worden ist. Da aber andererseits so schwache Schnürung keine Verdoppelung bewirkt, so ist auch nicht anzunehmen, daß sie Regulationprozesse auslöst und dadurch das Ergebnis der Durchschnürung trübt. - Wenn die Teilstücke anfangen, sich beträchtlicher zu strecken, muß die Schlinge gelöst werden; wenn die Larven größer werden und sich lebhafter bewegen, nimmt man sie am besten aus den Hüllen heraus, damit sie sich in dem zu engen Raum nicht verkrümmen.

Zum Zerschneiden müssen die Keime aus der Eikapsel genommen und vom Dotterhäutchen befreit werden; ersteres geschieht kurz. nach der Befruchtung, vor dem Auftreten der ersten Furche, letzteres unmittelbar vor der Operation. Die nackte Gastrula wird dann auf dem Wachsboden des Operationsschälchens so gedreht, daß der Urmund nach oben sieht, und mit einer feinen Glasnadel in der gewünschten Richtung durchschnitten. Wenn man das sehr langsam ausführt, so kleben die Wundränder von Anfang an zusammen (etwa wie die Ränder eines mit der Schere durchschnittenen Gummischlauchs), die Infektionsgefahr wird vermindert und die Heilung erfolgt fast ohne Zellverlust. Mit freier Hand läBt sich das schwer so langsam machen, sehr leicht und genau aber auf folgende $W$ eise. Man legt einen möglichst

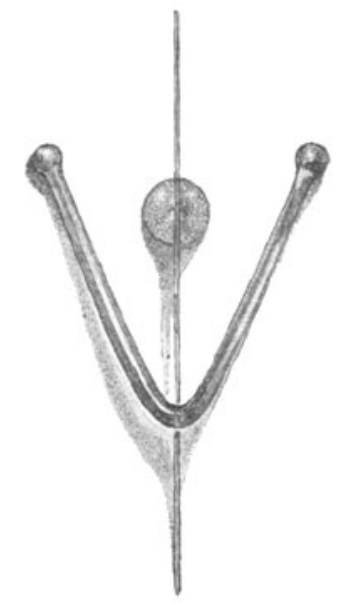

Abb. 3. Langsame mediant: Durchquetschung einer Gastrul.. von Tritom mittels Glasfadens und Glasreiters. Vergr, $\Varangle 4$. feinen Glasfaden über den Keim und beschwert ihn durch einen kleinen Glasreiter, den man über der Mikroflamme gebogen hat (Abb.3). Währcnd man den Glasfaden an seinem freien Ende mit einer Haarschlinge in Glasgriff etwas hebt, kann man leicht mit einer zweiten Haarschling den Keim so lange wälzen und drehen, bis der versuchsweise etwas herabgelassene Glasfaden genau in der gewünschten Richtung einschneidet. Dann läßt man ihn nieder; der Druck des Reiters kann durch Verschiebung genau nach Bedarf geregelt werden. Die Durchtrennung erfolgt nun so langsam, da $B$ sie noch nicht vollendet $\mathrm{zu}$ sein braucht. wenn die Teile über dem Glasfaden schon wieder verwachsen sind; ich habe eine völlig normale Larve konserviert, durch welche der Glasfaden median durchgeschnitten hatte, wie bei dem bekannten Versuch ein beschwerter Draht durch einen Block Eis. Natürlich läßt sich das 
leicht verhindern; die Durchtrennung der letzten dünnen Verbindung muß häufig mit der Hand vorgenommen werden. Wegen Einzelheiten dieser Methode vgl. 1920, S. 20. - Die Versuche werden am besten in Brunnenwasser ausgeführt, welches man, wo es nötig ist, vorher durch ein Tonfilter gereinigt hat. Trotzdem ist, wie gesagt, die Sterblichkeit sehr groß und ältere Larven konnten wir nur ausnahmsweise crhalten. Triton alpestris ist noch empfindlicher als Triton taeniatus; was sehr zu bedauern ist, weil bei alpestris der Farbenunterschied zwischen der dunklen animalen und der hellen vegetativen Hälfte viel ausgesprochener ist als bei taeniatus, wodurch die Verfolgung der einzelnen Teile des Keimes während der Gastrulation sehr erleichtert würde.

Die Versuche, welche im folgenden mitgeteilt werden sollen, wurden von Fräulein Gudrun Ruul und mir in den Sommorn 1916 und 1917 im Kaiser-Wilhelm-Institut für Biologie in Dahlem begonnen und von Frl. Ruud im Sommer 1920 im Zoologischen Institut in Freiburg zu Ende geführt. Ihr Ergebnis entsprach nicht in jeder Hinsicht den Erwartungen, welche zu dem Versuche geführt hatten. Vor allem lieB sich die Abnahme der Regulation der dorsalen Keimhälfte nicht so exakt feststellen, wie ich gchofft hatte. Dagegen lieferte die mediane Durchtrennung wichtige Aufschlüsse in der vor vielen Jahren von Roux aufgeworfenen und immer noch umstrittenen Frage der Postgeneration, so daß mir die Versuche schon aus diesem Grunde der Mitteilung wert erscheinen.

\section{Die Regulation der dorsalen Keimhalfte nach frontaler Durchtrennung wïhrend der Gastrulation.}

Die Keime wurden in verschiedenen Stadien der Gastrulation, vom ersten Auftreten des Urmundes bis zu seinem Schluß, in frontaler $\mathbf{R i} \mathbf{h}$ tung durchtrennt, d. h. in einer Ebene, welche die Eiachse enthält und senkrecht zur medianen steht. Die Durchtrennung wurde entweder innerhalb der Hüllen vorgenommen, mittels schwacher Einschnürung längs der ersten Furche und folgender Durchschnürung nach Erreichung des gewünschten Entwicklungsstadiums, oder aber am nackten Keim mittels eines beschwerten Glasfadens. Zur Beurteilung, inwieweit Regulation eintritt, diente die Größe der Medullarplatte, die in ihrem Verhältnis zur Epidermis abgeschätzt wurde. Mehr als eine erste Annäherung kann dadurch freilich nicht erreicht werden, wurde aber auch nicht angestrebt; die Ergebnisse des Experiments waren nicht gleichartig genug, um genauere Messungen lohnend erscheinen zu lassen. Dafür lassen sich verschiedene Gründe angeben.

Zunächst wurden sicher nicht alle Keime in genau derselben Ebene 
durchtrennt. Während es nur eine Medianebene gibt, welche die ganze Entwicklung hindurch dieselbe bleibt und bei symmetrisch ausgebildeter oberer Urmundlippe mit Leichtigkeit bestimmt werden kamn, ist schon der Begriff der frontalen Ebene mehr oder weniger willkürlich, ihre Lage wegen der Einstülpungs- und Uberwachsungsvorgänge wechselnd und ihre genaue Bestimmung auch in einem und demselben Stadium schwierig. Je nachdem man nun näher oder entfernter von der oberen Urmundlippe durchschneidet, erhält das dorsale Stück eine geringere oder größere Menge von Entodermzellen zugeteilt; es leuchtet ein, daB die weitere Entwicklung danach rerschieden sein wird. Bei Vermindorung der Entodermzellen ist die Medullarplatte in ihrem hinteren Teil durch eino mehr oder weniger tiefe quere Furche gegen den Urmund und die nach vorn angrenzende Bauchflache abgesetzt oder gar ventralwärts eingerollt, gerade so, wie wenn sie verhältnismäBig zu groß wäre. Dasselbe wurde beobachtet, wenn sich ein großes Extraovat gebildet hatte. Eine derartig gestaltete Medullarplatte ist nicht immer mit Sicherheit von einer solchen zu unterscheiden, dic zu groß3 ist, weil sie schon für die Verhältnisse des ganzen Keims determiniert war und nicht mehr reguliert werden konnte. Eine ähnliche Zuspitzung, ja manchmal selbst eine leichte Einrollung des Hinterendes der Neurula tritt auch ohne Operation an Keimen ein, welche ohne den äußeren Halt des Dotterhäutchens gastruliert hatten; solche birnförmigen Embryonen kamen bei den Versuchen über frühzeitige embryonale Transplantation nicht salten zur Beobachtung (vgl. z. B. 1918, Taf. 18, Abb. 7, 8, 14; Taf. 19, Abb. 22, 26; Taf. 21, Abb. 62). Zu all diesen Verschiedenheiten, die mit der Regulationsfähigkeit des Keims nichts zu tun haben, mögen dann noch solche in der Schwere des Eingriffs und der individuellen Widerstandsfähigkeit der Keime kommen; wie sie bewirken können, daß der eine Keim rasch heilt, der andere langsamer, der dritte zugrunde geht, so mögen sie auch die Regulationsfähigkeit der Keime beeinflussen.

Darnach ist es nicht weiter verwundorlich, daB die Experimente wohl im allgemeinen eine Abnahme der Regulationsfahigkeit mit zunehmendem Alter des Operationsstadiums ergaben, jedoch nicht ausnahmslos, indem manchmal ein älterer Keim noch regulierte, während ein jüngerer dazu nicht mehr fähig schien. Aus den eben angeführten Gründen wird man dabei den Fallen, wo Regulation stattgefunden hatte, eine größere Bedeutung beimessen als denen, wo sic untcrblieben war. Unbeschadet der kleinen Schwankungen tritt aus der Gesamtzahl der Fälle deutlich die Tatsache hervor, daß die Regulationsfähigkeit der dorsalen Keimhälfte zu Beginn der Gastrulation eine volkommene ist, daß sie während ihres Verlaufs immer mehr abnimmt und mit ihrer Beendigung erlischt. 
104 Gudrun Ruud und Hans Spemann: Die Entwicklung isolierter dorsaler

a) Durchtrennung zu Beginn der Gastrulation.

Als Beispiel für die normal proportionierte Entwicklung der dorsalen Keimhälfte, wenn die Durchtrennung kurz nach Beginn der Gastrulation

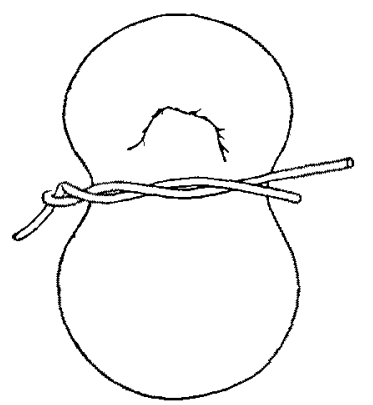

Abb. 4. Keim von lition taeniat us zu Beginn der Gastrulation; längs der erston Furche (= tránsversal) schwach eingeschnint. Vergr. $\succ 20$. vorgenommen worden war, möge ein Fall frontaler Durchschnürung und ein Fall frontaler Durchschneidung dienen.

Beim ersten Fall (Trit. taen. $R$ 1916, 29) ist der Keim längs der ersten Furche schwach eingeschnürt worden. Nach etwas über zwei Tagen war die Gastrulation im Gang, der Urmund fast halbkreisförmig; er lag auf der einen Seite der Ligatur (Abb.4), mit seiner Symmetrieebene annähernd senkrecht zu ihr, bezeichnete also die dorsale Hälfte der Gastrula. Nun wurde vollends durchgcschnürt. Nach etwa drei weiteren Tagen war aus der dorsalen Gastrulahalfte eine Neurula entstanden, deren Wülste von der Nackengegend an nach hinten zusammengerückt waren, während sie vorn noch weit klafften und ein länglich

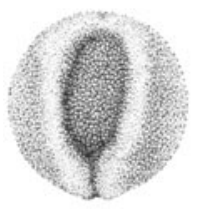

$a$

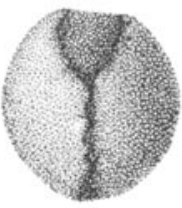

$b$

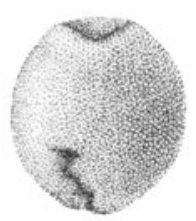

te

Abb. 5 a t. Annähernd normal proportionierte Neurula (vgl. Abb, 6), $a$ von vorne, $b$ von oben, c von unten; aus der dorsalen Hăfte der frontal durchschnürten Gastrula (vgl. Abb. 4) ent; standen. Vergr. $<20$.

ovales breiteres Feld begrenzten $(A b b .5 a-c)$. Die verhältnismäßige Größe der Medullarplatte und ihrer Teile ist annähernd normal, höch-

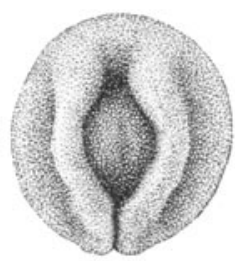

Abb. $6 a-c$. Normale Neurula von

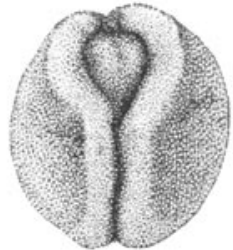

$b$

Triton taenialus, $a$ von vorne, $b$ von oben, $c$ von unten gesehen. Verge. $\times 20$.

stens ist die ventrale Entfernung zwischen ihrem Vorderrand und dem Urmund etwas zu kurz (vgl. Abb. $5 a-c$ mit dem Kontrolltier Abb. 6a-c). - Ähnlich verbielt sich eine Anzahl anderer Keime, die 
und lateraler Gastrulahälften von Triton taeniatus und alpestris usw. 105

in gleicher Weise frühzeitig eingeschnürt und im selben oder noch etwas späteren Stadium (bei U-förmigem, ja selbst bei weit ringförmigen Urmund) vollends durchgeschnürt wurden. Abweichungen erklären sich leicht aus den oben angeführten Ursachen, namentlich dem schwer zu vermeidenden Verlust an Dotterzellen.

Beim zweiten Fall (Trit.taen. $R$ 1917, 17) ist der Keim vor Beginn der Furchung aus der äußeren Eihülle genommen und im ersten Anfang der Gastrulation vom Dotterhäutchen befreit mit beschwerter Glasnadel frontal durchgequetscht worden. Abb. 7 und 8 geben eine Vorstellung davon, wie er während der Operation und kurze Zeit nachher aussieht. Nach Abziehen des Dotterhäutchens plattet er sich von oben nach unten ab, wobei die Eiachse stark verkürzt wird, aber ihre vèrtikale Lage annähernd beibehält, wenigstens im allerersten Beginn der Gastrulation, wo die radiale Symmetrie

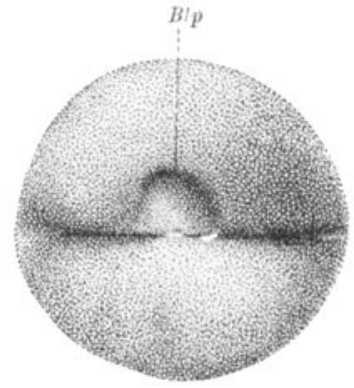

Abb. 7. Hüllenloser Keim von Trilou treniatus zu Beginn der Gastrulation, im Begriff, von einem frontal aufgelegten Glasfaden in eine dorsale und ventrale Halfte zerteilt zu werden; wp Urmund. Vergr. $>20$. des Blastulastadiums noch nicht durch die Zellverschiebungen wesentlich gestört ist. Kippt man ihn nun mit Hilfe von zwei Haarschlingen rasch um, so liegt der Urmund in der Aufsicht ungefähr in der Mitte zwischen dem Zentrum und dem Kontur des linsenförmigen Keimes, also ähnlich wie nach vorheriger Einschnürung längs der ersten Furche (vgl. Abb. 1 auf S. 96); demnach nimmt der vegetative Pol mehr oder weniger genau das Zentrum ein. Man kann nun leicht den Glasfaden so auflegen, daß er längs der Eiachse und quer zur Medianebene, also frontal, ein- und durch. schneidet, Abbildung 7

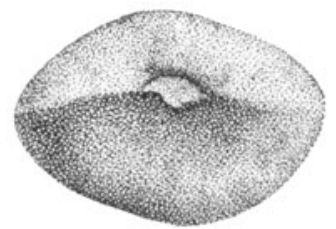

a

Abb. $8 a$ und b. Dorsale $(\alpha)$ und ventrale $(b)$ Keimhalfte von Witon taeniatus, einige Stunden nach frontaler Durchtrennung einer etwas alteren Gastrula als Abb. 7 ; deutliche Verwachsungsnalut zwischon dunkler animaler und heller vegetativer Keimhalfte. Vergr $>20$

$(R 1917,2)$. Die Durchtrennung geht so langsam und schonend von statten, daß eigentlich gar keine $W$ unde entsteht und nur wenige aus getretene weiße Dotterzellen der Verwachsungsnaht ansitzen. Abb. 8 $(R 1917,86)$ zeigt das Bild einige Stunden später; animale und vegetative Wundränder sind glatt verheilt, aber durch ihre verschiedene Färbung noch scharf gegeneinander abgegrenzt. Auf der dorsalen Hälfte ist die Gastrulation weiter fortgeschritten, auf der ventralen hat sie begonnen. - Aus einer derart abgetrennten dorsalen Gastrulahälfte 
wurde nun im vorstehenden Fall eine anscheinend völlig normal proportionierte Neurula gewonnen (Abb. $9 a-c)$. Sie ist nicht rundlich wie die innerhalb der Eihüllen verbliebene des zuerst beschriebenen Falles, sondern lang gestreckt, wie der ebenfalls vou Beginn der Gastrulation an außerhalb der Hüllen aufgezogene Kontrollkeim der Abb. 10a-c. Die Medullarwülste sind hinten zusammengerückt, vorn

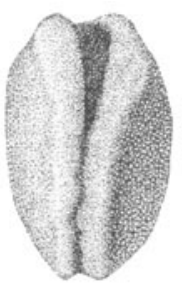

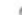

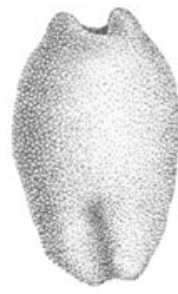

u

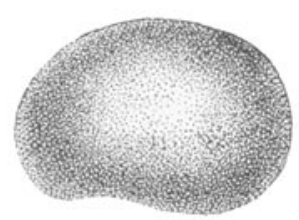

Abb. $9 a-c$. Normal proportionierte Neurula (vgl. Abb. $10 a-f$ ), $a$ von oben. $b$ von unten, $c$ von rechts; aus der dorsalen Hälfte der frontal durchschnittenen Gastrula (vgl. Abb. 7 ) entstanden. Vergr. $>20$.

klaffen sie noch etwas; ihr Größenverhältnis zum übrigen Keim ist fast völlig normal, die ventrale Entfernung zwischen Medullarplatte und Urmund nur ganz wenig verkürzt.

In derselben Weise wurde noch eine größere Anzahl (38) von Gastrulen durchgequetscht, von denen etwa $2 / 3$ (25) einen annähernd normal proportionierwen dorsalen Fmbryo lieferten, während dieser in etwa $1 / 3$ der Fälle (13) mehr oder weniger abnorm gestaltet war. Bei diesen

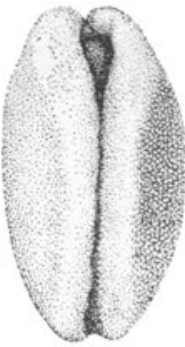

Abb. $10 a-c$. Normale hüllenlose Neurula von Triten taeniatas, $a$ von oben, $b$ von unten, c won rechts. Vergr. $>20$.

letzteren ist die Medullarplatte S-förmig gekrümmt, oder ist ihr Hinterende zu dünn und ventralwärts gebogen oder spiralig eingerollt. Fast immer ist hier im Protokoll bemerkt, daß bei der Operation viel Entodermzellen verloren gegangen waren, entweder durch Austritt bei der Durchtrennung oder durch Führung des Schnittes zu nahe der oberen Urmundlippe; das genügt zur Erklärung der abnormen Bildung. Daß sie mit frühzeitiger Determination und mangelnder Regulation nichts 
und lateraler Gastrulahälften von Triton taeniatus und alpestris usw. 107

zu tun hat, geht auch aus folgendem mit Wahrscheinlichkeit hervor. Jene 38 operierten Gastrulen waren nicht alle genau gleich alt; 20 von ihnen standen im allerersten Anfang der Gastrulation, während bei 18 der Urmund schon bogenförmig war. Wenn nun der Zeitpunkt der festen, nicht mehr regulierbaren Determination schon in diesen $\mathrm{Ab}$ schnitt der Entwicklung fiele, so müßte man erwarten, daß die größere Zahl der normal proportionierten Embryonen aus der jüngeren Gruppe stammat. Das Gegenteil ist der Fall. Jene 20 jüngeren Gastrulen lieferten 12 normale dorsale Embryonen, also $60 \%$, während aus den 18 älteren Gastrulen 13 normale Embryonen hervorgingen, also $72 \%$. Das kam eben daher, daß in jenem jüngeren Stadium die Zahl der geschädigten Stücke - vielleicht zufällig - eine größere war.

Aus diesen Versuchen geht also hervor, daß die Regulationsfähigkeit der dorsalen Keimhälte zu Beginn der Gastrulation noch eine ganz oder jedentalls nahezu vollkommene ist.

\section{b) Durchtrennung zu Ende der Gastrulation.}

So deutlich die Regulationsfähigkeit zu Beginn der Gastrulation ist, so sicher fehlt sie gegen ihren Schluß. Trennt man an einem Keim mit kleinem länglichem Dotterpfropf die ventrale Hälfte $a b$, so entwickelt sich an der dorsalen eine Medullarplatte, welche verhältnismäßig viel zu groß ist, sich daher sehr stark ventralwärts umbiegt, ja einrollt und nicht imstande ist, sich zum Rohr zu schließen. Als Beispiel möge wieder ein Fall frontaler Durchschnürung und ein solcher frontaler Durchschneidung dienen.

Der Keim (Trit.taen. $R$ 1916,8) war längs der ersten Furche schwach eingeschnürt worden. Nach einem Tag begann die Gastrulation, und es ließ sich an der Lage des Urmunds erkennen, daß frontal geschnürt worden war. Nach weiteren $15^{1 / 2}$ Stunden war die Gastrulation fast zu Ende, der Urmund klein und längsoval, der Dotterpfropf eben noch sichtbar (Abb. 11); er lag nicht genau unter der Ligatur, sondern ganz in der dorsalen Hälfte. Nun wurde die Ligatur angezogen und der Keim vollends durchgeschnürt. Die Wunde heilte langsam. Nach etwa 11 Stunden wurde an der dorsalen Hälfte eine zu große Medullarplatte unter.

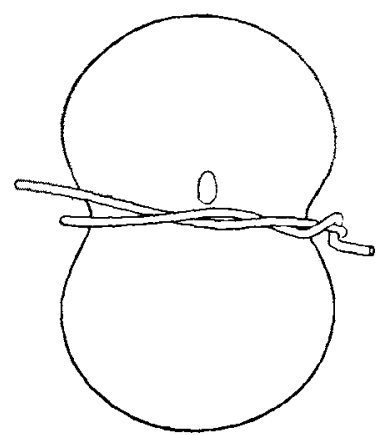

Abb. 11. Keim von Triton tueviatus am Ende der Gastrulation; vor etwa 40 Stunden längs der ersten Furche (= iransversal) schwaeh einge schnurt. Vergr, $\times 20$. scheidbar. Am nächsten Tage, 24 Stunden nach der Durchschnürung, wurde der Keim konserviert (Abb. 12). Die Medullarplatte ist durch etwas stärkere Pigmentierung und kaum sichtbare Wülste gegen die 
umgebende Epidermis abgegrenzt. Sie ist noch weit offen, obwohl sie ihrer Längenausdehnung nach zu urteilen schon geschlossen sein

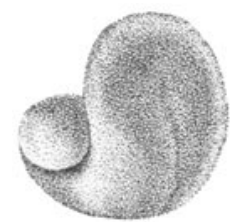

Abb. 12. Neurula mit viel zu grober Medullarplatte, ventralwärts eingerollt; entstanden aus der dorsalen Bälfte der vollendeten Gast-

rula (Abb. 11).

Vergr $، \times 20$. sollte. Außerdem ist sie viel zu groß; ihr hinteres Ende ist stark ventral und auBerdem nach links eingerollt, so daß eine nach links ausgezogene Spirale entsteht. Auf Schnitten quer durch ihr vorderes Ende zeigt sich ihr UmriB stark gewölbt, fast halbkreisförmig, mit medianer Einzichung namentlich im vorderen Teil des breiten Feldes, und seitlicher stärkerer Krümmung da, wo sie rasch sich verdünnend in die Epidermis übergeht. Diese stärkere Krümmung und die Pigmentierung ermöglichen die Abgrenzung der Platte im Oberflächenbilde; eigentliche Wülste sind nicht entwickelt.

Ein anderer Keim (Trit. taen. $R$ 1916,36) wurde erst zu Beginn der Gastrulation frontal, also parallel zur oberen Urmundlippe, eingeschnürt und 30 Stunden später vollends durchgeschnürt. Der Urmund war genau wie in dem vorhergehenden Fall klein, längsoval, senkrecht zur Ligatur gestellt, und lag ganz auf der dorsalen Hälfte (Abb. 13). 22 Stunden nach der Durchschnürung war der dorsale Embryo stark ventralwärts eingekrümmt; die Medullarrinne war deutlich, die Medullarplatte aber noch weit offen und nach den Seiten nicht abgegrenzt. So blieb sie, bis der Embryo $651 / 2$ Stunden nach der Durchschnürung

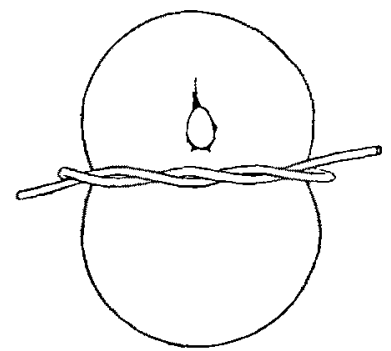

Abb. 18. Keim von Titon taeniáns am Ende der Gastrulation; vor 30 Stunden zu Beginn der Gastrulation frontal eingeschnirt. Vergr. $\times 20$

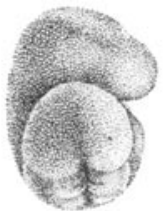

Abb. 14 .

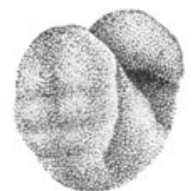

A.bb. 15 .

Abb. 14 und 15. Neurula mit zu groBer zungentörmiger Medullarplatte, ohne Wuiste, unfahtg sich zu schlieben, metamer gegliedert; entstanden aus dorsaler Halfte der vollendeten Gastrula (Abb. 13). Vergr, $>20$.

konserviert wurde. Im einzelnen ließ sich folgendes an ihm erkennen (Abbild. 14 und 15). Nimmt man das symmetrisch ausgebildete Vorderende der Medullarplatte als fest an, so weicht ihre Mittellinie hinten im breiten Felde zunächst etwas nach links ab und biegt dann energisch nach rechts um, auf das spiralig eingerollte Hinterende. Das zungenförmige Vorderende der Medullarplatte ist durch eine mediane Rinne in eine rechte und linke Hälfte geschieden und durch einige quere 
Furchen in metamer hintereinander gelegene Felder gegliedert. Sehr deutlich ist die vorderste dieser Querfurehen, etwa in der Mitte des breiten Feldes, ebenfalls deutlich eine zweite Querfurche in gleichem Abstand dahinter, etwa dem hinteren Ende des breiten Feldes entsprechend; dagegen ist eine zwischen diesen beiden gelegene mittlere Furche sehr seicht und nur schwach sichtbar. Diese metamere Gliederung war in Fällen von verhindertem Schluß der Medullarplatte öfters zu sehen, weniger deutlich in der normalen Entwicklung, wenigstens bei Triton taeniatus. Bei Bombinator dagegen ist sie oft sehr scharf ausgeprägt; hier ist sie die erste Andeutung der späteren Gliederung in die Hauptabschnitte des Gehirns. Das lehren Defektversuche, die ich in anderem Zusammenhang mitzuteilen denke. Wenn sich die dort gewonnenen Ergebnisse auf den Triton-Keim übertragen lassen, woran kaum zu zweifeln ist, so würde die Region zwischen den beiden deutlichen Querfurchen dem späteren Mittelhirn entsprechen, die Region davor dem primären Vorderhirn, die dahinter dem Hinterhirn. Bei normaler Ausbildung und Schluß der Wülste ist das präsumptive Vorderhirn scheinbar viel kleiner, jedenfalls weil sehr früh die Zusammendrängung und Einwucherung des Materials für die primären Augenblasen einsetzt.

Dasselbe Bild wie diese beiden Keime zeigten mehr oder weniger deutlich noch einige andere in ähnlicher Weise durchschnürte (Trit. taen. $R$ $1916,12,15,16,24)$; die Medullarplatte war viel zu groß, ventralwärts eingerollt, hatte keine oder nur schwache Wülste und schloß sich verspätet oder gar nicht. Darunter war einer $(1916,24)$, bei welchem der kleine Dotterpfropf nicht unter oder dicht neben der Ligatur gelegen hatte, sondern in ziemlich großer Entfernung von ihr, so daß die Durchschnürung nicht rein frontal erfolgte, sondern so, daß sie der dorsalen Keimhälfte hinten noch ein Stück der ventralen zuteilte, während sie vorn dicht vor der präsumptiven Medullarplatte durchschnitt oder gar ein kleines Stück von ihr wegnahm. Eine solche Durchschnürung habe ich schon einmal vor Jahren ausgeführt (1902, S. 521/22, Textabb. 61 und 62), mit demselben Ergebnis, aus dem ich denselben Schluß zog. Es bildete sich auf dem einen Stück eine Platte mit einer medianen Furche, welche aussah, wie eine eben deutlich gewordene Medullarplatte, und aus hohen Zylinderzellen bestand, wie auf Schnitten zu sehen war. Diese Platte war sehr stark ventralwärts eingekrümmt, ragte vorn zungenförmig über und war nicht imstande, sich zum Rohre zu schließen. Wohl infolge dieser Unfähigkeit gingen solche Keime damals und jetzt zugrunde, nachdem sie sich einige Tage nicht weiter verändert hatten.

In derselben Weise entwickelten sich dorsale Keimhälften nach frontaler Durchschneidung, die am Ende der Gastrulation vorgenommen 
wurde. 10 Keime (Trit. taen. $R$ 1916, 20, 31, 33, 52, 54, 55, 56, 78, $79,92)$ wurden in dieser Weise operiert; bei keinem hat sich die Medullarplatte merklich zum normalen Größenverhältnis reguliert; die Nedullarwülste waren nur schwach entwickelt oder fehlten ganz; mindestens in der Hälfte der Fälle war die Medullarplatte unfähig, sich zum Rohre zu sohließen.

Diese Erscheinungen hängen offenbar ursächlich zusammen. Die Epidermis spielt zwar beim Schluß der Medullarplatte zum Rohr keine aktive Rolle, otwa derart, daß sic selbst wachsend jene vor sich hor schöbe; vielmehr liegen die Kräfte, welche die Umformung bewirken, in der Medullarplatte selbst. Das hat Roux (Ges. Abh. II, S. 247, 426) in einem seiner allerersten Orientierungsversuche (1885) gezeigt, bei dem er die Mcdullarplatte durch einen Schnitt gegen die angrenzende Epidermis isolierte. Jede Transplantation von Stückchen der Medullarplatte, etwa unter die Epidermis, lehrt dasselbe. Aber ebenso ist es lklar, daß die Epidermis sich entsprechend ausdehnen oder wachsen muß, wenn die Medullaxplatte aus der Oberfläche des Keimes, von der sie einen beträchtlichen Teil gebildet hat, ausscheidet und nun ihre Stelle von Epidermis eingenommen wird, wobei das Volumen des Keimes nicht abnimmt, sondern im Gegenteil um das mit zu bedeckende Medullarrohr vermehrt wird. Ist nun dic Medullarplatte im Verhältnis viel zu groß, so muß sie an ihren Rändern von der zu knappen Epidermis gewissermaßen festgehalten werden, so daß sie sich nicht zum Rohr zusammenkrümmen, ja nicht einmal Wülste bilden kann. Dadurch kommt diese sehr charakteristische Erscheinung zustande, welche ein sicheres Merkmal mangelnder GröBenregulation von Medullarplatte and Epidermis ist.

Aus diesen Versuchen folgt also, daß die Fähigkeit zur Größenregulation zwischen Medullarplatte und Epidermis zu Ende der Gastrulation erloschen ist.

c) Nahere Bestimmung des Zeitpunkts der Determination.

Nachdem durch die geschilderten Experimente die Gastrulation als der Entwicklungsabschnitt festgestellt ist, an dessen Anfang die Regulationsfähigkeit noch vollkommen vorhandon, an dessen Ende sie völlig erloschen ist, wäre die nächste Aufgabe, diesen Zeitraum von vorn und hinten her immer mehr einzuengen und so festzustellen, ob sich die Abnahme der Regulationsfähigkeit über eine längere Strecke ausdehnt oder ob sie auf eine kurze Zeitspanne zusammengedrängt ist. Doch erweist sich die Methode für solche genauere Feststellungen aus den oben angegebenen Gründen als nicht fein genug; die Ergebnisse waren ziemlich wechselnd. Ich will daher von der Mitteilung einzelner Fälle absehen und nur einige zusammenfassende Angaben machen. 
Nach Durchtrennung im Stadium des U-förmigen Urmunds haben manche Keime noch recht gut reguliert. Auch nach Durehtrennung in etwas späterem Stadium, wenn die untere Urmundlippe angedeutet war, konnten noch ziemlich normal proportionierte Neurulen entstehen. Daneben aber traten auch solche auf, deren Medullarplatte zwar noch Wülste bildete und sich zum Rohre schloß, aber deutlich zu groß war; ja cs entstanden selbst typisch unregulierte, mit zungenförmiger Medullarplatte, ohne Wülste, ventralwärts zusammengebogen, unfähig sich zu schließen. So nähert sich der Keim dem Stadium, wo bei zusammengezogenem Urmund die Regulationsfähigkeit ganz erloschen ist, und es hat den Anschein, als ob letztere dabei nicht gleichmäßig abnähme, sondern gewissermaßen ins Schwanken geriete, so daß sie beim einen Keim etwas länger erhalten bliebe als beim anderen. Obwohl das an sich nicht unwahrscheinlich ist, wäre es doch angesichts der nachwcisbaren Fehlerquellen übereilt, es aus den wechselnden Ergebnissen zu schließen. Nur soviel wird sich mit Sicherheit sagen lassen, daß die Regulationsfähigkeit des Ektoderms während des Verlaufs der Gastrulation nachweislich abnimmt.

Schon vor Jahren (1903) haben mich ähnliche Versuche zu fast demselben Ergebnis geführt. Mediane Einschnürungen, in verschiedenen Stadien der Entwicklung vorgenommen, haben gezeigt, daß sich zu Beginn der Gastrulation noch eine weitgehende Verdopplung des Vorderendes bewirken läßt; daß die Regulationsfähigkeit, die hierzu nötig ist, mit dem Fortschreiten der Gastrulation mehr und mehr abnimmt und schließlich mit ihrer Vollendung erlischt. Auf diese älteren Versuche und die neueren oben geschilderten gründeten sich dann die Transplantationen kleiner Ektodermstücke in verschiedenen Stadien der Gastrulation (1918), deren nächster Zweek es war, den Determinationsgrad solcher Stücke direkt zu prüfen, dadurch daß sie aus ihrer normalen Umgebung mit ihren Einflüssen genommen und unter die neuen Bedingungen einer abnormen Umgebung versetzt wurden. Dabei zeigte sich, daß sich die einzelnen Ektodermbezirke zu Beginn der Gastrulation in weitgehendem Maße gegenseitig vertreten können, derart, daß sich z. B. aus präsumptiver Epidermis Medullarplatte entwickeln kann und umgekehrt. Es zeigte sich ferner, daß diese Vertretbarkeit zu Ende der Gastrulation wohl auch noch vorhanden, aber doch schon deutlich eingeschränkt ist. So kann ein Stück präsumptiver Epidermis, in diesem Stadium in den Bereich der präsumptiven Medullarplatte verpflanzt, aller Wahrscheinlichkeit nach zwar auch noch Medullarplatte bilden, aber es fügt sich trotz anlünglich glatter Einheilung nicht mehr dauernd ununterscheidbar in den neuen Verband ein, sondern hebt sich scharf aus der Umgebung heraus (1918, S. 482); 


\section{Gudrun Ruud und Hans Spemann: Die Entwicklung isolierter dorsaler}

und ebenso ist die prïsumptive Medullarplatte nicht mchr völlig indifferont, sondern kann unter besonderen Umständen auch innerhalb von Epidermis zu Medullarsubstanz werden (S.483).

Vergleicht man die Frgebnisse beider Versuchsreihen, so zeigt sich, da $B$ die Indifferenz beziehungsweise Umbildungsfähigkeit des Ektoderms in etwas spätere Stadien hincinreicht als die Regulationsfähigkeit der dorsalen Keimhälfte. Denn diese letztere war schon nicht mehr nachweisbar, als der Urmund zwar klein und längsoval, aber doch noch offen war, während die Ektodermbezirko der präsumptiven Medullarplatte und Epidermis sich noch nach völligem SchluB des Urmunds gegenseitig vertreten konnten. Das ist nicht weiter üborraschend, denn die Regulationsfähigkeit setzt wohl die Indifferenz bzw. Umbildungsfähigkeit des Materiales voraus, nicht aber umgekehrt. Wenn gegen Ende der Gastrulation die Determination der Medullarplatte schon im Gang ist, wofür klare Anzeichen vorliegen (1918, S. 483), so ist es nicht unverständlich, daß ein Stück Ektoderm aus diesem Bereich durch besondere Einflüsse noch dazu gebracht werden kann, Epidermis statt Medullarplatte zu bilden, während die regulatorischen Vorgänge violleicht nicht rasch genug cinsetzen, um die Ausdifferenzierung der Medullarplatte in ursprünglicher Ausdehnung zu verhindern.

Wenn demnach die Ergebnisse beider Versuchsreihen durchaus miteinander verträglich sind, so gibt doch ihr Vergleich Anlaß zu einer weiteren Utberlegung. Ich habe es bisher der Einfachheit wegen immer als Regulation bezeichnet, wenn die Medullarplatte eines aus einer' dorsalen Gastrulahälfte entstandenen Keimes dessen verminderter Größe angepaßt war. Es fragt sich nun aber, ob dieser Ausdruck unter allen Umständen berechtigt ist. Zum Begriff der Regulation gehört doch wohl, daß eine schon bestehende Struktur verändert oder ein schon eingeleiteter EntwicklungsprozeB in neue Bahnen gelenkt wird. Dann würde man aber von einer GröBenregulation der Modullarplatte nur reden könnon, wenn ihr präsumptiver Bereich schon irgendwie gogen die Umgebung verschieden geworden, wenn also ihre Determination schon eingeleitet ist. Das ist nun aber keineswegs sicher; im Gegenteil macht es stutzig, daß in dem Stadium, wo es nachweisbar der Fall ist, nämlich nach Beendigung der Gastrulation, eine Größenregulation nicht mehr stattfindet. In früheren Stadien, wo sie noch beobachtet werden konnte, gaben die 'Iransplantationsversuche keinen Anhaltspunkt dafür, daß die präsumptive Medullarplatte schon nach vorn "geschlossen « ist; vielmehr erklärt sich die Vertauschbarkeit des Ektoderms in diesem Stadium am einfachsten durch die Annahme seiner Indifferenz. In diesem Fall könnte aber die Determination der Medullarplatte in der abgetrennten dorsalen Keimhälfte in gleicher Weise vor sich gehen wio im ganzen Keim, nämlich von einem Organisations- 
und lateraler Gastrulahälften von Triton taeniatus und alpestris usw. 113

zentrum in der oberen Urmundlippe aus nach vorn fortschreitend, bis der Keim gewissermaßen mit Medullarplatte "gesättigt « wärc, nach einer für dio Specics typischen Proportion. Dieser Augenblick der Sättigung würde natürlich beim halben Keim frühor eintreten als beim ganzen. Da die Größenabmessung der Medullarplatte im halben Keim nach derselben "Methode " erfolgen würde wie im normalen ganzen, so würde ihre Bezeichnung als regulatorisch den eigentlichen Sinn verlieren.

Dies fïhrt zu einer weiteren Fragestellung. Ich habe vor kurzem mitgeteilt (1921, S. 568), daß man in indifferentem Keimmaterial die Bildung einer Medullarplatte dadurch hervorrufen kann, da 3 man einen »Organisator «, d. h. ein kleines Stück des Organisationszentrums eines anderen Keimes, implantiert. Man könnte nun erwarten, daß durch dieses Hinzukommen einer zweiten Medullarplatte die mSättigung: des Keims mit Medullarsubstanz früher eintritt, und da $B$ daher die primäre Medullarplatte nicht ihre volle Größe erreicht. Das wird sich wohl exalit prüfen lassen.

Diese Uberlegungen scheinen mir von allgemeiner Bedeutung für das Problem des harmonisch-äquipotentiellen Systems zu sein.

Wie es sich nun in dem vorliegenden Fall der isolierten dorsalen Keimhälfte mit der Frage der Regulation verhält, wird davon abhängen, ob das vertauschbare Ektoderm der beginnenden Gastrula wirklich noch indifferent oder ob es bloß noch in hohem Maße umbildungsfahig ist. Dem Begriff der Indifferenz liogt die Vorstellung zugrunde, daB die Wege der Entwicklung, welche vom Ei zu den einzelnen Organen hinführen, nicht von Anfang an getrennt sind, sondern für Organe des gleichen Mutterbodens zunächst gemeinsam verlaufen und sich erst später gabeln und verzweigen. Vor Erreichung der Gabelungsstellen wären die betreffenden Zellen jeweils unter sich gleich, indifferent « (1918, S. 525). Sind die Zellen nur umbildungsfähig, so hätten sie min ihrer Entwicklung den Punkt schon überschritten, an welchem sich der ursprünglich gemeinsame Weg zu den einzelnen Organen hin gabelt, ja dicser Punkt könnte selbst ganz am Anfang der Entwioklung liegen «. Die bisherigen Versuche genügen nicht, um zwischen diesen beiden Möglichkeiten zu entscheiden. Bei den Transplantationen wurden wdie zu prüfenden Zellkomplexe zwar den differenzierenden Einflüssen ihrer ursprünglichen Umgebung entzogen, aber dafür unter spezifische Einflüsse einer neuen Umgebung gebracht; diese könnten wohl imstande sein, auch eine schon eingeschlagene Richtung wieder zu ändern. Um zu erkennen, welche Entwicklungstendenz solche Stücke in sich selbst enthalten, müßte man sie in indifferenter Umgebung sich entwickeln lassen, an indifferenten Stellen eines anderen Keims, in einer Nührlösung oder auch einfach in Wasser «(1918, S. 525/6). Sollte sich dabei 
herausstellen, daß sie schon zu Beginn der Gastrulation die Richtung auf Medullarsubstanz hin eingeschlagen haben, daB also die präsumptive Medullarplatte schon dann in ihren Grenzen festgesetzt ist, wenn auch nicht in unwiderruflicher Weise, so würde die Ausbildung der proportional kleineren Medullarplatte einen RegulationsprozeB voraussetzen. Aber auch dann wäre es fraglich, ob dasselbe für den normal proportionierten Keim gilt, welcher nach Durchschnürung im Zweizellenstadium aus dor dorsalen Blastomere entsteht. Diese Frage wird sich wohl nur dann beantworten lassen, wenn die Regulation unvollkommen ist, und da sie das schwerlich in höherem Maße sein wird als nach Isolicrung zu Anfang der Gastrulation, so werden etwaige Abweichungen von der normalen Proportion wahrscheinlich zu klein scin, um eine sichere Entscheidung zu ermöglichen.

\section{Die Postgeneration der seitlichen Keimhialten nach medianer Durchtrennung zu Beginn der Gastrulation.}

Nach den frontalen Keimdurchtrennungen in den fortschreitenden Stadien der Gastrulation erscheint als nächstliegende Aufgabe, die dort gewonnenen Ergebnisse durch die entsprechenden Durchtrennungen längs der Medianebene zu ergänzen. Ein Anfang dazu ist schon mit den oben erwähnten medianen Einschnürungen (1903) gemacht, welche dieselbe Abnahme der Regulationsfähigkeit ergaben; an jene Versuche hätten sich also völlige Durchtrennungen anzuschließen. Diese stoßen auf keine Schwierigkeit, wenn sie zu Beginn der Gastrulation vorgenommen werden; die beiden Keimhälften verheilen und entwickeln sich weiter. Anders bei vorgeschrittener Gastrulation. Da ist es neben der zunehmonden Differenzierung der Zellen und der abnehmenden Dicke der Rückenplatte wohl vor allem die bald einsetzende Längsstreckung, welche den Schluß der weit klaffenden Wunde verhindert. Dieselbe Erfahrung hatte ich schon früher gemacht, bei dem Versuche, die gleichseitigen Hälften zweier median gespaltener Keime zusammenzufügen. Im ersten Beginn der Gastrulation heilten z. B. zwei rechte Keimhälften ohne weiteres zusammen und jede der beiden Urmundhälften ergänzte sich aus dem anstoßenden Zellmaterial des anderen Keims (1918, S. 497ff.). In späteren Stadien dagegen gelang wohl die erste Zusammenfügung, aber das gemeinsame Weiterwachsen scheiterte an dem eigensimnigen Streckungsbestreben der beiden Keimhälften. Unter diesen Umständen erschien es nicht lohnend, die medianen Durchtrennungsversuche systematisch auf spätere Gastrulastadien auszudehnen.

Dagegen zeigten die Gastrulahälften nach früher Durchtrennung ganz typische Postgenerationserscheinungen. Diese waren schon $H$. Falkenberg bei den Durchschnürungsversuchen aufgofallen, welche ex 
auf meine Veranlassung an noch etwas jüngeren Entwicklungsstadien, an Blastulen von Triton tacnialus ausgeführt hatte. An den Neurulen, welehe aus den beiden Keimhälften entstanden, waren die Medullarwülste nicht selten asymmetrisch, und zwar manchmal so sehr, daß der Keim wie eine Halbbildung aussah. Einen solchen Fall hat Falkenberg auch abgebildet (1919, S. 385, Abb. 1 und 2). Nach der Beschreibung im Protokoll entsprachen diese Zwillinge genau den Gebilden, welche Roux als seitliche Halbembryonen auffaßt; die innonständigen Medullarwülste waren zuerst nicht zu erkennen, die Ergänzung begann dann anscheinend am vorderen Ende und schritt nach hinten fort. Da nun die ganze Frage der Halbembryonen, ihre Entstehung und Postgeneration noch keineswegs völlig geklärt ist, so erschien es. lohnend, diese Verhältnisse wciter zu verfolgen. Die allgemeinen Ergebnisse meiner darauf gerichteten Versuche habe ich schon ganz kurz mitgeteilt (Spemann-Falkenberg 1919, S.385ff.). Die Versuche wurden dann im Sommer 1920 von Frl. Gudrun Ruud im Freiburger Institut fortgesetzt.

a) Die typische Entwieklung der Keimhäften bis zum Neurulastadium.

Bei der langsamen Durchquetschang der jungen Gastrula entsteht, wie schon erwähnt, keine klaffende Wunde, vielmehr verkleben die frischen Ründer, die durch den Druck des Glasfadens zusammengebracht werden, und verwachsen miteinander. Jeder Halbkeim ist dann auf seiner äußeren Seite abgerundet, auf der inneren dagegen zu einer Schneide zusammengebogen, die sich an ihren beiden Enden in je einen Zipfel auszieht; etwa wie ein mitten durchschnittener Gummiball, dessen Ränder man zu einer Naht zusammongefügt hat, Da die Eiachse bei der Operation möglichst senkrecht gestellt wird, so lkommen die übereinander gelegenen Eipole in der Naht zusammen und bilden deren Mitte, während zwei entgegengesetzte Punkte des Äquators ihre beiden Enden einnehmen. Im mittleren Teil der Naht grenzen also die kleinen Zellen des dünnen Daches der Gastrula an die großen Zellen ihres dicken Bodens; beide sind infolge ihrer kontrastierenden Färbung auch äußerlich scharf voneinander zu unterscheiden. Diese Grenze bleibt noch lange Zeit erkennbar, während die beiden Zipfel an den Enden der Naht sich bald abrunden, unter Zellverschiebungen, die im einzelnen schwer zu verfolgen sind.

Die Gastrulation der Halbkeime läßt sich besonders an Triton alpestris gut beobachten, weil hier der Farbenkontrast zwischen den dunkeln animalen und den hellen vegetativen Zellen stark ausgeprägt ist und daher die Verwachsungsnaht zwischen ihnen lange und deutlich erkennbar bleibt. Die äußerlich sichtbaren Veränderungen sind nach den zahlreichen genauen Beobachtungen von Frl, Ruzd sehr 
charakteristisch und zwar die folgenden. Die obere Urmundlippe, welche kurz nach der Operation unter rechtem Winkel auf die Verwachsungsnaht trifft, Abb. 16, dehnt sich allmählich nach beiden Seiten aus. Nach außen hin verlängert sie sich, der Grenze des Dotterfeldes folgend, zur seitlichen und unteren Urmundlippe, und stößt nach vollendetem Halbbogen wieder auf die Verwachsungsnaht (Abb. 17 und 18); nach innen greift sie ein Stück weit auf die Verwachsungsnaht über (Abb. 17). Gleichzeitig krümmt sich diese letztere im mittleren Teil ihrer Länge, welcher zwischen der oberen Urmundlippe und der gegenüberliegenden Grenze des Dotterfeldes liegt, gerade als würden diese

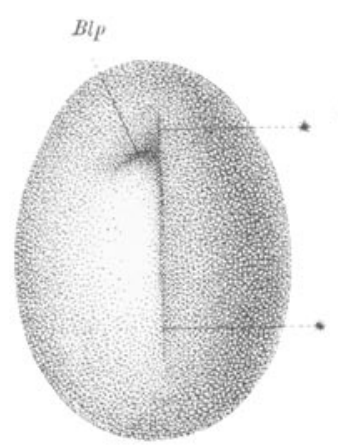

Abb. 16.

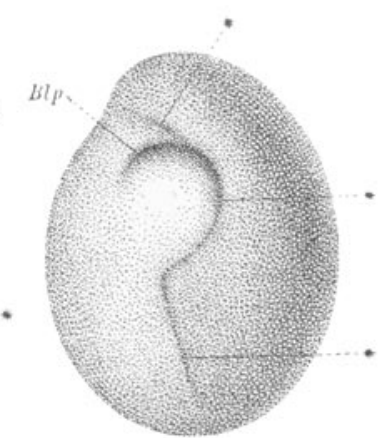

Abb. 17.

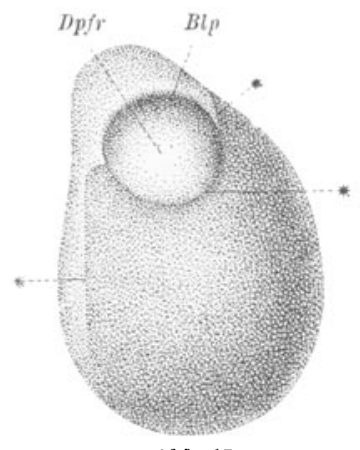

Abb. 18.

Abb. 16-18. Gastrulation einer abgetrennten linken Keimhälfte, etwas schematisiert. Abb. 16, bis etwa 6 Stunden nach der medianen Durchschneidang; linke Urmundhalfte $B l p$ endigt scharf an der geraden Verwachsungsnaht $*$ in welcher dunkle animale und helle vegetative Keimhalfte zusammenstoben.

Abb. 17, bis 18-20 Stunden nach der medianen Durchschneidung; die obere Urmundlippe hat sich nach links ausgedehnt, nach rechts hat die Einstilpung auf die Verwachsungsnaht ibergeIgriffen; dadurch und durch den Zug der Entodermzellen hat die Verwachsungsnaht ** eine Ausbiegung und Einknickung erfahren.

Abb. 18, bis 24-30 Stunden nach der medianen Durchschneidung; die linke Urmundlippe hat die Verqachsungsnabt ** erreicht, an der Stelle der noch verschäriten Einknickung.

Punkte gegeneinander gezogen und das Dotterfeld könnte sich verkürzen, nicht aber das durch die Operation mit ihm verbundene animale Dach der Gastrula. Dies ist aber genau das, was man erwarten muB, wenn die einzelnen Teile des Halbkeims trotz ihrer Trennung und abnormen Neuvereinigung die schon eingeleiteten Zellbewegungen der Gastrulation unter leichten Abänderungen weiterführen. Die Dotterzellen drängen gegen den Urmund und nehmen die durch die Operation mit ihnen verbundenen animalen Zellen mit; die obere Urmundlippe ihrerseits, die über die Dotterzellen vorwächst und sich gleichzeitig einrollt, zieht dabei die anstoßenden animalen Zellen nach. So wird der obere Winkel zwischen Verwachsungsnaht und Urmund aus einem rechten oder stumpfen ein spitzer (Abb. 17), und der mittlere Teil der Naht krümmt sich ein, wie ein Bogen bei Verkürzung seiner Sehne. 
und lateraler Gastrulahälften von Triton taeniatus und alpestris usw. 117

Die Erscheinungen unter diesen eigentümlich abgeänderten Bedingungen stimmen also völlig überein mit derjenigen Auffassung von der Gastrulation, welche schon früher durch verschiedene Tatsachen gefordert wurde und jüngst durch meine Transplantationsversuche eine neue Stütze erhalten hat (1918, S. 517ff.; 1921, S.548ff.). Nach einer anderen Auffassung, nach der von $O$. Hertwig (1892) im Anschluß an Roux (1888) vertretenen Konkreszenztheorie, käme die Úberwachsung des Dotterfeldes bekanntlich durch seitliche Zusammenschiebung und mediane Verschmelzung der oberen Urmundlippe zustande. Die Bewegung der oberen Urmundlippe und der Dotterzellen in sagittaler Richtung gegeneinander wäre also nur eine scheinbare, in Wirklichkeit fänden bloß Zellverschiebungen in seitlicher Richtung statt. Man müßte daher bei der Gastrulation der Halbkeime erwarten, daß das mediane Ende der halbierten oberen Urmundlippe auf der Verwachsungsnaht nach hinten rückte; zu einer Ausbiegung der Verwachsungsnaht und ihrer scharfen Einknickung, wie Abb. 18 sie zeigt, fehlte bei Wegfall der sagittalen Zellverschiebungen jeder Anlaß. Die Konkreszenztheorie würde also, wie sie (mindestens in ihrer reinen Fassung) unvereinbar mit den Ergebnissen der oben erwähnten Transplantationsversuche ist, auch unfähig sein, die eigentümlichen Erscheinungen bei der Gastrulation der Halbkeime zu erklären.

Während die obere Urmundlippe unmittelbar nach der Operation an der Verwachsungsnaht scharf abgeschnitten endigt, greift sie einige Zeit nachher auf dieselbe ü ber (A bb. 16 und 17). Die Erscheinung selbst ist fast immer zu beobachten; ïber ihre Ursache und Pedeutung sind verschiedene Auffassungen möglich. Die Ursache könnte eine rein mechanische sein, indem die jenseits der Naht liegenden animalen Zellen von der oberen Urmundlippe, mit der sie verwachsen sind, einfach mit eingestülpt werden. Dabei könnten sie ihren ursprünglichen Charakter beibehalten, also gar keine eigentliche obere Urmundlippe werden, oder aber könnte der ursprünglich rein mechanische AnstoB, welcher die Einstülpung bewirkte, die Potenzen zur oberen Urmundlippe wecken, mit allen Folgen für die weitere Entwicklung. Dieser auslösende Einfluß von seiten der halbierten Urmundlippe könnte aber auch schon früher einsetzen, so daß schon die erste Einstülpung längs der Verwachsungsnaht seine Folge und nicht rein mechanisch bedingt wäre.

Der Fall liegt ähnlich wie bei einem früheren Experiment, wo zwei rechte oder zwei linke Gastrulahälften mit gleich gerichteter Achse zur Verschmelzung gebracht wurden (1918, S. 497ff.). Dabei ergänzte sich jede Urmundhälfte aus den anstoßenden Zellen des angeheilten Keimstücks, welche normalerweise etwa untere Urmundlippe gebildet hätten, und dann ging die Entwicklung weiter wie normal. Auch hier bleibt zweifelhaft, was die erste Ursache der übergreifenden Einstülpung 
ist, der rein mechanische Zug der Urmundhälfte, welcher die anstoßenden Zellen mitnimmt, oder ein von ihr ausgehender differenzierender Einfluß, der das fremdartige Material in "Zellen der oberen Urmundlippe « verwandelt, die sich dann selbsttätig einstülpen. Dagegen läßt sich hier aus dem weiteren Verlauf der Entwieklung erkennen, daß es sich wirklich um eine Gastrulation handelt; denn die eine Hälfte der Medullarplatte bildet sich aus dem Material vor der ergänzten Urmundhälfte, der Sehluß des Urmunds erfolgt normal und es entsteht ein normales einheitliches Schwänzchen.

Zwei dieser Kriterien können wir nun auch auf die Gastrulation der Halbkeime anwenden, nämlich den Urmundschluß und die eng damit zusammenhängende Ausbildung des Sehwänzchens. Bei Triton taeniatus kann sich nach meinen Beobachtungen der Urmund völlig schließen; sehr häufig aber bleibt die Utberwachsung des Dotters unvollständig. Dieses letztere fand Frl. Ruud auch für Triton alpestris, ja sie kommt sogar zu dem Schluß, daß bei genau medianer Durchtrennung der Dotter nie völlig . bedeckt wird. Ein Grund hierfür könnte darin liegen, daß im Halbkeim das Ektoderm, welches sich nicht beliebig verdünnen und ausdehnen kann, zu knapp wird, um das Entoderm ganz zu umschließen; eine Verminderung des relativ zu massigen Dottermaterials müßte also die Gastrulation erleichtern. In der Tat fand Frl. Ruud nach unsymmetrischer Durehtrennung völligen Schluß des Urmunds am kleineren dotterärmeren Stück, während beim größeren der Dotter unbedeckt war (Trit. alp. R. 1920, 46). - Zu diesem Miß. verhältnis zwischen Deckmaterial und Inhalt könnte nun aber noch etwas weiteres kommen. Wenn bei der normalen Gastrulation der kreisförmig gewordene Urmund sich verengt und allmählich zu einem kleinen Loch zusammenzieht, so setzt das ziemlich verwickelte Vorgänge in den Urmundlippen voraus, wie ungleiches Wachstum, Verschiebungen von Zellen und vielleicht auch Ausscheiden von solchen, Vorgänge also ganz typischer Art, die nicht schon einem Umschlagsrand als solchem- zukommen. Bei der Gastrulation des Halbkeimes würde sich also die Zusammenziehung des Urmunds, falls die Verwachsungsnaht unverändert bliebe, auf die eigentlichen Urmundlippen beschränken müssen; die Verwachsungsnaht würde sich im günstigsten Fall bis fast zum Kreis zusammenkrümmen, sie würde aber immer ein großes Stïck des Dotters unbedeckt lassen. Wenn daher der Dotter, wie meistens der Fall, nicht vollständig bedeckt ist, so könnte das in dem Widerstand der unveränderten Verwachsungsnaht seinen Grund haben, es könnte aber auch durch das ungünstiger gewordene Mengenverhältnis zwischen Deckmaterial und Inhalt seine genügende Erklärung finden. Wenn dagegen der Urmund, wie manchmal geschieht, ganz zusammengezogen wird, so ist sicher die Verwachsungsnaht ein 
Teil von ihm geworden, die Gastrulation hat wirklich auf sie übergegriffen, mit allen Folgen für die weitere Entwicklung.

Die beiden, den Urmund überragenden Enden der Verwachsungsnaht verhalten sich verschieden. Der Teil, welcher unter der unteren Urmundlippe liegt, bleibt viel länger unterscheidbar, als der über der oberen Urmundlippe gelegene. Zum Teil mag dieser letztere mit eingestülpt werden, $\mathrm{Abb}$. 17, zum Teil mag eine stärkere Aktivität in dieser Region die spurlose Verschmelzung der zusammengeheilten Hälften beschleunigen.

Während der Gastrulation ändert der Keim seine äußere Form. Anfangs, nachdem die spitzen Zipfel an den Enden der Verwachsungsnaht sich abgerundet haben, ist er oval, Abb. 16; allmählich wird er birnförmig, inden er sich auf der Seite der oberen Urmundlippe zuspitzt, $A b b .17$ und 18, auf der anderen Seite etwas verdickt. Diese Form hat der Keim noch, wenn die Medullarplatte mit den Wülsten sichtbar geworden ist, Abb. 19 und 20. Auch ganze Keime, welche ihre Gastrulation auBerhalb des Dotterhäutchens durchgemacht haben, sind nicht rund oder länglich wie innerhalb der Eihüllen, sondern birnförmig, indem sich ihr hinteres Ende nach dem Urmund zu mehr oder weniger stark verjüngt. In extremen Fällen sieht auch der Urmund nicht ganz normal aus, sondern wie nach außen gepreßt; das mag dann eine leichte Abweichung vom normalen sein, welche während der Gastrulation durch den Wegfall des formgebenden Dotterhäutchens entstanden ist ( $O$. Mangold 1920, S. 255ff.). Eine schwache birnförmige Verjüngung des Keimes nach hinten zu könnte aber auch seine normale Gleichgewichtsgestalt sein, während er innerhalb des Dotterhäutchens unter Beanspruchung seiner Elastizität deformiert wäre. Das müßte sich durch spätere Entfernung des Dotterhäutchens im Neurulastadium leicht feststellen lassen. So erinnere ich mich, öfters beobachtet zu haben, daB die Medullarwïlste sich nach Befreiung aus dem Dotterhäutchen sofort schärfer abgrenzten, gerade als ob sie vorher gepreßt gewesen wären. Von dieser einfachen Birnform hüllenloser Ganzkeime weichen die Halbkeime darin ab, daß ihre innere, der ursprünglichen Medianebene entsprechende Seite eingezogen ist, und zwar am stärksten am hinteren Ende. Dieses ist wie ein rundlicher Höcker eingeschlagen und über das Dotterfeld, falls es noch offen ist, herüber gebogen.

Völlig deutlich wird die schwächere Ausbildung der Innenseite des Keims, wenn die Medullarplatte sichtbar geworden und von Wülsten umgeben ist. Ihre Medianlinie, durch die Medullarrinne bezeichnet, ist in ganzer Länge nach innen umgebogen, vorn weniger, nach hinten zu immer stärker. Die Medullarwülste können am vorderen Ende ziemlich symmetrisch ausgebildet sein; nach hinten zu wird der innenständige, oft ganz plötzlich, schwach und undeutlich oder hört ganz auf. 
Von besonderem Interesse ist Ausbildung und Verlauf seines hintersten Endes in den Fällen, wo die Gastrulation nicht normal zu Ende geführt werden konnte und das Dotterfeld zum Tejl unbedeckt blieb. Der innere Wulst biegt dann an der Stelle, wo er auf das Dotterfeld trifft, in scharfem Winkel von der Medullarplatte ab, deren äußere Begrenzung er bis dahin bildete, und umsäumt das Dotterfeld, dem Verlauf der Verwachsungsnaht folgend (Abb. 19 und 20).

Die lang erkennbar bleibende Verwachsungsnaht und das offene Dotterfeld machen es möglich, die einzelnen Teile der Neurula auf die Gastrula zurückzuführen und damit wenigstens in großen Zügen festzustellen, wie sich die wirklich entstandene ganze Medullarplatte zu

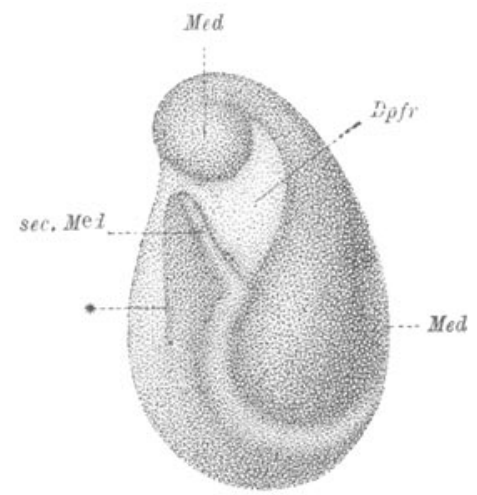

Abb 14

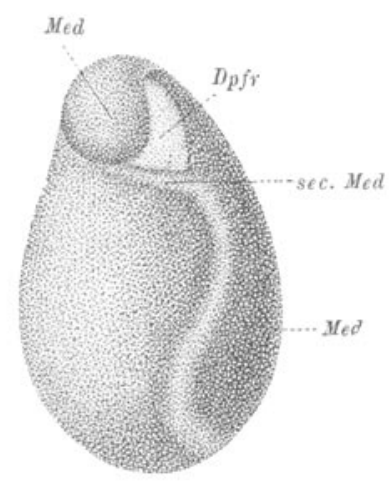

Abb. 20.

Abb. 19 und 20, etwa 3 Tage nach der medianen Durchschneidung. Aus halber linker Gastrula (Abb, 16-18) entstandene Neurula mit verkummerter fnnenständiger (rechter) Seite und eingerolitem Hinterende; in $\mathbf{A b b} .19$ die Verwachsungsnaht * mit ihrem scharien Knick noeh zu erkennen, der Dotter $D p f r$ noeh in groBer Ausdehnung unbedeckt; der innere Medularwulst setzt sich in einen schwachen sekundären Wulat sec. Med fort, der längs der ursprüruglichen Verwachsungsnaht nach hinten zieht.

der präsumptiven halben verhält. Zu Beginn der Gastrulation reicht das Material für die Medullarplatte normalerweise nach hinten bis zu der Stelle über dem Urmund, bis zu welcher sich die obere Urmundlippe bei der Einstülpung umrollt; nach vorn erstreckt es sich bis fast zum animalen Pol. Bei der medianen Durchquetschung der Gastrula wird dieses Material symmetrisch halbiert und bei ihrer Zusammenkrümmung zur Verwachsungsnaht in scharfem Knick gewaltsam umgebogen. In der Abb. 16 würde es also links von der Naht etwas äber dem Urmund beginnen, sich nach vorn über den Umriß des Keims hinaus auf dessen abgewendete Seite erstrecken und im Bogen auf die Seite rechts von der Naht bis gegen deren Mitte herunterreichen. Vergleicht man nun mit dieser Gastrula der Abb. 16 die annähernd gleich orientierte Neurula der Abb. 19, so erkennt $\operatorname{man}_{2}$ daß die wirklich entstandene Medullarplatte im großen und ganzen dieselbe Lage einnimmt 
wie die präsumptive halbe Medullarplatte im Gastrulastadium, nur haben die einzelnen Teile der letzteren eine durchgreifend andere Verwendung gefunden. Abgesehen davon, daß die wirkliche Medullarplatte nicht halb, sondern auf ihrer Innenseite ergänzt ist, nimmt auch ihr Vorderende eine andere Stelle ein. Dasjenige der präsumptiven halben Medullarplatte entsprach ungefähr der Stelle, wo der innere Medullarwulst in scharfem Winkel von der Medullarplatte abbiegt, Abb. 19; diese Stelle liegt jetzt am inneren Rand der Medullarplatte, ziemlich weit hinter dem Vorderende. Alles in allem kann man sagen, daß die Medianebene der wirklichen Medullarplatte gegen die Medianebene der virtuellen oder präsumptiven Medullarplatte um einen spitzen Winkel nach außen gedreht ist.

Es könnte für manche Zwecke wertvoll sein, diese Lokalisation noch genaver durchzuführen. Das läßt sich dadurch erreichen, daß in den Keim, der median durchtrennt werden soll, vorher an verschiedenen Stellen kleine Stückchen indifferenten Ektoderms eines anders gcfärbten Keimes als Marken eingesetzt werden (vgl. Spemann-Falkenberg 1919, S. 387). Man entnimmt diese Stückchen am besten cristatusKeimen, deren völlig pigmentlose Zellen von den dunkleren Keimen von taeniatus und alpestris sehr scharf abstechen und dauernd unterscheidbar bleiben. Diese transplantiert man in der früher (1918) geschilderten Weise mittels der Mikropipette. Soll eine bestimmte Stelle der animalen Keimhälfte markiert werden, an welcher eine Orientierung wegen der gleichmäßigen Pigmentierung nicht möglich ist, so muß vor der Implantation die Medianebene von der vegetativen Keimhälfte aus durch zwei kleine Kerben bezeichnet werden, die man mit der Glasnadel am Rande des Keims so anbringt, daB sie auch vom animalen Pol aus sichtbar sind. Nun wird das Stück an der gewünschten Stelle eingesetzt, und wenn es glatt eingeheilt ist, $1^{1 / 2}-2$ Stunden später, der Keim median durchschnitten; da auch dies von der animalen Hälfte aus geschieht, muß wieder die Medianebene vorher leicht angegeben werden. Wie exakt und genau symmetrisch die kleine Marke sich bei medianer Lage durchtrennen und auf die beiden Keimhälften verteilen läßt, zeigen die Abb. 23, 24, 29, 33, 38 .

Die Ergebnisse sind noch nicht lückenlos; hier nur einige wenige Beispiele.

Trit taen. Sp 1918, 1. Beginnende Gastrula (Abb. 21); auf der animalen Hälfte kleines Stück cristatus-Ektoderm eingesetzt, median und in der Höhe der oberen Urmundlippe (Abb. 22); median durchschnitten (Abb. 23); die Marke ist auf beide Keimhälften verteilt und liegt an der Verwachsungsnaht genau neben dem halbierten Urmund (Abb. 24 $l u$ u. $r$ ). 22 Stunden später ist die Gastrulation ziemlich beendigt; die beiden Marken sind noch sehr deutlich; sie grenzen an das Dotterfeld und 
haben sich etwas in die Länge gestreckt (Abb. $25 l$ und $r$ ). 18 Stunden später zeigen beide Keime eine dunkel pigmentierte Medullarplatte mit

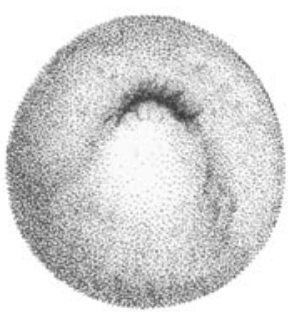

Abb. 21.

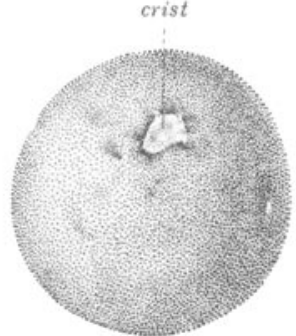

Abb. 22.

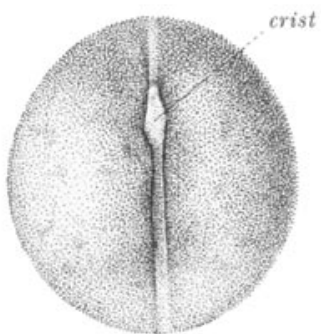

$\mathrm{Abb}, 23$.

Abb. 21. Keim von Triton taeniatus zu Beginn der Gastrulation, ohne Eihüllen, vom vegetativen Pol gesehen.

Abb. 22. Derselbe Keim, vom animalen Pol gesehen; in der Höhe des Urmunds kleines Stück cristatus-Ektoderm als Marke eingesetzt.

Abb. 29. Derselbe Keim vom animalen Pol gesehen; feiner Glastaden schneidet eben median durch und halbiert die Marke (crist).

Vergr. $>20$.

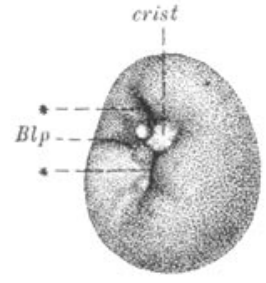

l

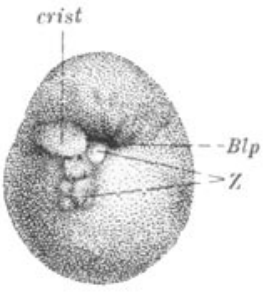

Abb. $21 l$ und $r$. Linke und rechte Gastrulahälfte, 40 Min. nach der medianen Durchschneidung; Verwachsungsnaht ** noch nicht scharf ausgebildet; einige anggetretene Zellen $Z$; die cristatus-Marke (crist) genau in der Höhe des halbierten Urmunds $\left\{B l_{p}\right\rangle$. Vergr. $\times 20$.

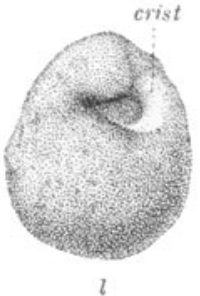

A.bb. $25 l$ und 1 . Dieselbe linke und rechte Gastrulahälfte wie Abb. 24, 223/4 Stunden nach der Durchschneidung; das Dotterfeld noch nicht ganz gedeckt, Medullarplatte noch nicht unter. scheidbar, aber Marke (crist) schon gestreckt, grenzt an das Dotterfeld. Vergr. $\times 20$.
Beginnende Gastrula (Abb. 27); auf der animalen Hälfte kleines Stück cristatus-Ektoderm eingesetzt, median, vor der Höhe des Urmunds (Abb. 28); dieses Stück beider medianen Durchquetschung ziemlich gleichmäßig auf beide Keimhälften verteilt, liegt an der Verwachsungsnaht, über dem halbierten Urmund (Abb. 29l und $r$ ). 42 Stunden später sind beim rechten Keim die Medullarwïlste schon ziemlich zusammengerückt, das

Hinterende ist nach links eingekrümmt; das weiße Stück liegt langgestreckt in diesem Hinterende. Der linke Keim sah schlecht aus und 
war unbrauchbar. 11 Stunden später sind die Wülste fast in ganzer Länge zum Rohr geschlossen, klafften nur vorn noch etwas (Abb. $30 r$ ). Der Urmund ist auf die linke Seite verschoben und wird von der Fortsetzung des rechten Medullarwulstes im Bogen umzogen. In diesem Teil liegt derStreifen cristatus-Gewebe; am lebenden Keim war er deutlich (Abb. 30r), an dem

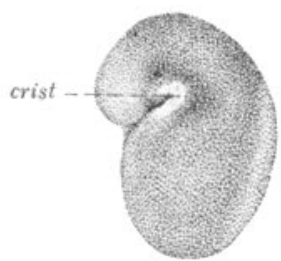

$A b b .26 l$ und $r$. Ginke und rechto Neurula, orientiert wie die Gastrulae der $\mathbf{A b b}, 25 l$ und $r$, ans denen sie entstanden sind, 41 Stunden nach der Durchschneidung; Medullarplatten vorne ziemlich symmetriseh und daher gerade, in der Mitte und hinten auf der Innenselte verkümmert und daher eingekrimmt; Marken (crist) schmal ausgezogen liegen am inneren Rande der Medullarplatte. Vergr. $>20$.

mehrere Jahre alten konservierten Objekt ist er äußerlich nicht mehr zu erkennen, jedenfalls ist er auch durch SchluB des Wulstes zum Halbrohr ins Innere gerückt.

Trit.taen. Sp 1918, 48. Operation wie im vorigen Fall, Abb. 31 und 32. Die zertrennte Marke muß wohl zunächst etwas über dem Urmund gelegen haben (Notiz darüber fehlt); $3^{1 / 2}$ Stunden nach der Durchtrennung greift die Gastrulation auf die Verwachsunsgnaht über und die Marke berührt den Urmundrand ( $\mathrm{Ab}$ bild. $33 l$ und $r$ ). Weitere 40 Stunden später ist die Medullarplatte an beiden Keimen angedeutet; das Dotterfeld ist noch weit offen; die Marken sind langge-

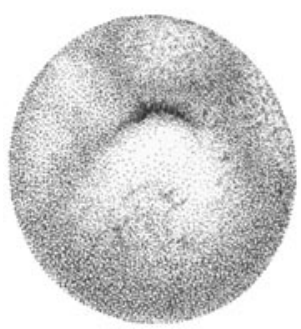

Abb. 27.

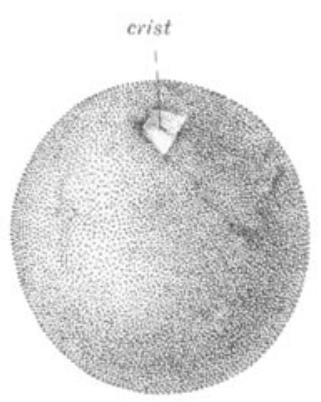

Abb. 28.

Abb. 27. Keim von Triton tasniatzss zu Beginn der Gastrulation, ohne Eihullen, yom vegetativen Pol gesehen.

Abb. 28. Derselbe Keim, vom animalen Pol gesehen; vor der Höhe des Urmunds kleine Marke (crist). Vergr. $>20$.

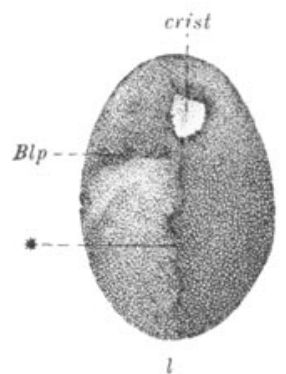

Abb. $29 l$ und r. Linke und rechte Falfte desselben Keims, etwa 3 Stunden nach der medianen Durchschneidung; die halbierte Marke (crist) gitzt an der Verwachsungsnaht (*), ein wenig vor der oberen Urmundlippe $(B l p)$. Vergr. $\times 20$. streckt und umziehen im Bogen das Dotterfeld, ganz nahe dem inneren Rande der Medullarplatte (Abb.34lund $r$ ). 12 Stunden spä ter wurden die 
Keime konserviert; der linke ist geborsten und nicht mehr brauchbar, der rechte zeigt folgende Verhältnisse (Abb. 35). Die Medullarplatte ist an ihrem Vorderende einheitlich, mit stärkerer äußerer und schwächerer innerer Seite; nach hinten spaltet sie sich in zwei Hälften von

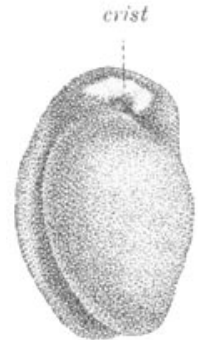

Abb. 30 r. Rechter Keim mit zusammengerhokten Medullarwïlsten, orientiert wis die Gastrula der Abb. $29 \%$, aus der er entstanden ist; 44 Stunden nach der medianen Durchschneidung; Dotterfeld noch nicht ganz gedeckt; an oder nahe seinem Rande die Marke (crist). vergr. $\times 20$.

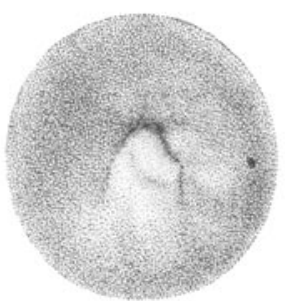

Abb. 31 .

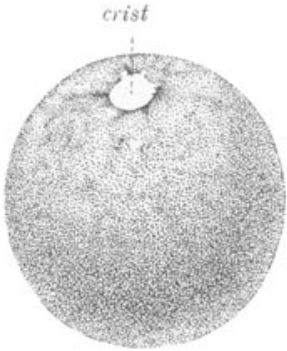

Abb. 32.

Abb. 31. Keim von Triton taentatus zu Begina der Gastrulation, ohne Eihüllen, von der vegetativen Seite gesehen.

Abb. 32. Derselbe Keim, von der animalen Seite gesehen; vor der Höhe des Urmunds Marke (crist).

Vergr. $\times 20$.

entsprechend verschiedener Stärke, welche das weit offene Dotterfeld umziehen. Dieses ist

rautenförmig, mit einem spitzen Winkel vorn und hinten. Drei Seiten dieser Raute werden durch die außenständige Hälfte der Medullarplatte begrenzt, die vierte durch den kurzen, ganz flachen sekundären inneren Medullarwulst. $1 \mathrm{~m}$ vorderen spitzen Winkel, zwischen den auseinander

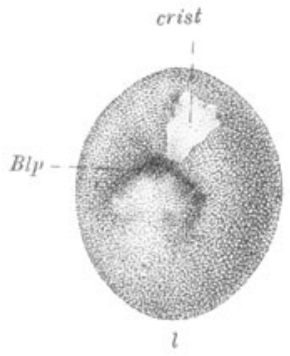

Abb. $33 l$ und $*$. Linke und rechte Hälte desselben Keims, $31 / 2$ Stunden nach der medianen Durchschneidung; die halbierte Marke (crist) berïhrt die obere Vrmundlippe ( $B(p)$, welche weit aut die Verwachsungsnaht tibergegriffen hat. Vergr. $>20$.

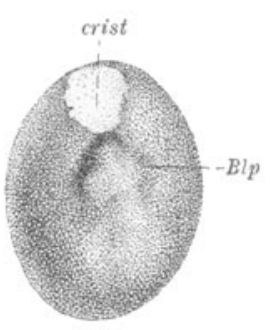

tretenden beiden Schenkeln der Medullarplatte, senkt sich das Dotterfeld zu einem ganz kleinen Loch ein, welches jedenfalls unter das Vorderende der Medullarplatte in den Kopfdarm führt. Der hintere spitze Winkel des Dotterfeldes ist in größerer Länge spaltförmig vertieft, auch hier jedenfalls ein Zugang zum Inneren des Darmes.

Im übrigen ist die äußere Hälfte der Medullarplatte dem Dotterfeld fest angepreßt; ihr Rand wird von der lang und schmal ausgezogenen Marke eingenommen, welche den hakenförmigen Knick des äußeren Medullarwulstes umzieht und sich nach vorn bis fast an die Gabelungsstelle der Medullarplatte, nach hinten nicht ganz bis an das Ende 
und lateraler Gastrulahälften von Triton taeniatus und alpestris usw. 125

des Medullarwulstes erstreckt. Die Übereinstimmung gerade dieses Keimes mit dem Schema der Abb, 19 ist eine vollständige.

Trit. taen. $S p$ 1918, 49. Marke noch näher dem Äquator eingesetzt (Abb. 36 und 37), nach der symmetrischen Durchquetschung daher ziemlich weit über dem Urmund (Abb. 38). 37 Stunden später rechter

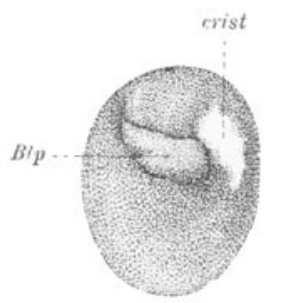

$l$

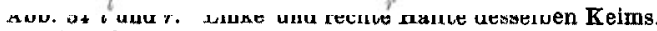
43:/2 Stunden nach der Operation; Urmund $(B l p)$ noch weit offen, am inneren Rande von der gestreckten Marke (crist) im Bogen umzogen. Vergr. $\times 20$.

Embryo unbrauchbar; beim linken Embryo Medullarplatte angedeutet. In ihrer Mittellinie liegt langgestreckt die Marke (Abb. 39).

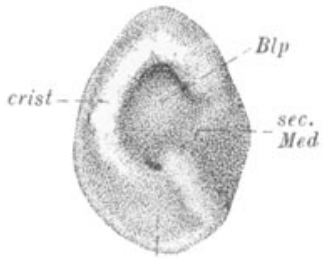

Med

Abb. 35. Der Kelm der Abb. $94 r$, in gleicher Orientierung, 12 Stunden spater; Urmund $(B l p)$ noch weit offen, auf der äuBeren Seite be grenzt von der gebogenen Medullarplatte (Hed) mit der lang ausge. zogenen Marke (crist), auf der inneren Seite von einem ganz fachen sekundăren Medullarwulst (sec. Med) Vergr. $>20$.

12 Stunden später wurde der Keim konserviert. Die Wülste sind etwas näher zusammengerückt, die Medullarplatte ist aber noch weit offen; hinten ist sie stark nach der inneren Seite umgebogen. Das Dotterfeld scheint ganz überdeckt zu sein, aber die Form des Urmunds ist nicht

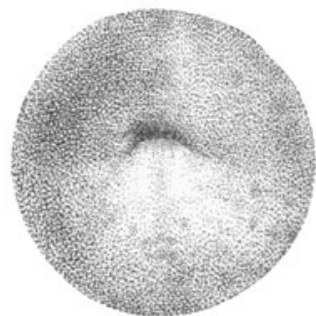

Abb. 36.

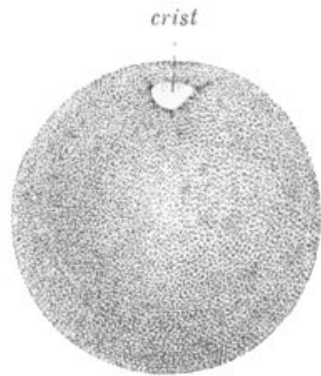

Abb. 8 \%.

Abb. 36. Keim von Triton taeniatus zu Beginn der Gastrulation, ohne Eihullen, von der vegetativen Seite gesehen.

Abb. 37. Derselbe Keim von der animalen Seite geselien; weit vor der Höhe des Urmunds die Marke (crist). Vergr. $\times 20$.

normal. Er hat die Form eines kurzen Bogens, der schräg hinter der Medullarplatte liegt und dessen rechtes Ende etwas weiter nach vorn reicht als das linke, entsprechend der Verkürzung der rechten Hälfte der Medullarplatte. Die Marke ist zu einem ganz schmalen Streifen ausgezogen, dem rechten Medullarwulst etwas mehr genähert als dem 
linken; nach hinten reicht sie bis zum Urmund, und zwar bis zu seinem vorderen Winkel, den man auch auf $\mathbf{A b b} .39$ von oben sieht. Die Marke liegt also nicht am inneren Rande der Medullarplatte, wie in Abb. 35, sondern in ihrer Mitte, entsprechend ihrer größeren Entfernung vom Urmund, vgl. Abb. 38 mit Abb. 33 .

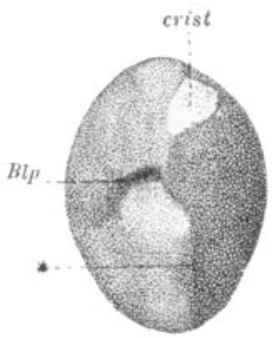

l.

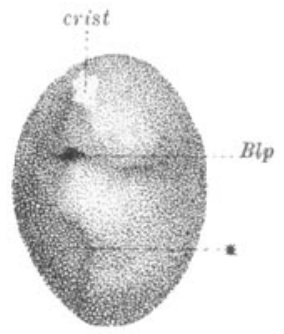

$r$

Abb. 38 und $r$. Linke und rechte Halfte desselben Keims, $53 / 4$ Stunden nach der medianen Durchschneidung; die halbierte Marke (crist) liegt an der sehr deutlichen Verwachsungsnaht * ziemlich weit über dem Urmund (Blp) Vergr. $\times 20$.

Trit. taen. Sp 1918, 70. In diesem Fall (Abb.40) wurde die Marke wieder ziemlich nah dem Äquator, aber dabei etwas links von der Medianebene eingesetzt, so daß sie nach der medianen Durchtrennung des Keims ganz seiner linken Hälfte zufiel (Abb. 41). Sie lag dann nur ein klein wenig weiter vom Urmundrand weg als im vorigen Fall (Abb.42,

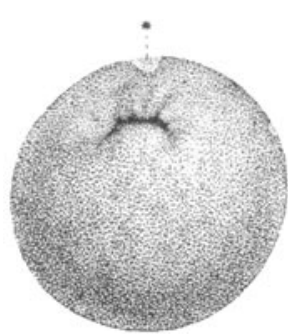

Abb. 40.

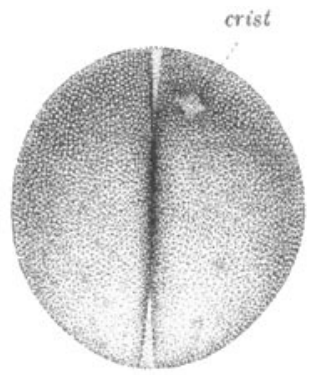

Abb. 41

Abb. 40. Keim von Friton taeniatus zu Beginn der Gastrulation, ohne Wihullen, vom vegetativen Pol gesehen; bei * Kerbe zur Markierung der Medianebene.

Abb. 41. Derselbe Keim vom animalen Pol, whrend der Durchschneidung; die eingepflanzte Marke (crist) in der linken Keimhälfte, etwa in der $\mathbf{H}$ öhe des Urmunds, Vergr, $>20$.

vgl. mit $A b b .38 l$ ), dagegen ziemlich viel weiter von der Verwachsungsnaht entfernt. Es ist alșo nach dem, was oben an der Hand der schematischen Abb. 16-20 ausgeführt wurde, zu erwarten, daß sie wieder in der Mittellinie der Medullarplatte auftreten wird, aber mehr nach ihrem Vorderende zu. Und das traf auch in der Tat ein, Abb. 43, als $221 / 2$ Stunden später die Medullarplatte sichtbar geworden war. 
Nach diesem letzten Experiment zu schließen müßte eine Marke, welche gerade die Mitte des Vorderendes der Medullarplatte bezeichnen sollte, noch etwas weiter von der primären Medianebene und etwas näher zum animalen Pol liegen. Solch ein Fall fehlt mir leider; auch sonst sind die Versuche der Vervollständigung bedürftig. Um sie in vollkommener Weise durchzuführen, müßte man immer zwei Keime an möglichst genau derselben Stelle mit einer Marke versehen, dann den einen median spalten, den anderen sich normal entwickeln lassen; so ließen sich alle charakteristischen Punkte des Halbkeims auf die des Ganzkeims zurückführen.

Besonders wertvoll wäre es, die beiden Endpunkte des sekundären innenständigen Medullarwulsts (vgl. S. 120, Abb, 19 und 20) durch Marken genau zu bestimmen, also den Punkt, wo er in stumpfem Winkel von der Medullarplatte abbiegt, um am Rande des offenen Dotterfeldes

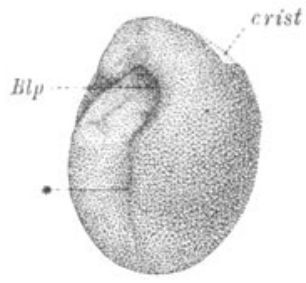

Abb. 42. Linke Keimhälfte der Abb. 41, 4 Stunden spater; Urmund $(B l p)$ hat auf die Verwachsungsnaht * übergegriffen; rechts von ihm die Marke (crist). Vergr. $>20$.

nach hinten zu verlaufen, und den zweiten Punkt, wo er mit dem

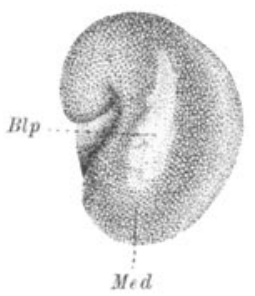

Abb. 43. Der Keim der Abb. 42, in gleicher Orientierung, etwa 27 Stunden nach der Operation; Medullarplatte (Med) mit kaum angedeuteten wulsten, das Hinterende hakenförmig nach der rechten (inneren) Seite umgebogen; in der Medianlinie die Marke (crist), naher dem Vorderende als in $\mathrm{Abb} .39$. Vergr. $\times 20$. Ende des primären Medullarwulstes zusammentrifft. Zweifellos entsteht diese Strecke aus animalen Zellen längs der Verwachsungsnaht; wahrscheinlich entspricht ihr Anfang dem Vorderende der präsumptiven primären Medullarplatte. Darnach wäre dieser sekundäre Medullarwulst aus Zellmaterial gebildet, welches normalerweise nichts mit der Bildung der Medullarplatte zu schaffen gehabt hätte; als Ursache seiner Entstehung könnte nach Lage der Dinge nur ein determinierender Einfluß in Betracht kommen, der von dem vorderen Teil des innenständigen Medullarwulsts ausging. Entsprechend angebrachte Marken würden darüber Sicherheit schaffen.

Aber auch jetzt schon läßt sich aus den Ergebnissen der Versuche mancherlei entnehmen.

Zunächst erläutern die beiden Halbkeime kurz nach der Operation (Abb. 24, 29, 33, 38, 42) sehr schön, wie die übereinander gelegenen Punkte der animalen und vegetativen Keimhälfte in der Verwachsungsnaht zusammenkommen. Median eingesetzte Marken liegen ihrer Mitte 
um so mehr genähert, je näher dem Zentrum der animalen Keimhälfte die Einpflanzung erfolgt war.

Während der Weiterentwicklung verändern die Marken ihre Form in ganz typischer Weise, und zwar verschmälern und strecken sie sich in der Längsrichtung der Medullarplatto. Dieselbe Erscheinung läßt sich regelmäßig an Implantaten in der normalen Medullarplatte beobachten (1918, S.463ff.; 1921, S.546ff.), in ihrer ganzen Länge mit Ausnahme des vordersten Teils des breiten Felds; sie lassen auf eine Iängsstreckung schließen, welche die Medullarplatte von ihrer ersten Differenzierung an erfährt. Dieselbe Längsstreckung erfolgt also auch im halben Keim; da dessen Medullarplatte aber um den Urmund und das Ende der Verwachsungsnaht herumgebogen ist, so ist es anch der helle Streifen, in welchen sich die Marke auszicht; er verrät die Streckung und ihre Richtung zu einer Zeit, wo von der Medullarplatte noch nichts deutlich zu erkennen ist. Bei der normalen Entwicklung beginnt die Längsstreckung erst, nachdem der Urmund geschlossen ist. Bei den Halbkeimen dagegen kann der SchluB noch unvollkommen sein (z. B. Abb. 25, 34). Dann macht man die überraschende Beobachtung, da $B$ das Dotterfeld, welches schon fast bedeckt war, wieder sichtbar wird und beträchtliche Größe erreicht. - Es ist zu erwarten, daß eine Marke, welche das Vorderende der Medullarplatte trifft, auch im Halbkeim ihre rundliche Form dauernd beibehält.

Auf diese Weise lassen sich nun bestimmte Stellen der Gastrula für die Beobachtung festhalten und in ihrer Weiterentwicklung verfolgen. So muß sich durch genau median angebrachte Marken die Lage der Verwachsungsnaht und einzelner charakteristischer Punkte auf ihr dauernd bezeichnen lassen, und ebenso muB es möglich sein, die sekundäre Medianebene auf den normalen Keim zurück zu projizieren. Lückenlos durchgeführt ist das noch nicht; aber schon jetzt läßt sich deullich erkennen, daß die sekundäre Medianebene gegen die primäre um einen spitzen Winkel nach außen gedreht ist. Die markierten Koime bestätigen also durchaus die Auffassung, zu der die Beobachtungen von Frl. Ruud an Triton alpestris und der Vergleich ihrer schematischen Zeichnungen mit der normalen Entwicklung gefuhrt haben; weitere Verfolgung dieser Fxperimente verspricht noch mehr ins einzelne gehende Aufklärung.

Mit der Ausbildung der Medullarplatte sind zwar die Regulationsvorgänge noch nicht völlig abgeschlossen, aber doch die weiteren Entwicklungen im wesentlichen vorgezeichnet. Ehe wir daher diese noch etwas weiter verfolgen, erscheint es zweckmäBig, die bisherigen Ergebnisse mit denen anderer Experimente zu vergleichen und in ihrer allgemeinon Bedeutung zu erörtern. 


\section{b) Diskussion der Ergebnisse im Vergleich mit älteren Versuchen an Ampluibien und Echinodermen.}

Rouxs Hemiembryonen mit Postgeneration der fehlenden Seite. Die aus den seitlichen Gastrulahälften von Triton entstandenen Neurulen haben die größte Ähnlichkeit mit den bekannten "lateralen Hemiembryonen mit postgenerativer innerer Hälfte ", welche Roux aus ciner der beiden ersten Blastomeren des Froscheis nach Abtötung der anderen Blastomere erzielte. Die auffallendste Ubereinstimmung ist vielleicht die, daß die Ergänzung in beiden Fällen anscheinend am Vorderende beginnt und nach hinten fortschreitet. Das ist auch bei Triton oft sehr deutlich und bestimmt die ganze spätere Entwicklung; der Kopf einer solchen ergänzten Halblarve kann fast symmetrisch sein, wenn Rumpf und Schwanz nach innen eingebogen oder gar zu einer engen Spirale aufgewunden sind.

Für eine restlose Vergleichbarkeit beider Experimente scheint nuu aber die erste Voraussetzung zu fehlen, die Gleichheit oder wenigstens Ähnlichkeit des experimentellen Eingriffs. Im einen Fall war die eine Keimhälfte vom ersten Anfang der Entwicklung an aus der lebendigen Teilnahme an ihr ausgeschaltet worden, blieb aber als tote Masse mit der anderen Keimhälfte in Verbindung; im anderen Fall geschah die Trennung sehr viel später, zu Beginn der Gastrulation, war aber von Anfang an eine vollständige. Wäre die Art der Isolierung beidemaI dieselbe gewesen, so müßte man aus dem ähnlichen Ergebnis schließẹn, daß das Regulationsvermögen der Versuchsobjekte verschieden ist, indem bei Rana die frühe Isolierung denselben Erfolg hat wie die spätere bei Triton; das könnte man dann mit dem verschiedenen Regenerationsvermögen der erwachsenen Formen in Zusammenhang bringen, könnte auch darauf hinweisen, daß isolierte $1 / \mathrm{a}$-Blastomeren von Triton sofort, ohne nachweisbare Postgeneration, kleine Ganzembryonen liefern. Dieser Auffassung widersprechen aber andere Versuche. So hat einerseits Barfurth (1892, S. 138) zwar nicht bei Triton, aber doch bei einem anderen Urodelen, dem Axolotl, nach Anstich der einen Blastomere aus der anderen einen seitlichen Halbembryo erhalten; sollte er auch nicht wirklich rein halb gewesen sein, was sich mangels genauer Beschreibung mit Abbildungen nicht entscheiden läßt, so war er doch sicher zum mindesten stark asymmetrisch. Andererseits hat $O$. Schultze (1894) und Mc Clendon $(1909,1910)$ auch bei Rana aus der einzelnen $1 / 2$-Blastomere einen ganzen Embryo erzielt, ersterer durch Umordnung der verschieden schweren Eisubstanzen, letzterer durch völlige Abtrennung der abgetöteten Blastomere. Daraus wurde schon damals der Schluß gezogen, daß die Verschiedenheit im Ergebnis nicht auf einem verschiedenen Regulationsvermögen der beiden Objekte, des Anurenand Urodelenkeims beruht, sondern auf der Verschiedenheit des experi- 
mentellen Eingriffs; die anhaftende tote Eihälfte erhält die überlebende zunächst in ihrer normalen Form und verhindert oder verzögert dadurch die Regulations- und Ergänzungsvorgänge, welche an der völlig isolierten Hälfte sehr bald einsetzen. Dieses Hemmnis fällt weg, wenn die überlebende Hälfte sich von der toten Masse ablöst und in sich abschließt. Es liegt nahe, anzunehmen, daß die ersten ausgiebigeren Zellverschiebungen zu Beginn der Gastrulation diesen Vorgang befördern. Es würden sich also die beiden oben angeführten Unterschiede zwischen Rouxs Experiment und dem meinigen gegenseitig aufheben, so daß ihre Folgen beidemal auf dasselbe hinausliefen. Beim Anstichversuch wird die Ausschaltung der einen Keimhälfte zwar früher vorgenommen, aber ihre Wirkung wird dadurch, daß die tote Hälfte noch mit dèr lebenden in Zusammenhang bleibt, hinausgeschoben bis zu etwa demselben Zeitpunkt, in dem beim Durchtrennungsversuch die Ausschaltung erst eintritt.

Wenn nun unser Versuch mit dem von Roux in der Anordnung vergleichbar ist und im Ergebnis übereinstimmt, so kann er zu seiner Stütze dienen und zu seiner Erklärung beitragen. Beides scheint mir nicht überflüsssig.

Brachet, der in einer früheren Arbeit (1904) die Möglichkeit der Postgeneration wenigstens auf sich beruhen ließ, lehnt in einer neueren Arbeit (1910, S.77) die Annahme eines solchen Vorgangs entschieden ab. "Ni à l'occasion de ces recherches, ni dans mes autres travaux, je n'ai jamais observé de processus pouvant être sérieusement assimilés à un phénomène de postgénération. Je suis d'accord en cela avec presque tous les auteurs qui ont expérimenté sur l'oeuf de grenouille, et, notamment, pour ne citer que les derniers, $K$.Ziegler et Konopacka." Daß diese Ablehnung der Postgeneration im allgemeinen gilt, nicht nur einer bestimmten Art derselben, wie etwa der Wiederbelebung. der toten Keimhälfte, geht klar aus den darauffolgenden gegen Laqueur (1909) gerichteten Sützen hervor. $Z u$ dieser entschiedenen Stellungnahme kommt Brachet, weil er in den Versuchen Rouxs und Laqueurs eine mögliche Fehlerquelle entdeckte, indem er bei seinen eigenen Anstichversuchen auf eine Erscheinung stieß, welche Postgeneration vortäuschen könnte. Er fand bekanntlich, daß die erste Furchungsebene manchmal mit der Symmetrieebene des befruchteten Eis, erkennbar an dem sogenannten grauen Feld, nicht zusammenfällt, sondern einen spitzen Winkel mit ihr bildet, und daß dann die Medianebene des späteren Keims der Symmetrieebene, nicht der Furchungsebene folgt. In solchen Fällen liefert nun die eine der beiden Blastomeren nach Anstich der anderen hinten etwas weniger und vorn entsprechend mehr als eine halbe Medullarplatte. Das seien, meint er, die Keime mit vorn beginnender Postgeneration der fehlenden Keimhälfte; Laqueur 
habe versäumt, vor dem Anstich darauf zu achten, ob die erste Furchungsebene genau mit der Symmetrieebene zusammenfällt.

Dieser Einwand wird, auch wenn man Brachets Forderung erfüllt, nicht leicht abzuwehren sein. Denn da einerseits reine Halbembryonen vorkommen, andererseits die Lage der ersten Furchungsebene im diffusen grauen Feld, welches die Symmetrie bestimmt, immer nur annähernd genau festgestellt werden kann, so wird bei jedem Fall, wo auf der innenständigen, der abgetöteten Zelle zugewendeten Seite etwas mehr als die Hälfte entstanden ist, der Verdacht sich regen können, die erste Furchungsebene habe einen Winkel mit der Symmetrieebene gebildet, die abgetötete Blastomere habe nicht genau der einen seitlichen Hälfte entsprochen. Und der einzige Zeuge, welcher darüber Auskunft geben könnte, die angestochene Zelle, ist tot. Diese Schwierigkeit wird bei dem Durchtrennungsexperiment vermieden; hier kann jede Hälfte als Kontrollobjekt für die andere dienen. Wenn also beide auf der innenständigen Seite ergänzt sind, so muß das zum mindestens bei der einen von ihnen aus Material geschehen sein, welches diesseits der Medianebene gelegen hatte. Dadurch wird es aber sehr wahrscheinlich, daß das so ähnliche Endergebnis an Froscheiern auf demselben oder ähnlichen Wege zustande gekommen ist.

Mein Versuch bestätigt also einerseits die Ansicht Rouxs im wesentlichen. Andererseits aber scheint er mir in Verbindung mit anderen Experimenten geeignet, den Zeitpunkt näher zu bestimmen, in dem die Ergänzung stattfindet.

Es erscheint ausgeschlossen, da 3 sich die schon unterscheidbar gewordene Medullarplatte aus angrenzender Epidermis ergänzt. Gegen diese Annahme spricht die ganz klare Tatsache, daß ein Stück Medullarplatte, in Epidermis verpflanzt, keinen differenzierenden Einfluß auf seine Umgebung mehr ausübt, sondern von der Epidermis überwachsen wird und sich unter ihr zu dem weiter entwickelt, zu was es an seinem normalen Orte geworden wäre (Spemann 1918, S. 471 ; 1919). Es wird sich wohl exakt feststellen lassen, ob jüngere Stücke diese Fähigkeit, sich die Nachbarschaft zu assimilieren, noch besitzen. Wenn die Determination zu Medullarplatte, welche nachgewiesenermaßen vom Organisationszentrum in der oberen Urmundlippe ausgeht, normalerweise rein im Ektoderm fortschreitet, und nicht etwa durch die Unterlagerung des Entoderms vermittelt wird, so ist zu erwarten, daß ein in dieser Bahn liegendes Stück, welches eben den Impuls von hinten empfangen hat, um ihn nach vorn weiter zu geben, dies auch tun wird, wenn man es in diesem Augenblick aushebt und in indifferentes Ektoderm verpflanzt. Ein Stück der oberen Urmundlippe besitzt, wie ich jüngst nach einer Beobachtung von $H$. Pröscholdt mitteilte (1921, S.568), diese Fähigkeit; es macht sich die indifferente Umgebung dienstbar 
und wird zum Organisator einer Medullarplatte, welche um ein Vielfaches größer sein kann als es selbst. Diese Fähigkeit geht, wie gesagt, einem Stück Medullarplatte ab. Wenn also das Vorderende einer anscheinend halben Neurula sich etwas später ergänzt zeigt, so muß das Material, aus dem die Ergänzung geschehen ist, schon länger dazu vorbereitet, es kann keine eigentliche Epidermis mehr gewesen sein. Wahrscheinlich beginnt die Ergänzung, zunächst nicht erkennbar, schon sehr früh, während der Zellverlagerungen der Gastrulation; denn am Ende dieses Prozesses. scheint die Determination der ersten Organanlage im wesentlichen vollzogen zu sein. Auf ein interessantes Problem, welches sich hieraus ergibt, soll später noch kurz eingegangen werden.

Der sekundäre Medullarwulst der Halbembryonen nach unvollkommener Deckung des Dotterfeldes und das sekundäre Medullarrohr bei janusartigen Doppelbildungen. Es kommt, wie schon mitgeteilt, nicht selten vor, daß die Gastrulation der halbierten Keime zu keiner völligen Deckung des Dotterfeldes führt (vgl. Abb. 19, 20, 30, 35). Dieses wird dann zum Teil von der primären Medullarplatte begrenzt, die sich auf Grund der primären oberen und seitlichen Urmundlippe entwickelt hat, zum Teil vom Rande des animalen Ektoderms, welcher bei der Operation in einer scharfen Naht mit den Dotterzellen zuerst verklebt und dann verwachsen ist. Längs dieses ektodermalen Randes nun entwickelt sich nicht selten, wie auch schon geschildert, ein sekundärer Medullarwulst; er biegt in scharfem Winkel vom vorderen Teil des innenständigen Medullarwulstes ab und zieht in der Begrenzung des Dotterfeldes zum Hinterende, um neben dem primären außenständigen Medullarwulst $\mathrm{zu}$. endigen (Abb. 19 und 35). Er ist immer viel schwächer als dieser, öfters wurde auch beobachtet, daß er später sichtbar, also "postgeneriert " wird.

Brachet (1904) hat bei seinen Anstichversuchen einen Embryo erhalten und abgebildet (Taf. 4, Abb. 10), der ganz ähnlich aussieht wie der soeben geschilderte. Es ist eine Neurula, deren rechte Hälfte normal entwickelt erscheint. Von der linken Hälfte ist das Vorderende der Medullarplatte vorhanden, aber sehmächtiger als das rechte; das hintere Ende fehlt, es wird durch die Reste der abgestorbenen Keimmasse eingenommen. Der linke Medullarwulst scheint nun an der Stelle, wo er auf diese tote Masse stößt, nicht einfach aufzuhören, sondern nach außen abzubiegen, und sie ganz deutlich, wenn auch in schwächerer Ausbildung, zu umziehen. Brachet spricht von einem commencement de postgénération, par un processus quelconque (S. 124), ohne jedoch näher darauf einzugehen. Die Übereinstimmung mit dem von mir beschriebenen Keim scheint mir im Prinzip eine vollkommene; und so auch die Art der Entstehung. Brachet hatte in einem Fall, wo die erste Furchungsebene mit der Symmetrieebene einen Winkel von etwa $45^{\circ}$ 
bildete, die "hintere linke Blastomere " abgetötet, und dabei, wie erwartet, einen "vorderen rechten halben Embryo « erhalten, einen Embryo also, dessen Medianebene mit der Trennungsebene zwischen totem und lebendem Eimaterial einen spitzen Winkel bildet. Der Unterschied zwischen beiden Experimenten besteht nur darin, daß dieser Winkel bei Brachet schon im Augenblick des experimentellen Eingriffs vorhanden war, bei uns dagegen erst kurz darauf durch eine Schwenkung der Medianebene nach außen entsteht.

Die weitere Entwicklung der Triton-Keime zeigt, daß es sich bei

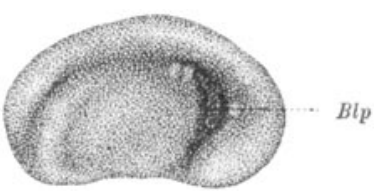

Abb. 44. Neurala, aus rechler Gastrulahalfte entstanden, mit eben zusammengertichten Wulsten; linke Halfte verkümmert, linker Medullarwulgt nur vorne deutlich, nach hinten verstrelchend; Dotter zum Tell noch unbedeckt (Bip). Vergr: $\times 20$

dem beschriebenen ssekundären Medullarwulst «wirklich um die Anlage eines halben Medullarrohrs handelt. Die Abb, 44 zeigt einen solchen etwas älteren Keim (Trit. taen. $S p 1915, G 41 r$ ) mit eben zusammengerückten Medullarwülsten. Der äußere Wulst ist von normaler Stärke,
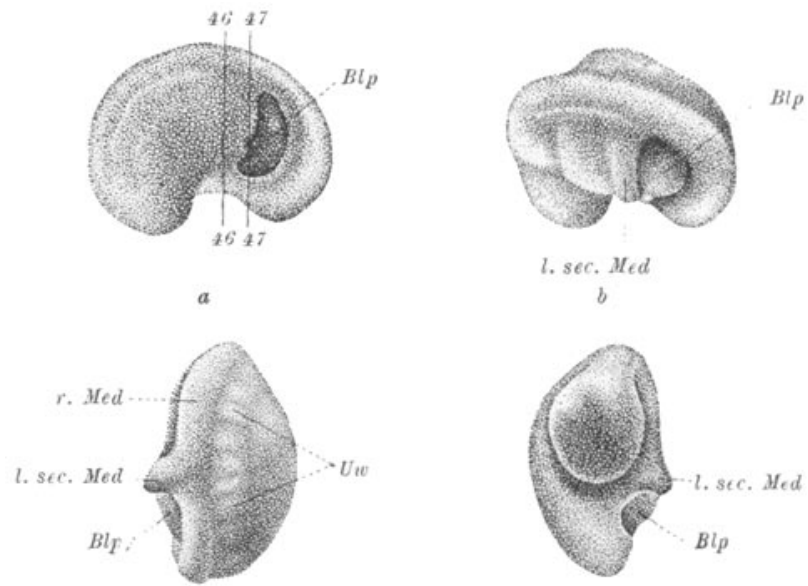

$d$

Abb. $45 a-d$. Derselbe Kelm wie Abb. 44, 26. Stunden spater; konserviert, daher etwas kleiner; $a$ von links, $b$ von links oben hinten, $c$ von oben, $d$ von unten. $B l \rho$ unbedecktes Entoderm; i. sec. Med linker sekundärer Medullarwulst, $r$. Med rechter Medullarwulst; $V_{i}$ Urwirbel. In a die ungefahre Lage der Schnitte der Abb. 46 und 47 angegeben. Vergr. $>20$.

der innere ist nur. vorn gut entwickelt, nach hinten verstreicht er allmählich. Am Hinterende liegt das Entoderm mit halbmondförmigem Umriß offen zutage. 26 Stunden später wurde der Keim konserviert; die Darmspalte (Abb.45a-d) hat noch dieselbe halbmondförmige Gestalt und ist nicht kleiner, sondern in Anbetracht dessen, daß der konservierte Keim stark geschrumpft ist, im Gegenteil etwas größer 


\section{Gudrun Ruud und Hans Spemann: Die Entwicklung isolierter dorsaler}

geworden. Das hängt jedenfalls mit dem Längenwachstum der Achsenorgane zusammen; ich habe es auch bei gewöhnlicher Asyntaxie beobachtet (1918, S. 519). Der Defekt ist von zwei Wülsten umschlossen; oben, hinten und unten, d. h. also an seiner dorsalen Seite, von einem

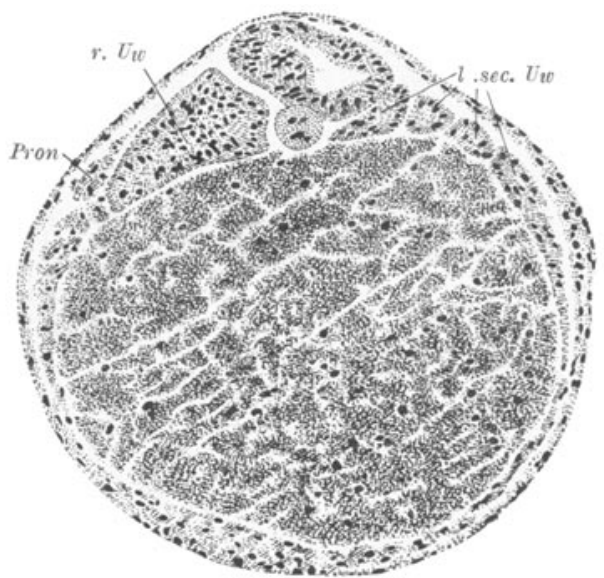

Abb. 46. Querschnitt durch den Keim der $A b b .45$, trifft gerade die sekundären Urwirbel (l. Bec. $l_{w}$ ); vgl. Abb. 45 a. Pron rechter Vornierengang; $r$. Uw Urwirbel der rechten Seite. Vergr. $\times 80$.

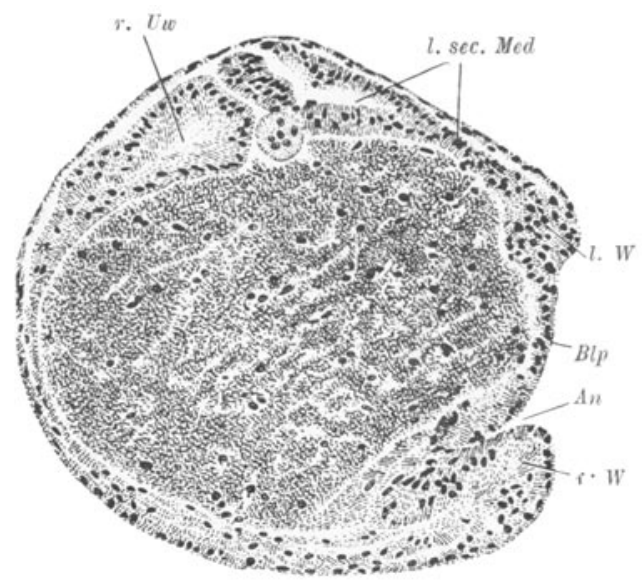

Abb. 47. Querschnitt durch denselben Keim, etwas hinter Abb. 46 (vgl. 45 a), trifft gerade die Abgangsstelle des sekundären Medullarrohrs (, sec. Med) und ein Stück des unbedeckten Entoderms (Blp); An entspricht der Afteröfinung; $r$. $l_{t}$ Urwirbel der rechten Seite. Vergr. $\rtimes 80$.

kräftig entwickelten, stark gekrümmten, vorn von einem schwächer gekrümmten, niedrigeren Wulst. Im oberen Winkel zwischen beiden Wülsten ist ein deutlicher Zugang zu dem abgeschlossenen Teil der Darmhöhle, etwas hinter dem unteren Winkel die Afteröffnung (Abb.45b, Abb. $47 A n$ ). Der Keim wurde genau quer zu seiner ventralen Fläche 
und lateraler Gastrulahälften von Triton taeniatus und alpestris usw. 135

geschnitten; die Lage der Schnitte ist in Abb. $45 a$ eingetragen. Der stark gekrümmte hintere Wulst liegt in der Fortsetzung des Vorderendes; er enthält den primären, außenständigen Anteil der Achsenorgane, Medulla, Chorda, Urwirbel, die nach hinten in das nicht weiter analysierbare Gewebe der Schwanzknospe übergehen (Abb. 45a, Abb. $47 \mathrm{rW}$ ). Auch der vordere Wulst enthält Achsenorgane; eine Chorda zwar ist nicht entwickelt, wohl aber ein deutliches Medullarrohr, das sich von dem primären rechten abzweigt (Abb. 47 sec. Med), an seiner Seite gegliederte Urwirbel (Abb. 46 sec. $U w$ ). - Im AnschluB an dieses sekundäre halbe Hinterende entsteht später ein kleines sekundäres Schwänzchen; darauf werde ich noch einmal zurückkomen.

Wenn man die Entstehungsweise dieser Keime mit klaffender Rückenplatte und offenem Darm nicht kennen würde, so würde man sie ohne weiteres für Fälle von Asyntaxia medullaris (Roux) oder Spina bifida (O. Hertwig) erklären und sich nur wundern, warum die eine Seite so defekt ist. In der Tat verhalten sie sich zu solchen Fällen "normaler « Asyntaxie wie die ergänzten, völlig geschlossenen Halbkeime zu normalen Keimen. Von dieser Stellung aus werfen sie ein überraschendes Licht auf eine Art von Doppelbildungen, um deren Erklärung ich mich lange Zeit vergebens bemüht habe.

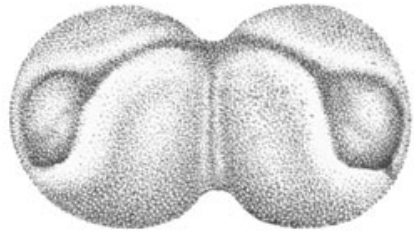

Abb. 48. Janus-Neurula von Tritan taeniatis, rom sekundăren Medullarrohr aus gesehen. Vergr. $\times 20$.

Durch mediane Einschnürung verschiedenen Grades lassen sich bekanntlich an Triton-Keimen neben gewöhnlichen Doppelbildungen auch solche erzeugen, welche als Janus-artig zu bezeichnen sind. A. Hey (1911) hat sie einer sehr gründlichen Bearbeitung unterzogen. Ich verweise für die erste Orientierung vor allem auf seine Abb, 13 und 14, S.154, und bilde noch einen neuen, besonders schönen Fall (Trit.taen. $S p$ $1901,38)$ ab (Abb. 48). Der Januscharakter liegt darin, daß von dem Punkte, wo die beiden Vorderenden zusammentreffen, nicht ein, sondern zwei Hinterenden ausgehen, welche den Keim ringförmig umgreifend in entgegengesetzter Richtung zum Urmund verlaufen. Sie sind von sehr verschiedener Ausbildung. Das primäre Hinterende geht von der ursprünglichen oberen Urmundlippe aus; es besteht aus Medullarrohr, Chorda und Urwirbeln in normaler Ausbildung und entwickelt später einen normalen Schwanz. Das sekundäre Hinterende dagegen ist sehr viel schwächer; es besaß (mit Ausnahme eines einzigen auch sonst abweichenden Falles) nie eine Chorda, die übrigen Organe mesodermaler Herkunft (Urwirbel, Unniere) sehr defekt oder in Spuren und meist nur ein sehr verkümmertes Medullarrohr. Wenn dieses den Urmund 
erreicht, was nicht immer der Fall ist, so endigt es in der ursprünglich unteren Urmundlippe; im Verlauf der weiteren Entwicklung wächst es in ein ganz kleines sekundäres Schwänzchen aus (z. B. Hey, S. 155, Abb. 14), von dem später, falls es nicht seitlichen Anschluß an den primären Schwanz gewinnt, meist nur ein unscheinbares Hautläppchen übrig bleibt. Ich habe sogar einen Fall in Erinnerung, wo die sekundäre Medullarplatte, die wie gewöhnlich durch Pigmentierung angedeutet, aber besonders schwach war, wieder völlig verschwand, ohne deutliche Spuren zu hinterlassen.

Die Entstehung dieser Janusbildungen ist schwer zu erklären. Wenn im sekundären Rücken mesodermale Organe vorhanden sind, muß doch wohl irgendeine Art von Gastrulation stattgefunden haben. Von wo ausgehend? Von der oberen Urmundlippe oder von der ursprünglich unteren, welche sich also wie eine obere verhalten hätte? Was könnte sie dazu veranlaßt haben?

Diese Schwierigkeit besteht nicht für jene Janusbildungen, welche schon früher von $O$. Schultze (1894) und $G$. Wetzel $(1895,1896)$ nach anderer Methode aus Froscheiern erzeugt wurden. $O$. Schultze hat bekanntlich Eier von Rana fusca nach der Befruchtung zwischen horizontalen Glasplatten gepreßt und im Zweizellenstadium umgedreht, die vegetative Hälfte nach oben, die animale nach unten; daraus entstanden Doppelbildungen versehiedener Art und darunter auch ein ganz typischer Janus (Schultze, Taf. XII, Abb. 12-14). G. Wetzel hat das Experiment wiederholt und auch einen Janus erzielt, der im Prinzip mit dem Schultzeschen übereinstimmt, aber eine interessante Abweichung zeigt. Man könnte sich ihn dadurch entstanden denken, daß man zwei Embryonen mit Asyntaxia medullaris mit ihren Rückenflächen aneinander legt und die zwischen den gespaltenen Medullarwülsten zutage tretenden Darmböden miteinander zur Verwachsung bringt. Die beiden zusammenstoßenden Vorderenden vereinigen sich nämlich nicht miteinander und ebensowenig die nach rechts und links auseinander weichenden Medullarwülste der beiden Partner untereinander; vielmehr sind die Vorderenden nur eng aneinander gepreßt und ebenso die zusammengekommenen rechten und linken, linken und rechten Hälften der Hinterenden. Zwischen ihnen bleibt ein den ganzen Keim umziehender Spalt, durch den man ins Innere der beiden Därme gelangt. Dieser Spalt tritt während der Gastrulation als zirkuläre Furche auf, an Stelle eines weißen Bandes, welches schon die Blastula umzieht; letzteres hat auch schon Schultze beobachtet. Nach Wetzel ist dieses Band der sichtbare Ausdruck einer Neuordnung der Eisubstanzen, welche in den umgedrehten Blastomeren zustande kam. Durch Absinken des schweren Dotters längs der ersten Teilungsebene wurden sie beim Fortschreiten der Furchung in einer Anordnung fixiert, daß 
die animalen Hälften der beiden Blastomeren ganz nach außen, die vegetativen nach innen gelagert sind; die Oberfläche der letzteren erscheint eben als weißes Band. Dadurch wäre in jeder Keimhälfte eine Anordnung erreicht, welche ungefähr derjenigen eines normalen Keimes. entspricht; ihre Achsen stehen senkrecht zur ersten Furchungsebene. Dem entspricht Beginn und Verlauf der Gastrulation (vgl. Wetzel 1895). Die beiden oberen Urmundlippen liegen einander gegenüber zu beiden Seiten des hellen Bandes; seinen Rändern folgend umgreifen sie nach und nach den ganzen Keim und begrenzen schließlich einen zirkulären Spalt. Je nachdem sie dabei untereinander verwachsen oder nicht, entsteht der typische Janus $O$. Schultzes oder die etwas abweichende Form Wetzels.

So einleuchtend diese Erklärung für die Fälle ist, für welche sie von Wetzel gegeben wurde, so stößt sie bei den durch Schnürung erzeugten Janusbildungen auf große Schwierigkeiten. Sie setzt voraus, das eine Schicht vegetativer Zellen die beiden Keimhälften trennt. Das kann in der Tat als Folge sehr starker Schnürung längs der ersten Furche eintreten; wahrscheinlich werden dabei vorwiegend die animalen Kuppen der beiden ersten Blastomeren durch die Ligatur auseinander gedrängt, so daß die zwischen den Zellen übrigbleibende Substanzbrücke rein vegetativ ist. Es bildet sich dann im Anschluß an die seitlichen Urmundlippen eine zirkuläre Furche um den engen Stiel. Daraus entsteht. aber niemals ein Janus; vielmehr schließen sich die Urmundlippen jeder Hälfte für sich und quetschen dabei den dünnen entodermalen Stiel vollends durch, welcher wie ein gemeinsamer Dotterpfropf die beiden Keimhälften verband (Spemann 1903, S. 589/90). Bei schwächerer Schnürung, welche Janusbildung im Gefolge hat, ist etwas derartigesnie zur Beobachtung gekommen; trotz aller darauf gerichteter Aufmerksamkeit ist es weder mir noch später Herrn Dr. Hey gelungen, etwas Ähnliches, etwas wie eine Spaltung der oberen Urmundlippe oder gar eine zirkuläre Furche an einer Janusgastrula wahrzunehmen. Dazu kommt, daß man auch durch Schnürung von Blastulen, ja selbst von beginnenden Gastrulen noch die eigentümliche Janusbildung hervorrufen kann.

Hier können nun die neuen Beobachtungen an den ergänzten Halbembryonen eine Erklärung wenigstens anbahnen. Wie man sich nämlich den Janus von Schultze und Wetzel aus zwei Halbkeimen mit normaler Asyntaxie zusammengesetzt denken kann, so kann man unseren Janus. von zwei Halbkeimen mit unvollkommen gedecktem Dotterfeld und sekundären Medullarwülsten ableiten. Man braucht nur, um sich das klar zu machen, etwa den Janus der Abb. 48 längs seiner Hauptmedianebene gespalten zu denken. Man erhält dann zwei Halbkeime mit jo einem ergänzten Vorderende, welches nach hinten in zwei das Dotter- 
feld umziehende Medullarwülste auseinander weicht. Der eine primäre Wulst ist von normaler Stärke; unter ihm liegt eine Chorda, an seiner Seite eine Reihe von Urwirbeln. Der andere sekundäre Wulst ist ganz schwach entwickelt; unter ihm fehlt die Chorda, Urwirbel sind nur in Andeutung vorhanden. Also genau das Bild der beschriebenen ergänzten Halbembryonen.

Bei dieser vollkommenen morphologischen Übereinstimmung liegt es nahe, auch bei unserem Janus die Entstehung der Doppelbildung zu derjenigen der ergänzten Halbbildung in Beziehung zu setzen. Ohne Schwierigkeit geht das beim sekundären Medullarrohr; seine Differenzierung aus dem Ektoderm um den Keim horum bis zur ursprünglich unteren Urmundlippe forderte schon zu ihrer Erklärung eine vom Gabelungspunkt der primären Medullarplatte ausgehende Determination. Daß sich dabei keine Chorda entwickelt, ist auch leicht verständlich. Woher aber stammt das Nesoderm für die Urwirbel des seliundären Rückens? Von wo aus wird seine segmentale Gliederung veranlaßt? Bei der median gespaltenen Gastrula stößt vegetatives Zellmaterial in der Verwachsungsnaht an das Ektoderm, aus welchem später der sekundäre Medullarwulst sich ontwickeln wird; aus diesem Material könnte das Mesoderm der Urwirbel entstehen. Beim asymmetrischen Janus dagegen fehlt diese Lagebeziehung; hier muB sich also das Mesoderm wohl auf andere Weise entwickeln.

Auch aus diesem Grunde wird es von großem Interesse sein, die Entstehung des sekundären Medullarwulstes bei den ergänzten Halbembryonen vollständig aufzuklären; das wird, wie oben ausgeführt, mit Hilfe von Transplantationsmarken wohl möglich sein. Außerdem wäre $\mathrm{zu}$ versuchen, ob sich nicht der asymmetrische Janus auch noch auf anderem Wege als durch Schnürung, etwa durch unvollkommene Durchquetschung der nackten Gastrula, erzeugen läBt.

Die Symmetrieverhältnisse der Zwillinge und Doppelbildungen von Echinodermenlarven. Es wurde mehrmals darauf hingewiesen, daß die neue Medianebene der ergänzten Halbkeime mit der ursprünglichen Medianebene des ganzen Keimes einen spitzen Winkel bildet, der sich bei den im Zusammenhang bleibenden Doppelbildungen einem rechten nähern kann. Im Falle völliger Durchtrennung der beiden Keimhälften läBt sich das erst durch unsere neuen Experimente feststellen, bei welchen die Durchtrennungsebene, d. h. die ursprüngliche Medianebene, noch einige Zeit erkennbar bleibt, indem in ihr die verschieden gefärbten Ränder der animalen und vegetativen Keimhälften zusammenstoßen; noch schlagender vermittelst eingesetzter Marken von abweichender Färbung. Wo dieses Merkmal fehlt, wie bei $Z$ willingen nach Durchschnürung im Zweizellenstadium, läßt sich über das Verhältnis won primärer und sekundärer Medianebene nichts mehr aussagen. 
Ganz klar ist es dagegen bei den längst bekannten Doppelbildungen (vgl. Abb. 48). Ieh weiß daher nicht, auf welche Tatsachen Driesch sich stützt, wenn er sagt (1908, S. 138): "Die Verwachsungszwillinge, welche $O$. Schultze bei Rana, Spemann bei Triton durch Anwendung besonderer Operationsmittel aus einem Ei gewannen, haben ihre Längsachsen und Symmetrieebenen parallel und gleichsinnig zueinander gestellt. « Für die Umdrehungszwillinge lehrt ein Blick auf Schultzes Abildungen, daß dieser Ausspruch unrichtig ist; er trifft aber auch für meine Spaltungszwillinge nicht zu. Daher besteht auch nicht der Gegensatz zwischen Wirbeltier- und Seeigelkeimen, den Driesch feststellen zu müssen glaubt, sondern eine überraschend weitgehende Übereinstimmung.

Die Lage der sekundären zur primären Medianebene ist verhältnismäßig einfach bei Doppelbildungen von Seeigelkeimen festzustellen. Solche hat Driesch (1906, S. 758ff.; 1908, S. 130ff.) dadurch erzeugt, da $B$ or die Eier eine halbe Stunde nach der Besamung oder auch später, selbst nach vollendeter $Z$ weiteilung, in verdünntes Seewasser (70 Teile Seewasser und 30 Teile Flußwasser) brachte; dadurch wird der Zusammenhang der Zellen längs der ersten Furche gelockert und wenn er nicht ganz gelöst wird, so erfolgt eine Zerrung des Keimes senkrecht zur ersten Furche, welche während der weiteren Entwicklung erhalten bleibt. Aus solchen Keimen können Doppelbildungen entstehen; die Medianebene der beiden Individualteile steht senkrecht zur ersten Furchungsebene.

Die erste Furchungsebene des Seeigeleis entspricht nun nach Boveri (1902, S. 87, Anm. 2; 1907, S. 81ff.) der späteren Medianebene; denn wenn man in einer der beiden ersten Blastomeren künstlich mehrpolige Mitosen hervorruft, so ist stets die eine seitliche Hälfte der Larve bis zur Medianebene pathologisch. Dagegen kam Driesch zu einem anderen Ergebnis, und zwar auf Grund des oben erwähnten Experiments. Neben Doppelbildungen entstanden nämlich auch — vielleicht bei schwächerer Streckung - etwas deformierte Einfachbildungen: deren Medianebene entsprach dann der größten Ebene des verzerrten Zweizellenstadiums, stand also senkrecht zur ersten Furchungsebene. Wenn Driesch dabei die Formänderung des Eies als Anhalt für die Beurteilung benützte, so setzte er voraus, daß sie ohne Einfluß auf den Verlauf der Entwicklung sei. Das trifft nun aber nicht $\mathrm{zu}$; wir wissen wieder durch Boveri, daß man durch solche Deformation die Medianebene neu bestimmen kann. Wenn man nämlich die Eier von Strongylocentrotus lividus, wo der Pigmentring die genaue Orientierung ermöglicht, durch Schütteln quer zur Eiachse streckt, so wird die dadurch entstandene größte Ebene des Eies zur Medianebene (1901, S. 160; 1907, S. 81ff.). Dadurch verliert Drieschs Schluß seine Bündigkeit und Boveris frühere Feststellung besteht zu Recht. 
Danach bilden also die sekundären Medianebenen der beiden Individualteile einen rechten Winkel mit der primären Medianebene des ganzen Keimes. Mit völliger Sicherheit läßt sich das in den Fällen feststellen, welche Driesch als "teilweise Zwillinge « und als "Verwachsungszwillinge mit Wahrung der Polarität" bezeichnet. Sie haben das Gemeinsame, daß die beiden Urdärme einen Winkel miteinander bilden, indem sie sich von getrennten Stellen aus einstülpen und entweder in ganzer Länge oder wenigstens mit ihren blinden Enden getrennt bleiben. So wird durch sie eine Ebene bestimmt, welche die ursprüngliche Eiachse enthält und senkrecht zur primären Medianebene steht. In dieser Ebene lkrümmen sich die Darmanlagen gegen die Mundbucht,

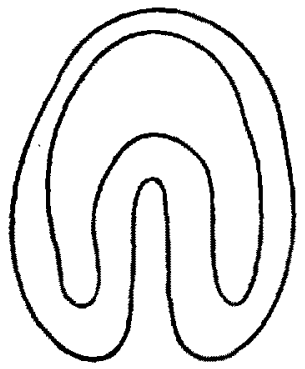

$\alpha$

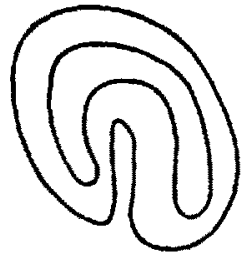

$b$

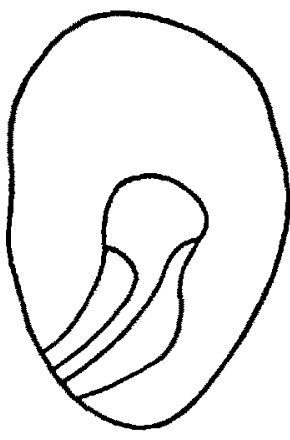

$c$

Abb. 49. Asterias; a normale Gastrula, radiär-symmetrisch; $b$ Gastrula aus isolierter 1/2-Blastomere, bilateral-symmetrisch infolge von Verkummerung dex inneren Seite; 6 daraus entstandene Larve. (Aus briesch 1905, S.17 und 18.)

symmetrisch zu ihr legt sich das Kalkskelett an; diese Ebene ist also die sekundäre Medianebene.

Dasselbe läßt sich mit Wahrscheinlichkeit für die Zwillingskeime von Asterias sagen, welche aus den durch Schütteln getrennten Blastomeren des Zweizellenstadiums entstehen. Im Gastrulastadium zeigen diesc Keime (Abb.49b) keine radiäre Symmetrie, wie die normalen Keime (Abb. 49a) und wie die Zwillingskeime von Echinus; sie wird dadurch gestört, daß der animale und vegetative Pol auf der einen Seite einander stark genähert sind. Driesch trifft sicher das Richtige, wenn er diese verkümmerte Seite für die innenständige, der ursprünglichen Medianebene zugelrehrte hält ${ }^{1}$ ). Dann steht aber die Symmetrieebene, welche sich durch die geneigten Keime legen läßt, senkrecht zur primären Medianebene; zugleich enthält sie die ursprüngliche Eiachse. Dricsch glaubt nun durch Verfolgung der Entwicklung nach-

1) J. Runnström hat neuerdings (1914, S. $534 \mathrm{ff}$.) aus isolierten 1/2-Blastomeren von Paracentrotus lividus asymmetrische Ganzembryonen gezüchtet; auch er hält die verkümmerte Seite für die innenständige. 
und lateraler Gastrulahälften von Triton taeniatus und alpestris usw. 141

weisen zu können, daß diese dem Keim von außen aufgeprägte Symmetrie in die endgültige der Larve übergeht (Abb. 49c). Ich halte das auch für wahrscheinlich, auf Grund der Verhältnisse bei den steilweisen und Verwachsungszwillingen "; aus dem Objekt selbst aber scheint es mir nicht mit Sicherheit zu folgen. Es könnten leicht zwei Prozesse nebeneinander hergehen; einerseits Ausgleich der Asymmetrie und Wiederherstellung der radiären Symmetrie, andererseits Ausbildung einer neuen, der endgültigen Symmetrie. Beide Symmetrieebenen könnten einen Winkel miteinander bilden, aber der Ubergang aus der einen in die andere könnte erfolgen, ohne daß sich die äußere Form der Keime so zu ändern braucht, daß man es bei Beobachtung einer Massenkultur, ja selbst einzelner durchverfolgter Objekte wahrnehmen könnte.

Die Asymmetrie der Halbgastrula von Asterias kommt nun dadurch zustande, daß die innenständige, der Durchtrennungsebene zugekehrte Seite des Keims schwächer entwickelt ist als die außenständige; und zwar ist nicht nur die Höhe des Keims, also die Entfernung vom animalen zum vegetativen Pol, auf dieser Seite geringer als auf der anderen, sondern auch die Länge des Urdarms und die Dicke seiner Wandung. Das ist wohl so aufzufassen, daB der Utbergang vom Halben zum Ganzen nur allmählich fortschreitet, indem die außenständige Hälfte etwas von dem ihr zustehenden Material für die Bildung der innenständigen Hälfte abgibt. Unterdessen geht die Entwicklung und damit die Determination der Organanlagen weiter und macht schließlich dem Ausgleich ein Ende. Daher kommt es, daß dieser um so vollkommener wird, je früher er einsetzt. In der Richtung der Durchtrennungsebene, der ursprünglichen Medianebene, betrachtet erscheint die Verkümmerung der innenständigen Seite des Keims als eine Störung der ursprünglichen radiären Symmetrie; nur senkrecht zu dieser Ebene ist der Halbkeim noch symmetrisch; er ist also bilateral-symmetrisch geworden. Zunächst in seiner äußeren Form; wir wissen aber durch Boveri, daß beim Seeigelkeim schon eine äußere Deformation genügt, un die Lage der Medianebene andernd zu bestimmen. Dazu kommt hier vielleicht noch das Weitere, daß die innenständige, schwächer entwickelte Seite eine geringere Wachstumsenergie besitzt als die außenständige; dasselbe müssen wir wohl auch beim normalen Keim für die sich einkrümmende Seite annehmen. Es wiirde also ein Faktor der regulatorischen Halbentwicklung für einen solchen der typischen Ganzentwicklung eintreten, ihn gewissermaßen imitieren. Daß das möglich ist, wäre im Grund ein zufälliges Zusammentreffen, das aber dadurch an Unwahrscheinlichkeit verliert, $\mathrm{daB}$ es sich nur um einen einfachen Auslösungsfaktor handelt. So etwas meint wohl auch Driesch, wenn er sagt (1905, S. 20), ves benutze der Organismus gleichsam eine nun durch die Umstände 
doch schon einmal vorhandene grobe Abweichung vom Radiären «. Eine im Prinzip ganz ähnliche Erklärung habe ich für die Inversion des Situs viscerum am rechten Zwillingsembryo gegeben.

Ganz ebenso könnten sich nun die Verwachsungszwillinge von Echinus verhalten. Bei ihnen ist zwar von einer Verkümmerung der innenständigen Seite bisher nichts beobachtet worden; aber ganz abgesehen davon, daß sie bei besonders darauf gerichteter Aufmerksamkeit vielleicht doch noch nachgewiesen wird, braucht sie auch gar nicht irgendwie stärker in die Augen zu fallen; dem normalen, radiär-symmetrischen Keim sieht man es auch nicht an, daß und in welcher Richtung er später asymmetrisch werden wird. Hier genügt offenbar ein kleiner Anstoß, um die ganze weitere Entwicklung in die eine oder andere Richtung zu werfen; das ist auch am Situsproblem eine der interessantesten Seiten. In diesem Zusammenhang wäre es natürlich doppelt wertvoll, festzustellen, nach welcher Seite die Därme eingebogen und die Mundöffnungen gerichtet sind, zur primären Medianebene hin oder von ihr weg. Driesch hat darüber noch nichts Endgültiges festgestellt.

Diese Auffassungen enthalten nach Grundlage und Schlüssen noch viel Hypothetisches. Wenn sie richtig sind, so stehen wir einem sonderbaren Sachverhalt gegenüber. Die Zwillinge von Triton und Echinodermen hätten nämlich das Gemeinsame, daß ihre sekundären Medianebenen einen Winkel mit der primären bilden, der bei Echinodermen einen rechten beträgt, bei Tritonen diesem Betrag manchmal nahe kommt; die Erklärung für diese Auswärtssehwenkung der Medianebene aber wäre in beiden Fällen verschieden, und wo Vergleichbarkeit besteht, bezöge sie sich nicht auf dieselben Vorgänge. Bei Asterias ist, ganz ähnlich wie bei Triton, während der Gastrulation die innenständige Seite verkümmert. Die weitere Entwicklung aber ist verschieden, und zwar darin, daß diese vinnenständige Seite " bei Triton und bei Asterias zu ganz verschiedenen Teilen der Larve wird. Bei Triton geht die Asymmetrie der Gastrula unmittelbar in eine solche der Larve, in eine seitliche Verkrümmung, über; bei Asterias dagegen wird die asymmetrische Krümmung des Urdarms gewissermaßen als dessen natürliche Einkrümmung übernommen. Im letzten Grunde beruht der Unterschied darauf, daß die normale Gastrula von Triton von Anfang an ein bilateral-symmetrisches Gebilde ist, während die normale Gastrula von Asterias einen wenigstens äußerlich radiär-symmetrischen Zustand durchläuft.

c) Die spätere Entwicklung der Zawillingslarven.

Der eigentümliche Bau der Zwillingslarven, welche nach später, medianer Durchtrennung der Keime entstehen, ist schon früher von 
und lateraler Gastrulahälften von Triton taeniatus und alpestris usw. 143

mir ausführlich geschildert worden (Spemann-Falkenberg 1919). Unsereneuen Beobachtungen bestätigen das, was dort über die Verkümmerung der inneren Seite und den Situs inversus des rechten Zwillings mitgeteilt wurde. Einige nicht uninteressante Einzelheiten kann ich neu hinzufügen.

\section{Bildung eines sekundären Schwänzchens bei verspätetem Urmundschluß.}

Es kommt, wie oben mitgeteilt, häufig vor, daB der Urmund der Keimhäften sich unvollkommen schließt und der Dotter in beträchtlicher Ausdehnung unbedeckt bleibt. Dann entsteht das Bild einer Asyntaxia medullaris (Roux) oderSpina bifida (O. Hertwig), und zwar einer asymmetrischen mit sehr defekter Entwicklung der einen, postgenerierten, Hälfte (vgl. S. 120, 125, 133ff.). Die weitere Entwicklung solcher Embryonen ist in mehrfacher Richtung interessant und soll an einem Beispiel genauer geschil-. dert werden.

DerKeim (Trit.taen. $R$ 1920, 102) wurde längs der ersten Furche

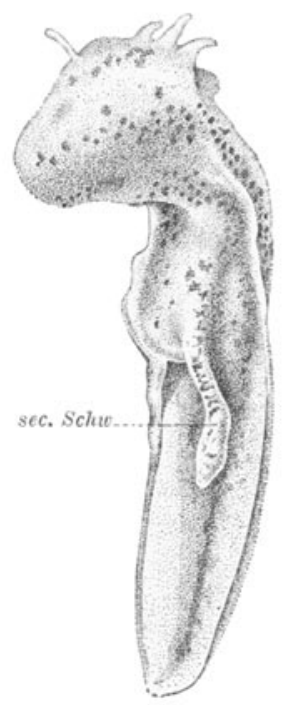

Abb. 50 .

Abb. 50 und 5f. Rechte Zwillingslarve mít sekundarem Schwänzchen (sec. Schw). Vergr. $\times \$ 0$.

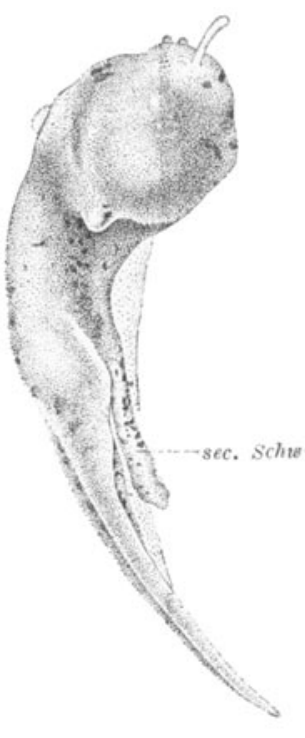
median eingeschnürt,

entwickelte sich unter schwacher Schnürung bis zum Beginn der Gastrulation und wurde dann ziemlich genau symmetrisch vollends durchgeschnürt. Beide Hälften entwickelten sich innerhalb der Eihüllen weiter. Die etwas kleinere linke Hälfte wurde fast normal; der Urmund schloß sich vollständig, die anfänglich vorhandene Einkrümmung der innenständigen-Seite glich sich später aus, es entstand eine gerade gestreckte Larve, äußerlich symmetrisch bis auf die geringere Größe des inneren Beinstummels. Die rechte Hälfte blieb stark nach innen gekrümmt und zwar sowohl in der Länge (Abb. 50 bis 52) wie auf dem Querschnitt (Abb. 55-58); Kiemen und Haftfaden der inneren Seite fehlen, die Beinanlage ist ein winziger Stummel (Abb.51). Vor allem aber blieb der Dotter lange Zeit unvollkommen 
144 Gudrun Ruud und Hans Spemann: Die Entwicklung isolierter dorsaler

bedeckt; noch 6 Tage nach der Operation ist das im Protokoll vermerkt. 5 Tage nach der Durchschnürung war am inneren Rande des Dotters, also längs der Verwachsungsnaht, eine sekundäre Medulla zu erkennen (wie in Abb, 45, S. 133), 2 Tage später setzte sie sich in ein sekundäres

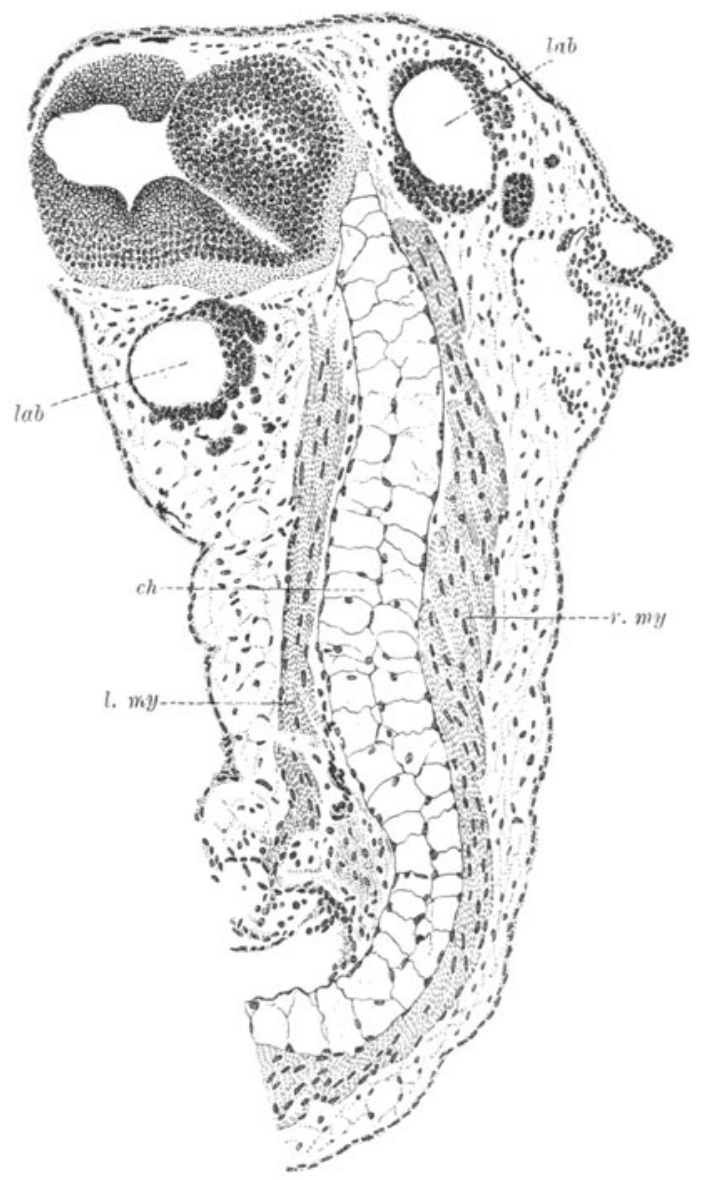

Abb. 52. Horizontalsohnitt durch Vorderende der Zwillingslarve von Abb. 50 und 51." Verge, $>20$.

Sehwänzchen fort. Weitere 6 Tage später, also 13 Tage nach der Durchschnürung, wurde die Larve konserviert.

Schon von außen läßt sich erkennen, daß die Larve zwei Schwänze hat (Abb. 50 und 51 ). Der größere rechte Schwanz liegt in der Verlängerung des Rumpfes, dessen dorsalen Flossensaum er übernimmt. Er -ist auf der linken, also der inneren Seite mäßig eingekrümmt, sowohl jn der Länge wie auf dem Querschnitt. Pigmentzellen sind auf seinen 
und lateraler Gastrulahälften von Triton taeniatus und alpestris usw. 145

beiden Seiten entwickelt. Von der Wurzel dieses primären Schwanzes entspringt auf der linken Seite ein viel kleineres sekundäres Schwänzchen (sec. $S c h w$.) von mehr rundlichem Querschnitt, aber ziemlich geradem Verlauf. Nach hinten überschreitet es etwas das erste Drittel
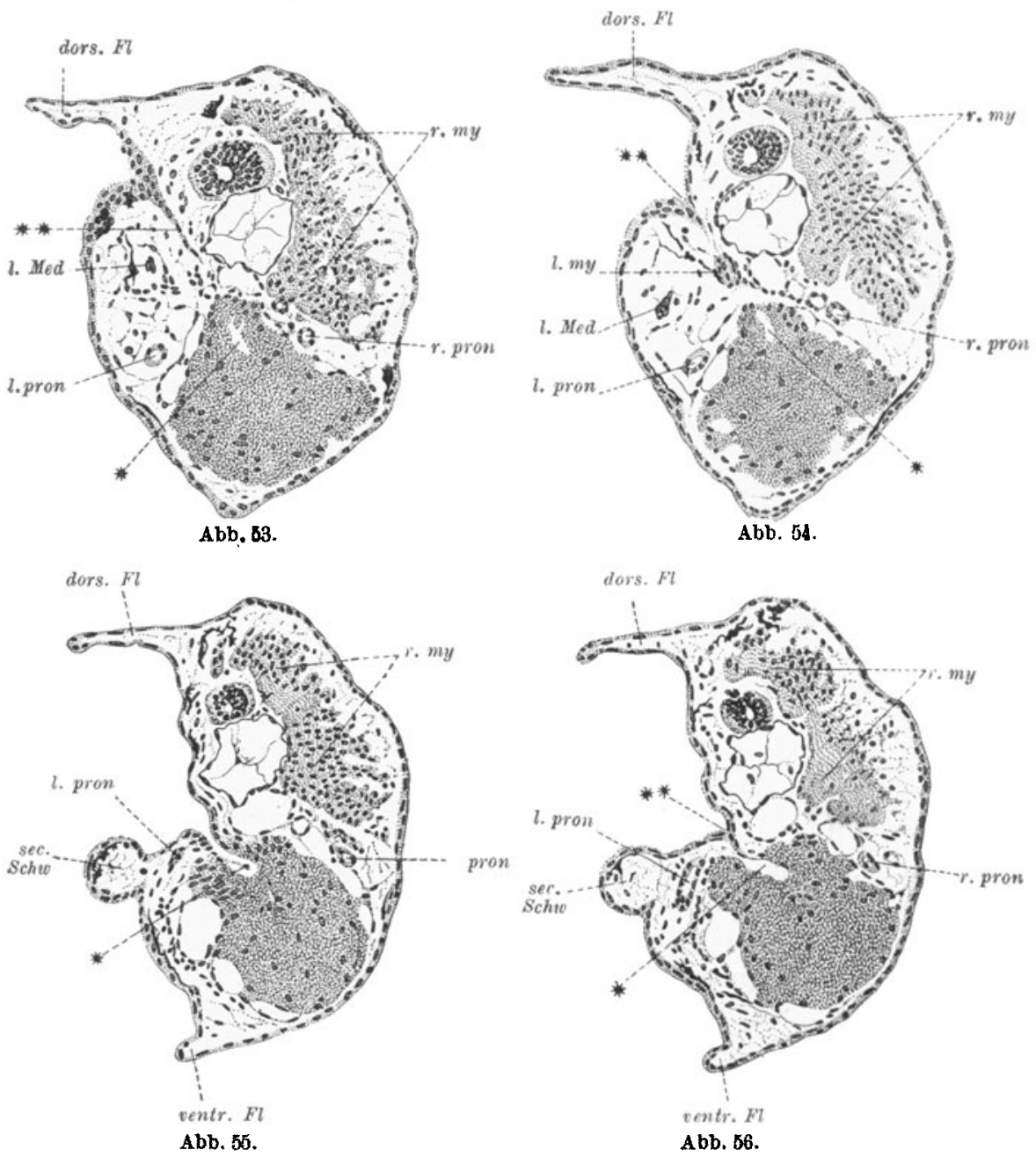

der Länge des primären Schwanzes, nach vorn geht es allmählich in den Rumpf über.

Völlige Klarheit über die feineren Verhältmisse und ihre Bedeutung geben die Schnitte. Sie wurden von hinten beginnend möglichst quer durch die Schwänze geführt (Abb.53-58), bis zu dem scharfen Knick im Rumpf hinter der Anlage des inneren Vorderbeinchens (Abb. 50). 
Der vordere Teil des Rumpfes wurde horizontal geschnitten; man sieht auf dem Schnitt der Abb.52 am schräg abgeschnittenen Hinterende Lage und Richtung des vordersten Querschnittes, der die linke Kopfseite eben gestreift hat.

Vom Vorderende interessieren uns hier vor allem Gehirn und Rückenmark, Augen und Hörblasen, Chorda und Rumpfmuskulatur. Zum größten Teil sind diese Organe auch auf der inneren Seite entwickelt, wenn schon erheblich schwächer als auf der äußeren. Das rechte Auge ist unvollständig abgegliedert, aber sonst im wesentlichen normal ausgebildet; das linke Auge fehlt wahrscheinlich ganz oder ist bis zur Unkenntlichkeit rudimentär. Die Hörblasen (Abb. 52, lab.) sind beide
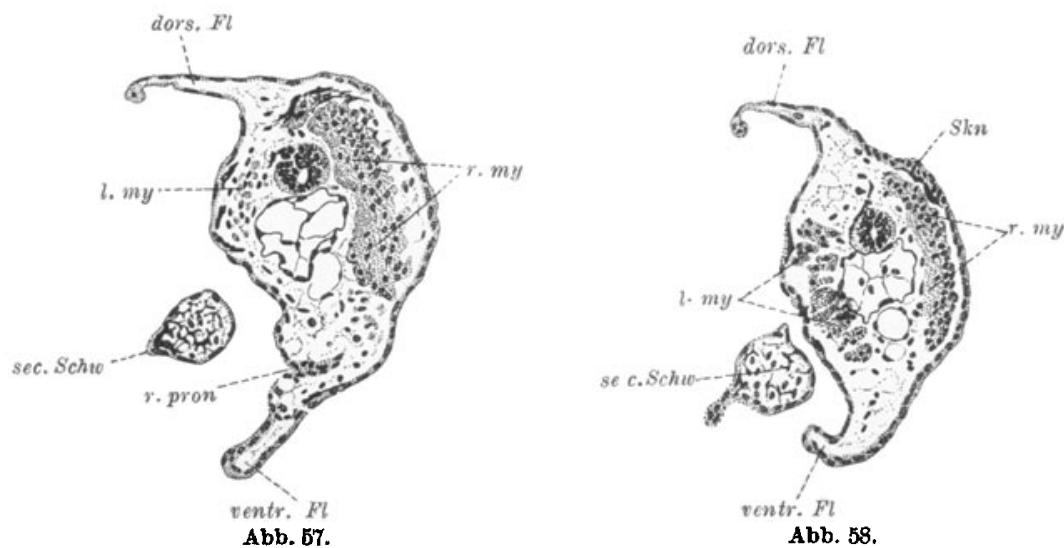

Abb. 53-58. Querschnitte durch Rumpf und Schwanz der Larve von Abb. 50 und 51 dors. $N l$ dorsaler Flossensaum; l. Med linkea Medullarrohr; l. my linke Muskelsegmente; l. pron linker Vornierengang; r. my rechte Muskelsegmente; r.pron rechter Vornierengang; sec. Schw sekundares Schwanzchen; ventr. Fl ventraler Flossensaum. Vergr. $\times 20$.

vorhanden, die linke kleiner als die rechte. Die Chorda $(c h)$ ist mehrfach gebogen; da, wo sie dem scharfen Knick des Rumpfes folgt, verjüngt sie sich plötzlich in auffallender Weise. An derselben Stelle hören auch die Muskelsegmente der inneren Seite (l.my.) auf, um erst viel weiter hinten, nämlich im Schwanz, allmählich wieder zu beginnen (Abb. 57 und 58).

Das Verständnis der Querschnitte erschließt sich am, leichtesten von einem mittleren Schnitte aus, wie ihn Abb. 56 zeigt. Das sekundäre Schwänzchen ist schon scharf abgesetzt, aber noch nicht vom primären Schwanz getrennt; danach läßt sich die Lage des Schnitts auf Abb. 50 ungefähr bestimmen. Auf diesem Schnitte nun steht der Darm mit der Epidermis im Zusammenhang; sein Hohlraum (*), der sich weiter nach vorn verfolgen läßt (Abb. 53-55) mündet nach außen. Diese Öffnung ist der letzte Rest des Urmưndes; nach den Beobachtungen am lebenden Keim hat er sich ursprünglich viel weiter nach vorn er* 
streckt. Später sind seine Ränder, an denen Ektoderm und Entoderm ineinander übergehen, von vorn her verwachsen; davon ist eine ektodermale Lamelle übriggeblieben, welche sich bis zum vordersten Querschnitt verfolgen läBt (Abb. 53-55**); auch auf dem Horizontalschnitt (Abb. 52) hinten links von der Chorda scheint sie noch vorhanden zu sein. Solche Lamellen und Stränge sind mir von anderen Versuchen her wohl bekannt; sie bilden sich fast regelmäBig nach operativer Eroffnung des Darmdachs. Bei der Heilung verschmelzen Ektoderm und Entoderm längs der Wundränder und dann erst zieht sich die Wunde zusammen (vgl. Spemann 1912, S. 10; S. 33 und 34; Taf. III, Abb. 19, $20,22,23,26,27)$.

Durch diese Offnung des Darmes nach außen und durch die Verwachsungslamelle, welche ihre Fortsetzung nach vorn bildet, ist eine Symmetrieebene gegeben, zu deren Seiten die beiden Schwänze liegen, außen der primäre, innen der sekundäre. Wären beide nach Ursprung und Ausbildung gleichwertig, so hätten wir das Bild einer gewöhnlichen Spina bifida zu erwarten, wie es die nach $O$. Hertwig

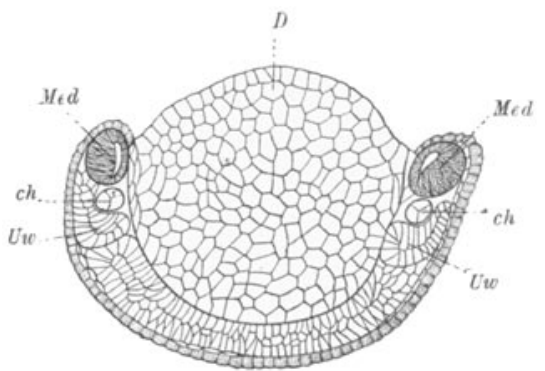

Abb. 59. Querschnitt durch Keim mit typisoher Spina bifida (nach O. Hertioig 1892).

(1892) wiedergegebene Abb. 59 zeigt; d. h. also, rechts und links rom offen zutage liegenden Darmboden ein geschlossenes, aber auf der inneren Seite verkümmertes Medullarrohr, darunter eine Chorda von halber Größe, aber rundem Querschnitt, daran anschließend eine Reihe von Urwirbeln. So aber finden wir diese Achsenorgane in voller Ausbildung nur auf derjenigen Seite, welche die primären Anlagen enthielt, also beim rechten Zwillingsembryo rechts; auf der erst sekundär postgenerierten linken Seite dagegen sind sie äußerst defekt, jedoch in Spuren mit Ausnahme der Chorda sämtlich nachweisbar.

Im primären Schwanz (Abb. 53-58) ist die Chorda bis zur Spitze gut entwickelt; ihr Umriß, ursprünglich jedenfalls rund, ist durch Schrumpfung unregelmäBig geworden. Uber der Chorda zieht das Medullarrohr nach hinten; seine innere (linke) Wand hat wie die äußere Fasersubstanz entwickelt, ist also nicht ein bloßes Verschlußhäutchen geblieben; nach hinten zu wird der Ausgleich immer vollkommener (vgl. Abb. 53 mit Abb. 58). Die Muskelsegmente fehlen auf der inneren Seite, soweit der Darm reicht, vollständig (Abb. 53-56); erst von der Höhe des Afters an (Abb. 57, l. my.), also im eigentlichen Schwanz, 
treten sie wieder auf und nähern sich nach hinten der Größe der äußeren (Abb. 58). Unter den Muskelsegmenten liegt der Vor nierengang (Abb. 53-57,r. pron.); er mündet hinter dem After nach außen (Abb.57).

Im sekundären Schwanz, soweit er sich frei vom Rumpf abhebt, fehlen alle spezifischen Organe, Medullarrohr, Chorda, Muskelsegmente; er ist ein langer Epidermissack, der mit lockerem Bindegewebe und zahlreichen verästelten Pigmentzellen erfüllt ist. Es ist also zwar wohl Mesoderm mit ihm ausgewachsen, hat sich aber nicht in die einzelnen Organanlagen differenziert. Anders ist es weiter vorn, im Bereich des Rumpfes. Eine Chorda fehlt freilich auch hier, dagegen sind Medullarrohr, Muskelsegmente und Vornierengang sicher nachweisbar, wenn auch zum Teil nur in Spuren. Am deutlichsten ist der Vornierengang; er geht auf den Horizontalschnitten aus den Vornierenkanälchen der linken Seite hervor und ist auf den Querschnitten bis zu seiner Ausmündung zu verfolgen (Abb. 53-56,l.pron.). Äußerst defekt, aber auch ganz deutlich sind die Muskelsegmente (z. B. Abb. 54, l.my.), welche links von der Verwachsungslamelle liegen, also auch längs des linken Randes des Dotterfeldes entstanden sind. Noch unscheinbarer sind die Reste des sekundären Medullarrohrs (Abb. 53 und 54,l.med.); trotz des eigenartigen Charakters der Zellansammlungen, welehe durchaus Ganglien gleichen, wäre die Deutung unsicher, wenn sich diese Zellen nicht nach vorn in einen Strang fortsetzten, der von der linken Seite des Medullärrohrs abgeht:

So merkwürdig diese Verhältnisse auf den ersten Blick erscheinen, so folgen sie doch zwanglos aus den jüngeren Stadien, welche oben beschrieben worden sind (S. 124 und S. 133); auch dort geht ein sekundäres Medullarrohr vom primären $a b(A b b .47, l$ sec. med.), begleitet von einer Reihe deutlicher Urwirbel (Abb. 46, l. sec. Uw.); gegen das hintere Ende des sekundären Wulstes verlieren sich beide ununterscheidbar in das Gewebe der sekundären Schwanzknospe.

Während beim rechten $Z$ willing des soeben beschriebenen Zwillingspaares der Schluß des Urmunds sich so lange verzögerte, daß er überhaupt nicht mehr in normaler Weise erfolgen konnte, und dadurch die Bildung von sekundären Achsenorganen und einem sekundären Sehwänzchen aus ganz fremdem Material induziert wurde, erfolgte beim linken Zwilling, wie beschrieben, der Urmundschluß so rechtzeitig, daß ein ganz normaler Embryo entstand. Zwischen diesen beiden äußersten Fällen ist nun ein mittlerer denkbar, wo der Urmundschluß zwar so früh erfolgt, $d a B$ ein einheitlicher, $d . h$. nicht gespaltener Schwanz entsteht, aber sich doch so lange verzögert, daß ein sekundäres Schwänzchen induziert wird. Dieses würde sich dann dem primären seitlich anschließen und mit ihm zusammen auswachsen. Genau das kann 
tatsächlich eintreten. Ein derartiger Fall (Trit. taen. $R 1920,103 r$ ) ist in den $\mathrm{Abb} .60-62$ dargestellt; es ist ein $\mathrm{Zwilling}$ der rechten Seite, die Schnitte sind also von vorn gesehen. Erwa in der Höhe des Afters erhebt sich auf der inneren (linken, vom Beschauer rechten) Seite ein zuerst flacher Wulst (Abb. 60, sec. Schw.), der allmählich höher wird und als sekundärer Flossensaum nach hinten zieht (Abb.61), um dann wieder niedriger werdend auf dem ventralen Flossensaum auszulaufen (Abb. 62).

Schón oben (S. 137) wurde dargelegt, wie sich durch Zusammenfügen von zwei Zwillingsembryonen mit sekundären Achsenorganen jene eigentümliche Janusbildung ableiten läBt, welche auf der einen Seite einen normalen Rücken besitzt, auf

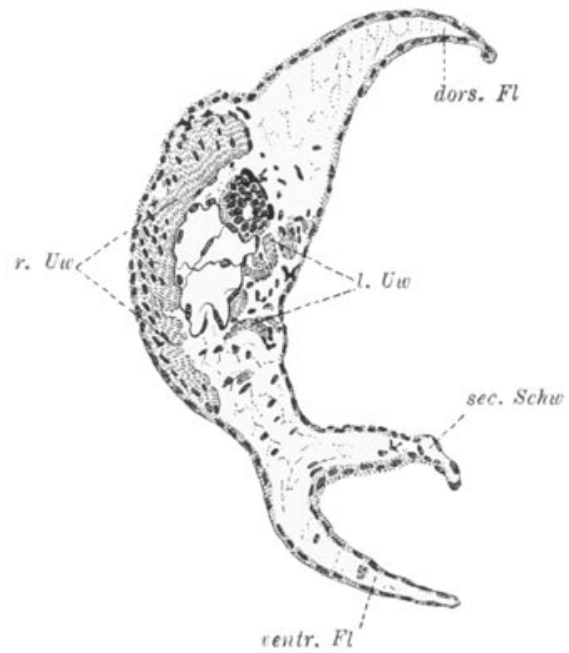

Abb. 61 .
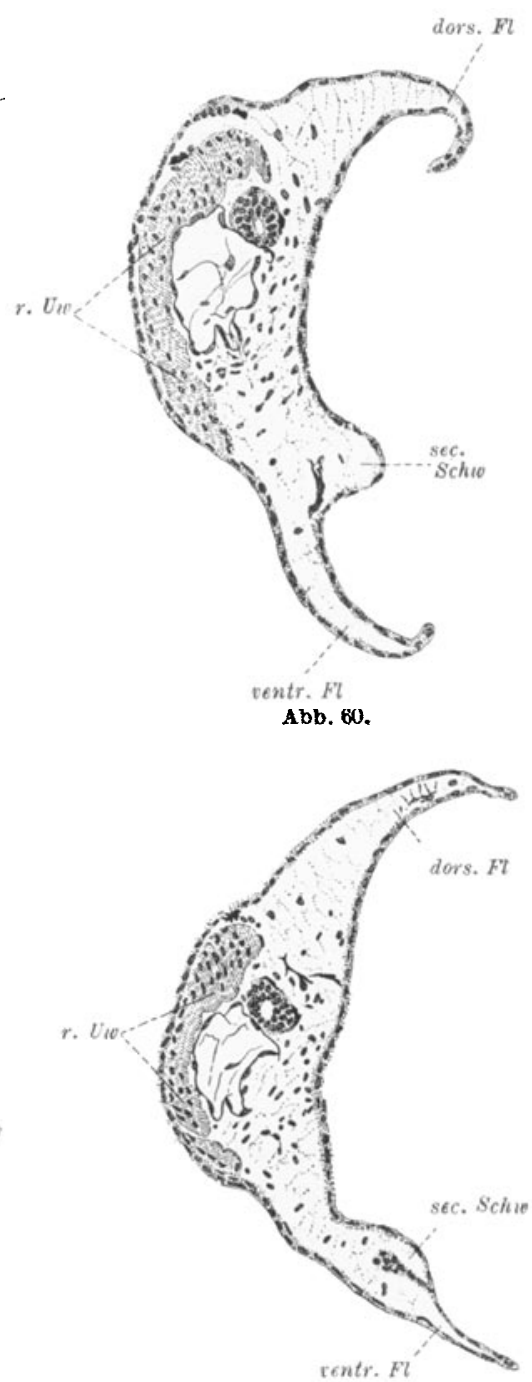

Abb. 62.

Abb. 60-62 Querschnitte dureh Schwanz einer rechten Zwillingslarve mit gekundaren Schwanzchen (sec. Schto), welches aber nicht frei wird wie in Abb. 55-58, sondern zuBammen mit dem primären Sohwanz auswëchst. Vergr. $\times 80$.

der anderen einen mehr oder weniger defekten (Abb. 48). Der erstere wächst bei weiterer Entwicklung in einen normalen Schwanz aus, der letztere in einen ganz rudimentären Stummel. A. Hey (1911) hat 
diese Verhältnisse ausführlich beschrieben (vgl. z. B. seine Abb. 10b, S. 136; Abb. 14, S. 155; Abb. 16, S. 161).

Diese ganz typische Form des Janus kommt dann zustande, wenn der primäre und sekundäre Rücken in einer Ebene liegen, ihre Hinterenden also geradlinig aufeinander stoßen. Statt dessen nähern sie sich häufig auf der einen Seite einander und laufen in einem mehr ccer weniger spitzen Winkel zusammen. Dann schlieBt sich das sekundäre Schwänzchen seitlich dem primären Schwanz an und wächst gemeinsam mit ihm aus. Es zicht also auf der Seite des großen Schwanzes oin sekundärer Flossensaum etwa vom After an nach hinten und läuft, niedriger werdend, an ihm aus (vgl. A. Hey, Abb.6, S. 123; Taf. VI, Abb. 12-14; ferner Abb. 12, S. 147; Taf. VII, Abb. 34 und 35).

Das sind genau dieselben Verhältnisse, wie sie soeben für die Zwillingsembryonen geschildert wurden, und auch ihre Entstehung ist insofern dieselbe, als beidemal eine selkundäre Schwanzanlage sich einer primären seitlich anschloB; nur sind diese Anlagen beim Janus von Anfang an ganz, bei den $Z$ willingen werden sie es erst durch eine inncreUmwandlung.

\section{Das Verhalten der Flossensäume.}

Bei den Zwillingsembryonen, welche aus seitlichen Gastrulahälften entstehen, ist die Entwicklung der innenständigen Seite wohl ausnahmslos, wenigstens in jüngeren Stadien, gegen die Entwicklung der äußeren Seite deutlich zurück. Das gilt für die ganze Länge der Larve, am meisten in der Regel für eine mittlere Strecke, weniger für den Schwanz, am wenigsten für den Kopf. Eine Folge dieser Verkümmerung is̀t die Finkrümmung der schwächer entwickelten Seite, die sich zu einer Einknickung verschärfen kann; letzteres besonders häufig in der hinteren Rumpfgegend, in der Höhe des Afters, so daß dann der Schwanz nach vorn gedreht, aber selbst ziemlich gerade gestreckt ist. Ohne Ausnahme ist diese Regel nicht. Während häufig der Kopf fast völlig symmetrisch ist, selbst bei stärkster Verkrümmung der hinteren Rumpfgegend und des Schwanzes (z. B. $R$ 1920, $103 l$ und $r$ ) kann doch auch das innere Auge fehlen (vgl. oben S. 146); und ebenso kann der Schwanz bis zu seiner Spitze spiralig aufgerollt sein, ein sicheres Zeichen dafür, daß seine innere Seite in ganzer Länge schwächer entwickelt ist. Einige Beispiele dieser unberechenbar an verschiedenen Stellen der inneren Seite auftretenden Defekte habe ich in einer früheren Arbeit (mit Falkenberg 1919, S. 377-382; Taf. XIII) mitgeteilt; hier möchte ich im Gegenteil den Nachdruck darauf legen, wie überraschend häufig doch der Defekt gerade in der Höhe des früheren Urmunds am stärksten ist. Woher das kommen mag, soll später erörtert werden. Vorher möchte ich noch zwei andere Fälle besprechen, welche die in jener früheren Arbeit (1919) aufgeführten ergänzen. 
und lateraler Gastrulahälften von Triton taeniatus und alpestris usw. 151

Die eine Larve (Trit. taen. $R$ 1920, $103 l$ ) gehört als linker $Z$ willing mit dem oben (S. 149) beschriebenen rechten (103r) zusammen, bei dem das sekundäre Schwänzchen mit dem primären verwachsen ist. Bei beiden ist der Kopf zu groß für Rumpf und Schwanz, dabei auffallend wohlgebildet und symmetrisch. Auch die innenständigen Kiemen sind noch gut entwickelt und reich verzweigt; die inneren Beinchen dagegen fehlen vollständig. Die Schnitte wurden möglichst quer durch das hintere Ende des Rumpfes und Schwanzes gelegt (Abb. 63-67). Die Gastrulation war bei dem halbierten Keim gut verlaufen und führte anscheinend $\mathrm{zu}$ einem völligen Schluß des Urmunds; 2 Tage nach der Durchschnürung, die zu Beginn der Gastrulation vorgenommen worden war, schien der Dotter ganz bedeckt. Dem entspricht auch die normale Entwicklung des Afters (Abb. 64) und des anschließenden ventralen Flossensaums (Abb. 65). In dieser Höhe und etwas dahinter (Abb, 64 u. 65) sind auch die Muskelsegmente der inneren Seite deutlich, wenn auch schwächer entwickelt, während sie nach vorn äuBerst defekt werden (Abb. 63) und auch nach hinten wieder verschwinden. Auf allen Schnitten ist die Einkrümmung der inneren Seite quer zur Längsachse an der Einbiegung der Medianlinie zu erkennen. Die beiden Flossensäume nähern sich nun im Verlauf nach hinten mehr und mohr einander (Abb. 66), wobei sie aber in einer Ebene bleiben, während die Achsenorgane immer mehr seitlich heraus treten (Abb.67). Dadurch wird es möglich, daß der Schwanz als Ganzes trotz der Verkümmerung seiner inneren Seite ziemlich gerade gestreckt ist; die Achsenorgane treten auf der äußeren Seite heraus und bilden (von oben betrachtet) einen Bogen, zu dem die Flossensäume die Sehne sind. Um die dabei treibenden Kräfte zu durchschauen, müßte man die bei der normalen Entwicklung des Schwanzes herrschenden Bildungstendenzen genauer kennen; jedenfalls geben solche Fälle Fingerzeige für weitere Untersuchungèn.

Dasselbe gilt für die Entstehung eines sekundären Flossensaums, wie ihn der nächste Fall zeigt.

Der Keim (Trit. taen. $R$ 1920, 110) hatte sich wie gewöhnlich unter schwacher Schnürung bis zum Beginn der Gastrulation entwickelt und war dann vollends durchgeschnürt worden. Von den beiden Zwillingen, welche entstanden, war der linke ziemlich normal, der rechte dagegen zeigte mehrere interessante Abweichungen. $31 / 2$ Tage nach der Durchschnürung war sein Dotter noch nicht ganz bedeckt gewesen, auch hatte sich eine sekundäre Medullaranlage auf der ánderen Seite des Dotters entwickelt. Der Urmundschluß blieb unvollkommen bis zuletzt, wo die Larve konserviert wurde, 15 Tage nach der Durchschnürung. Im Anschluß an die sekundäre Medullaranlage war ein sekundäres Schwänzchen ausgewachsen, welches aber weiter vorn als in dem oben be- 
152 Gudrun Ruud und Hans Spemann: Die Entwicklung isolierter dorsaler

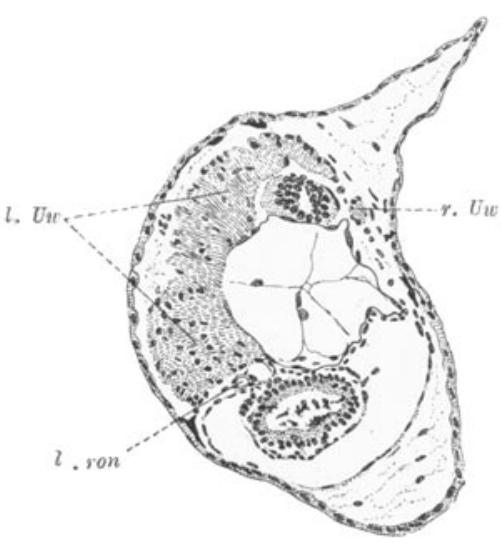

Abb. 63.

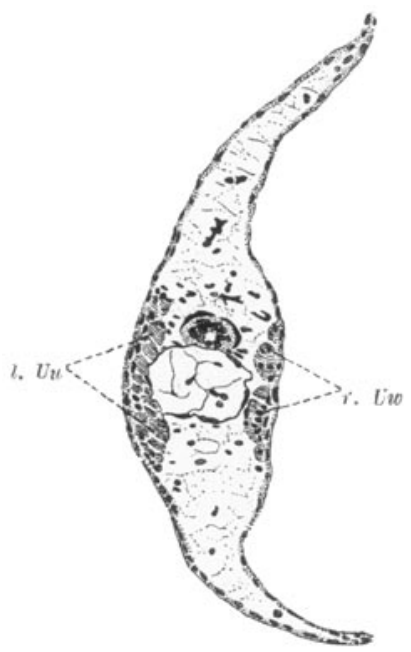

Abb. 65.

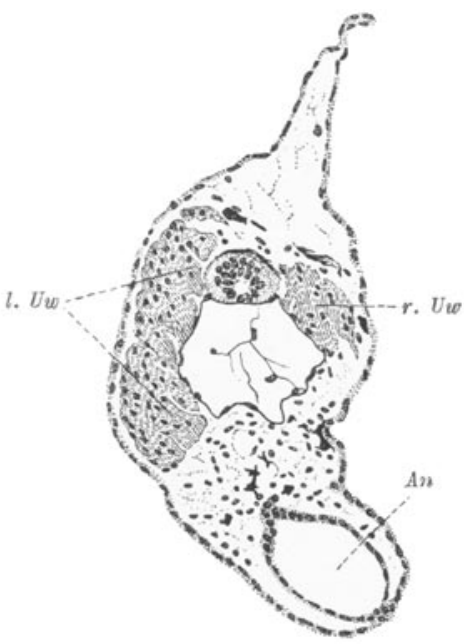

Abb. 64.

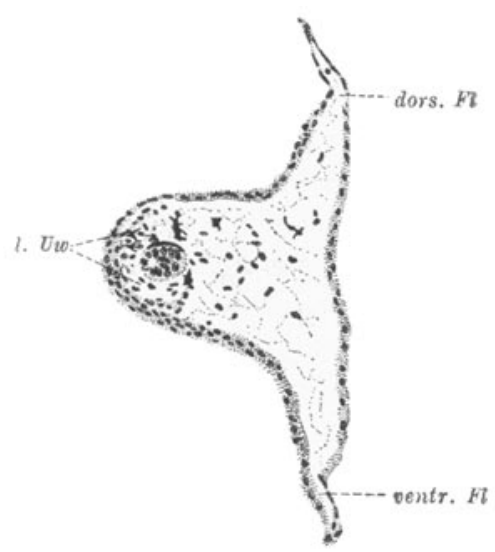

Abb. 66.

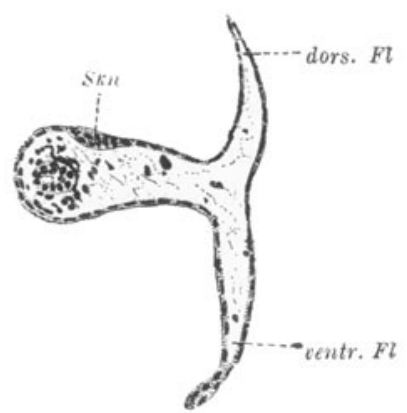

Abb. 67.

Abb. 63-67. Querschnitte durch linke'Zwillingslarve mit auf der auBeren Seite heraustretenden Achsenorganen und aut der inneren Seite verschmelzenden Flogsensal umen. Vergr. $>80$. 
und lateraler Gastrulahälften von Triton taeniatus und alpestris usw. 153

schriebenen Fall (102 r; vgl. S. 143 u.ff.) frei wurde. Der Embryo ist links sehr stark eingekrümmt und dabei um seine Längsachse so verdreht, daß sich das Schwänzchen, wenn man den Kopf symmetrisch von oben betrachtet, nach links oben vorn rechts wendet. Hier interessieren uns vor allem die Achsenorgane und Flossensäume des Schwanzes (Abb.68-74). Wie schon von außen zu sehen war, geht der dorsale Flossensaum auf die innenständige Fläche des Schwanzes über (Abb. 68-71, dors. Fl.) und läuft beständig niedriger werdend an ihm aus. Gleichzeitig beginnt ein neuer, sekundärer Flossensaum sec.dors. Fl. (Abb. 70), der höher und dünner wird (Abb.71 u. 72) und von einem normalen nicht mehr unterscheidbar (Abb. 73 u. 74) bis zur Spitze des Schwanzes zieht. Dabei treten die Achsenorgane auf der äußeren Seite heraus, nicht so stark wie bei der oben beschriebenen Larve $103 l$ (S. 151, Abb. 66 u. 67), aber doch ganz deutlich (Abb. 72-74); außerdem winden sie sich umeinander, so daß die Medulla erst nach innen von der Chorda rückt (Abb. 72 und 73), dann sogar unter sie zu liegen kormmt (Abb. 74). Die Muskelsegmente der inneren Seite sind in der Höhe des Afters (Abb. 68; r. pron. Ausmündung des rechten Vornierengangs) sehr kümmerlich, werden dann nach und nach gröBer (Abb. 69-72), um endlich wieder zu verschwinden; dann werden die Muskelsegmente der äußeren Seite ganz um die Chorda herum gezogen (Abb. 73 und 74).

Eine Erklärung dieser merkwürdigen Verhältnisse kann natürlich nur versuchsweise gegeben werden.

Die Verwindung der Achsenorgane ist vielleicht eine rein mechanische Folge davon, daß die beiden einander gegenüberstehenden Flossensäume, der ventrale und der sekundäre dorsale (Abb. 73), infolge der Verkümmerung der inneren Seite einander gegenïberrücken und die Achsenorgane seitlich herausdrängen; so kommen diese erst nebeneinander zu liegen ( $\mathrm{Abb} .73$ ), dann sogar in verkehrter Orientierung übereinander $(\mathrm{Abb}, 74)$. Ganz ähnlich war es auch bei dem Keim $103 l$.

Viel problematischer ist die Bildung des sekundären dorsalen Flossensaums. Da er in gleichem Maße höher wird, wie'der primäre auf die Seite hinabrückt und sich schließlich tot läuft, so liegt es nahe, an eine Längsspaltung des Anlagenmateriales zu denken. Die eine Hälfte würde durch die Verkümmerung der inneren Seite herabgezogen, die andere nach oben infolge eines regulatorischen Strebens, zwei einander gegenüberstehende gestreckte Flossensäume zu bilden (vgl. SpemannFalkenberg 1919, S. 378). Ja es brauchte dieser sekundäre Flossensaum gar nicht auf eine »Anlage « zurückzugehen, die sich von derjenigen des primären abgespalten hat; es könnte der ventrale Flossensaum einen dorsalen gewissermaßen als Gegenstück fordern (vgl. Spemann 1912, S. 27). Darauf wird noch einmal zurückzukommen sein. 
154 Gudrun Ruud und Hans Spemann: Die Entwicklung isolierter dorsaler

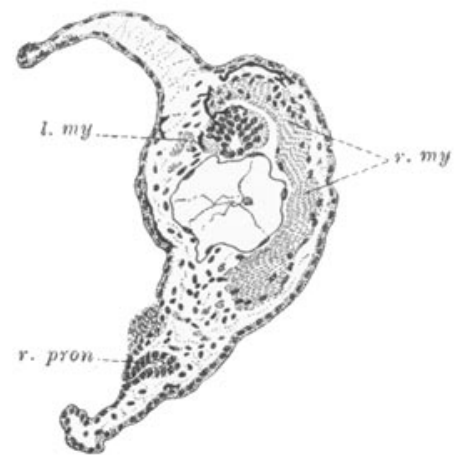

Abb. 68 .

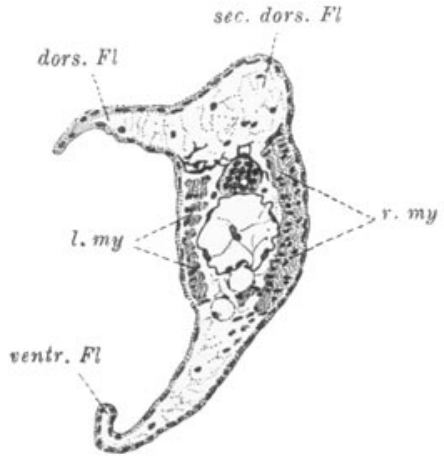

Abb. 70 .

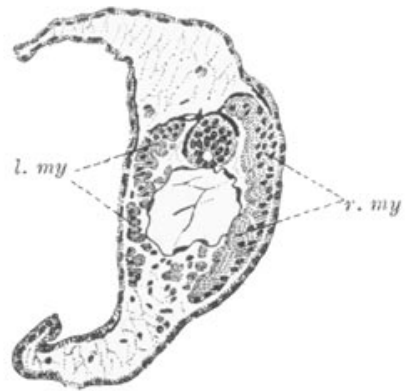

Abb. 69 .

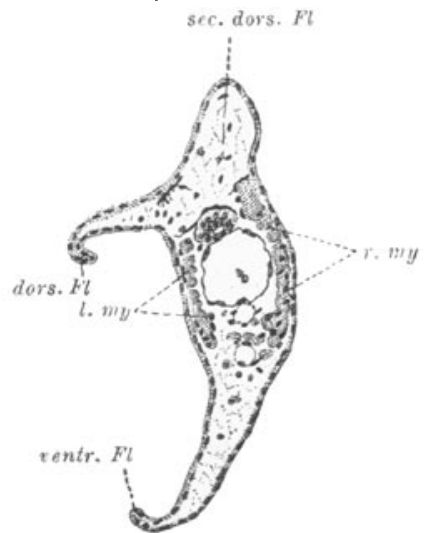

Abb. 71 .

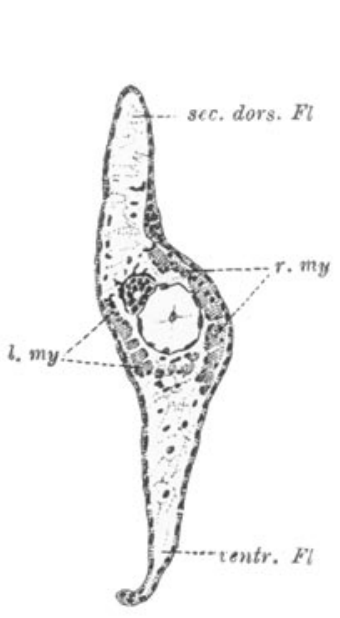

Abb. 72.

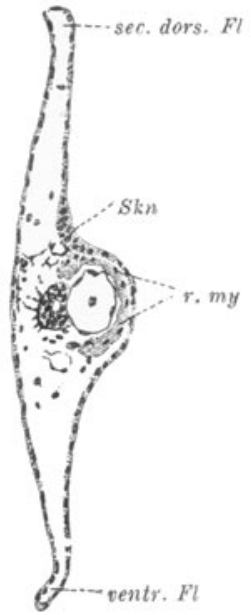

Abb. 73.
Abb. 68-74. Querschnitte durch Schwanz einer rechten Zwillingalarve mit starker Finkrümmung der inneren Beite, sekundarem dorsalem Flossensaum $(\mathrm{sec}$
Achsenorgane. Vergr. $\times 80$.

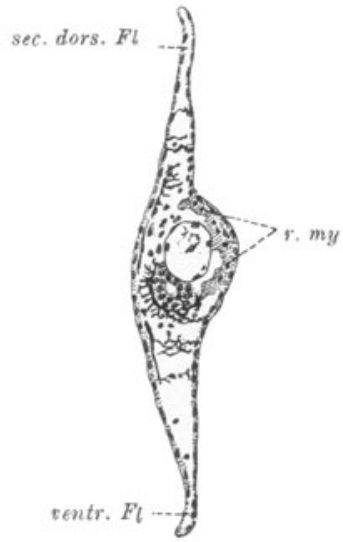

Abb. 74 . 


\section{d) Die Postgeneration der innenständigen Seite.}

Die eben angesteliten UUberlegungen führen uns in den Kern des ganzen Postgenerationsproblems. Wie kommt die Ergänzung des halbierten Keims zustande? Auf welchem Wege und durch welche morphogenetischen Elementarprozesse? Unsere Ergebnisse lassen zum mindesten einige neue Gesichtspunkte für die Lösung dieser Fragen aufstellen.

Sehr lehrreich scheinen mir dafür die Fälle, wo der Urmund sich verspätet und unvollkommen schließt. Bei der oben ausführlich beschriebenen Larve dieser Art (102 r; S. 143 ff., Abb. 50-58) lassen sich deutlich drei Strecken unterscheiden, in deren Bereich die Ergänzung in verschiedener Vollkommenheit und wohl auch auf verschiedene Weise zustande gebracht worden ist. Am vollkommensten ist das Vorderende ergänzt; in diesem Falle nicht einmal so gut wie sonst manchmal, wo die Symmetrie nur durch eine etwas schwächere Ausbildung der inneren Seite gestört ist (z. B. $R$ 1920, $103 r$ und $l$; vgl. s. 151). Immerhin sind auch hier die meisten Organe der inneren Seite, z. B. die Hörblasen, Muskelsegmente, Vornierengänge, gut entwickelt. Ähnliches gilt für das Hinterende; hinter dem After treten die Muskelsegmente wieder auf (Abb. 57) und nähern sich denen der Außenseite an Größe (Abb. 58); auch das Medullarrohr kann völlig symmetrisch werden (Abb. 58). Am unvollkommensten ist die Ergänzung im Gebiet einer mittleren Strecke, die gerade so weit nach vorn und hinten reicht wie ursprünglich der nicht geschlossene Urmund. Auf dieser Strecke fehlen die Muskelsegmente völlig, ebenso die Vornierengänge. Das Medullar. rohr ist auf der inneren Seite deutlich schwächer entwickelt als auf der äußeren; auf jüngeren Stadien hatte es hier sicher nur ein dünnes Verschlußhäutchen; es hätte also in diesem Bereich genau dasselbe Bild gezeigt wie bei der Spina bifida (Abb. 59, S. 147).

Die Larve ist also in einem mittleren Teil ihrer Länge - wenn man von den sekundär entstandenen Teilen auf der anderen Seite des Urmundes oder der Verwachsungsnaht absieht - rein halb angelegt worden und in weitgehendem Maße halb geblieben. Der Ausgleich des Medullarrohrs muß durch stärkeres Wachstum seiner inneren Hälfte erfolgt sein. Ob die fehlenden Muskelsegmente im weiteren Verlaufe der Entwicklung nacherzeugt worden wären, müßte noch experimentell geprüft werden; jedenfalls könnte das nur von vorn und hinten her geschehen, nicht von der Muskulatur der anderen Seite, wo die Chorda im Wege steht. Dieses letztere gilt nun aber auch für Kopf und Rumpf und für den Schwanz. Wenn sich hier Muskelsegmente auf der inneren Seite der Chorda befinden, so können sie nicht von jenseits derselben gekommen, sondern müssen an Ort und Stelle entstanden sein. Es muß also das zur Verfügung stehende mesodermale Material von Anfang 
an anders zwischen Chorda und Muskelsegmente verteilt worden sein, als im Bereich der mittleren Strecke und bei der normalen Entwicklung. Ebenso zeigt sich das Zentralnervensystem in seinem vorderen Teil schon im Stadium der Medullarplatte ergänzt (vgl. Abb. 19 und 20, S. 120; Abb. 26, S. 123; Abb. 35, S. 125; Abb. 39, S. 126; Abb. 43, S. 126). Ein versehieden kräftiges Wachstum der inneren und äußeren Seite mag dann noch den Ausgleich fördernd hinzukommen, keinesfalls aber ist es seine einzige oder auch nur wichtigste Ursache.

Das Wachstum erfolgt in diesen jungen Entwicklungsstadien ganz oder hauptsächlich auf Kosten des den einzelnen Zellen vom Ei her mitgegebenen Dotters. Rascheres Wachstum muß also einen rascheren Dotterverbrauch nach sich zichen. Danach ist zu erwarten, daß mindestens in der mittleren Strecke, wo der Ausgleich ausschließlich durch stärkeres Wachstum der inneren Hälfte zustande kommt, diese ihren Dotter fruher verbraucht hat als die äußere. Das trifft nun in ganz überraschender Weise gerade für unseren Fall zu. In der ganzen mittleren Strecke ist die linke (innere) Hälfte des Medullarrohrs fast dotterfrei, während die rechte (äußere) noch reichlich mit Dotterplättchen versehen ist. Der Unterschied läßt sich auch auf den Horizontalschnitten (Abb. 52) nach vorn bis zum Mittelhirn mit größter Deutlichkeit verfolgen. Im vordersten Teil des Hirns haben die beiden Seiten ihren Dotter schon ganz aufgezehrt, so daß nicht mehr festzustellen ist, ob sie gleichzeitig damit fertig geworden sind.

Diese Beobachtung ist auch sonst interessant als ein neuer Beweis dafür, daß stärkeres Wachstum nicht immer eine Folge reichlicherer Nahrungszufuhr ist. Hier, wo beide Hälften die gleiche Menge zur Verfügung hatten, zeigt sich deutlich, daß das Wachstum das primäre ist, nach dem sich der Verbrauch und in späteren Stadien wohl auch die Zufuhr der Nahrung richtet.

Daß sich die Partie um den Urmund anfangs halb entwickelt und. erst später unvollkommen ergänzt, könnte seinen Grund darin haben, daß sie von dem trennenden Schnitt nicht unmittelbar getroffen wird wie die Teile der oberen Urmundlippe, womit der auslösende Reiz für die Ergänzung fehlen würde. Das mag eine Ursache sein, aber schwerlich die einzige oder auch nur hauptsächliche. Jedenfalls träfe sie für den Schwanz nicht zu. Für den wichtigsten Grund möchte ich den halten, daß die Differenzierung in den Urmundlippen weiter vorgeschritten ist als in dem Ektoderm davor und der halben Schwanzknospe dahinter. Für die obere Urmundlippe dieses frühen Stadiums habe ich das durch Transplantation kleinere Stückchen nachgewiesen (1918), für die seitliche Urmundlippe späterer Stadien Lewis (1907); wie sich dieselben Stellen der Randzone zu Beginn der Gastrulation verhalten, wäre noch zu prüfen. 
und lateraler Gastrulahälften von Triton taeniatus und alpestris usw. 157

Mag dem sein wie ihm wolle, jedenfalls stehen wir vor der Tatsache, daß ein halbiertes Organisationszentrum die Bildung einer Medullarplatte induziert, welche um so vollkommener ergänzt ist, je weiter sie sich von dem Zentrum entfernt; also doch wohl, je später sie von der fortschreitenden Differenzierung erreicht wird. Entsprechendes würde für die Schwanzknospe gelten; so würden sich jene häufig beobachteten Fälle erklären, wo die Muskelsegmente der inneren Seite im Schwanz wieder auftreten, während sie im hinteren Teile des Rumpfes fehlen; so auch jene anderen, wo der dorsale Flossensaum im hinteren Teil des Schwanzes dem ventralen gegenüber gestellt ist, während sein vorderer Teil auf die Seite herab rückt. Doch liegen hier die Verhältnisse noch nicht so klar wie beim Rumpf und Kopf.

Diese Fragen werden vielleicht von einer anderen Seite her eine weitere Beleuchtung erfahren. Ich habe vor kurzem (1921, S. 568) mitgeteilt, daß ein kleines Stückchen aus der Mitte der oberen Urmundlippe von Triton cristatus im Ektoderm von Triton taeniatus eine symmetrische Medullarplatte induzieren kann, in deren Medianlinie es dann noch nachzuweisen ist. Daran wurde die weitere Frage geknüpft, wie sich ein seitliches Stückchen der Urmundlippe verhalten würde; ob es wenigstens zunächst die entsprechende Hälfte der Medullarplatte induziert, also nachher auf dieser Seite liegt, oder von Anfang an symmetrisch nach vorn und den Seiten eine ganze Medullarplatte, wonach es dann wieder median liegen müßte. Die Ergebnisse der Experimente, welche über diese Frage im Gang sind, werden vielleicht jene verwickelteren Verhältnisse der $\mathbf{Z}$ willingslarven weiter aufklären.

Trifft die hier vorgetragene Auffassung das Richtige, so würde sie weiter besagen, daß ein eigener Faktor auf die Herstellung der bilateralen Symmetrie hinwirkt, welcher der von hinten nach vorn im Rumpf und von vorn nach hinten im Schwanz fortschreitenden Differenzierung übergeordnet ist. Diese Anschauung wird in jüngster Zeit von $H$. Wilhelmi (1920) mit großem Nachdruck vertreten und ist von ihr zum Ausgangspunkt neuer Experimente gemacht worden.

Die meinen Ausführungen zugrunde gelegte Halbbildung der Achsenorgane tritt im Bereich des Urmunds wohl immer ein, wenn sein Schluß stark verzögert wird und unvollkommen bleibt; bei der scharfen Verkrümmung der Embryonen, die das zur Folge hat, ist es unwahrscheinlich, daß sich der Defekt jemals wieder völlig ausgleicht. Nun kommt es aber auch häufig vor und ist von mir mehrfach erwähnt worden, daß der Defekt von Anfang an geringfügig ist, daß die nur wenig gekrümmten Embryonen sich mehr und mehr strecken und endlich ganz symmetrisch werden. Das ist wohl nur möglich, wenn sich der Urmund rechtzeitig und völlig geschlossen hat. Wie sich die beiden Fälle zu- 
einander verhalten, läßt sich noch nicht mit Sicherheit sagen. Wenn man etwa im Keim der Abb. 19 und 20 (S. 120) oder der Abb. 35 (S. 125) den sekundären Medullarwulst mit der ihm angelagerten Reihe von Urwirbeln über den Dotter weggeschoben denkt bis zur Berührung und Verschmelzung mit dem halben primären Medullarwulst der anderen

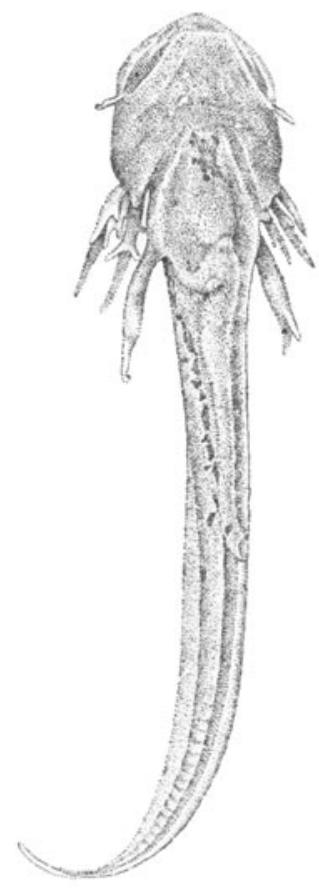

Abb. 75.

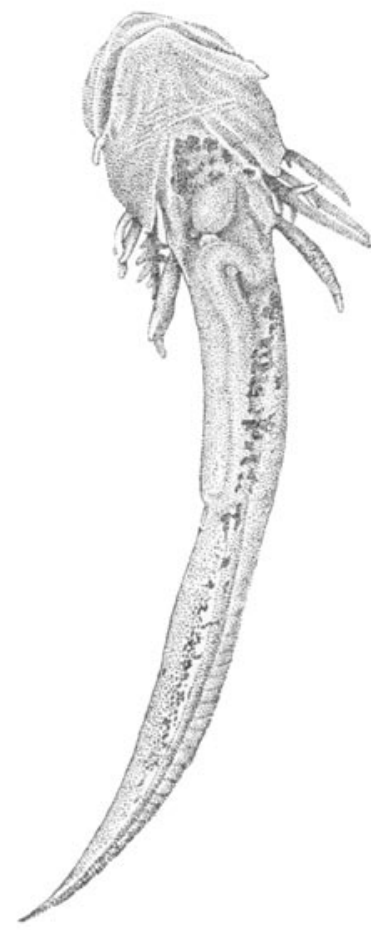

Abb. 76 .

Abb. 75 und 76 . Zwillingslarven von Tritosn tatniatus nach medianer Durchschnirung im Gastrulastadium. Beinchen und Kiemen auf der inneren Seite schwächer entwickelt als auf der auberen; beim linken Zwilling die Einkrümmung der inneren Seite deutlich, beim rechten durch Contraction whrend der Conservierung verdeckt. Situs viscerum des rechten Zwillings invers. Vergr. $\times 20$.

Seite, so erhält man das Bild der Neurula mit normalem Urmundschluß und versteht auch, warum jetzt die Urwirbel der inneren Seite von Anfang an ohne Unterbrechung in ganzer Länge entwickelt sind und wie daraus eine nur mäßig eingekrümmte Larve entstehen kann. Ob diese Vorstellung richtig ist und wie in beiden Fällen das Material der. halben Gastrula zum Aufbau des Keimes verwendet wird, das wird sich durch Implantation von Marken exakt feststellen lassen; ich will daher von der Erörterung von Möglichkeiten absehen. 
und lateraler Gastrulahälften von Triton taeniatus und alpestris usw. 159

\section{Der Situs inversus des rechten Zwillings.}

Die Frage der Inversion des Situs viscerum bei $Z$ willingsbildung gehört zwar nicht mehr zu den Problemen der Regulation und Post. generation, welche uns in dieser Arbeit beschäftigen; doch möchte ich die Gelegenheit benützen, den früher (Spemann-Falkenberg 1919) mitgeteilten Fällen einige weitere hinzuzufügen und zu einer neuen einschlägigen Arbeit von $H$. Wilhelmi (1921) Stellung zu nehmen.

Wie zu erwarten war, hat die spätere Durchtrennung zu Beginn der Gastrulation nicht weniger Erfolg gehabt als die in etwas jüngeren Stadien (an der frühen oder späten Blastula) vorgenommene jener älteren Versuche; es ist bei einer größeren Zahl von Larven Situs inversus aufgetreten. Ein besonders schönes Beispiel (Trit.taen. $R$ 1920, $105 l$ und $r$ ) ist in $\mathrm{Abb} .75$ und 76 dargestellt. Beide $Z$ willingsembryonen zeigen eine deutliche Verkümmerung entgegengesetzter Seiten; auf diesen, zweifellos den innenständigen, sind Rumpf und Schwanz der Länge und der Quere nach eingekrümmt, die Beinchen in Größe und Ausbildungsgrad erheblich hinter denen der anderen Seite zurück. Der nach diesen Kennzeichen linke Embryo hat einen normalen Situs des Darms und des Herzens, der rechte einen ebenso typischen inversen. Das war für den Darm im Leben und nach der Konservierung schon von außen klar zu erkennen (vgl. Abb. 75 und 76); für das Herz konnte es durch Abtragung der Bauchwand deutlich gemacht werden. Außerdem wurde der Situs noch an 7 linken und 8 rechten Embryonen, von denen 6 paarweise zusammen gehören, auf Horizontalschnittserien

Triton taeniatus 1920. Material von G. Ruud.

\begin{tabular}{|c|c|c|c|c|}
\hline \multirow{2}{*}{$\begin{array}{l}\text { Protokoll- } \\
\text { nummer }\end{array}$} & \multicolumn{2}{|c|}{ Linker Zwilling } & \multicolumn{2}{|c|}{ Rechter Zwilling } \\
\hline & Darm & Herz & Darm & Herz \\
\hline 102 & normal & normal & invers & invers \\
\hline 103 & normal & normal & $\begin{array}{c}\text { invers? } \\
\text { (nach Lage des } \\
\text { Pancreas) }\end{array}$ & invers \\
\hline 104 & ?? & normal & $\begin{array}{c}\text { invers } \\
\text { (Leber ziemlich } \\
\text { median, } \\
\text { Gallenblase rechts) }\end{array}$ & normal \\
\hline 105 & normal & normal & invers & invers \\
\hline 110 & normal & normal & ?? & ?? \\
\hline 113 & normal & normal & - & - \\
\hline 115 & - & - & normal & normal \\
\hline 116 & - & - & ?? & invers \\
\hline 118 & normal & normal & invers & invers \\
\hline 121 & normal & normal & abnorm & invers \\
\hline
\end{tabular}


untersucht. In einigen dieser Fälle war er nicht ganz deutlich entschieden normal oder invers, oder ließ sich wegen zu starker Verkrümmung der Larve, die bis zu spiraliger Aufrollung gehen konnte, nur für das Herz oder selbst für dieses nicht mit Sicherheit feststellen. Das Ergebnis ist in vorstehender Tabelle zusammengestellt.

Von 8 linken Zwillingsembryonen war also bei keinem der Situs invers, weder des Darmes noch des Herzens. Von 9 rechten Zwillingsembryonen dagegen war der Situs des Darms bei 2 unklar, bei 1 atypiseh, bei 2 zum Teil invers, bei 3 ganz invers, und nur bei 1 sicher normal; der leichter festzustellende Situs des Herzens bei 1 unklar, bei 2 normal, und bei 5 deutlich invers. Es war also wieder, wie bei jenen früheren Versuchen, etwa die Hälfte der rechten Zwillinge invers.

Zur Erklärung dieser auffallenden Erscheinung führte ich damals zwei Möglichkeiten an, entweder die Inversion einer auch aus anderen Gründen zu fordernden Intimstruktur, oder aber die Verkümmerung der innenständigen Seite. Durch beides würde der eine Embryo das Spiegelbild des anderen. DaB die Inversion nicht immer eintritt, käme im einen Fall daher, daß die Intimstruktur nicht mit Sicherheit invertiert wird, im anderen, daß die Verkrümmung durch eine entgegengesetzte natürliche Krümmungstendenz überboten wird. Eine Entscheidung schien mir nicht möglich, aber die größere Wahrscheinlichkeit für die zweite Annahme zu sprechen.

Diesen beiden Möglichkeiten stellte H. Wilhelmi (1921) eine dritte gegenüber. Auf Grund einiger zufälliger Befunde, die sich ihr bei Schnürversuchen an Triton-Keimen ergaben, bildete sie die Ansicht aus, daß sich in der linken Hälfte dieses Keimes ein "Faktor " befinde, welcher dafür sorge, daß der Situs des Darmes und Herzens sich in der Art asymmetrisch entwickelt, wie wir es normalerweise kennen. Danach würde die Inversion des Situs, welche durch Drehung eines bestimmten Stücks der Rückenplatte erzielt werden kann (Spemann 1906, K. Pressler 1911, R. Meyer 1913) sich daraus erklären, daß durch sie jener Faktor auf die andere Seite gebracht wird; der Situs inversus des rechten Zwillings daraus, daß der rechten Keimhälfte nach $\mathbf{A b}$ trennung der linken jener Faktor ganz fehlt, so daß es dem Zufall überlassen bliebe, ob normaler oder inverser Situs entsteht.

Es kann nur förderlich sein, wenn eine solehe Frage nicht zur Ruhe kommt; doch sollte der Widerspruch zu durchschlagenden Gegengründen oder entscheidenden neuen Experimenten führen, und in dieser Hinsicht scheint mir H. Wilhelmi doch etwas zu anspruchslos. Das gilt zunächst für das Experiment, welches die wertvolle positive Ausbeute ihrer Arbeit darstellt, die künstliche Erzeugung von Situs inversus durch Entfernung eines kleinen linken Stücks des Keimdachs in der frühen Neurula. Ich war selbst zu dem gleichen Versuch durch 
und lateraler Gastrulahälften von Triton taeniatus und alpestris usw. 161

die Überlegung geführt worden, daß auch eine irgendwie anders erzeugte Einkrümmung der linken Seite des Keims Inversion hervorrufen sollte (Spemann-Falkenberg 1919, S. 410), in welcher Utberzeugung ich durch die Versuche ven St. Warynski und $H$. Fol (1884) bestärkt wurde, ferner durch die damals noch nicht veröffentlichten, aber mir bekannten Versuche von Fedorow (Braus 1920). Ein Ergebnis hatte ich in den wenigen Fällen, in welchen ich den Versuch anstellte, nicht. $H$. Wilhelmi war darin glücklicher; sie erzielte in einem Teil der Fälle typischen Situs inversus viscerum et cordis (vgl. ihre Abb. 8 und 9). Sie hatte das gehofft auf Grund ihrer Voraussetzung, welche ihr den Gedanken des Experiments eingab, mit dem Stück jenen "Faktor \& zu entfernen, der die typische Asymmetrie bewirkt, so wie ich es auf Grund meiner Voraussetzung gefordert hatte. Man wird daher nicht erwarten, daß ich in dem Ausfall des Experiments eine Entscheidung der Frage zu gunsten der gegnerischen Ansicht sehe.

Gegen die Wirkung der Verkrümmung macht H. Wilholmi (S. 529) geltend, daß dann die Krümmung, die der Embryo in der zu eng werdenden Eihülle erfährt, ebenfalls Inversion bewirken müsse. Das beruht auf einem völligen Mißverstehen meiner Ansicht. Ich wäre nie auf den Gedanken gekommen, Biegungen des Körpers unter Beanspruchung seiner Elastizität, die jederzeit wieder aufgehoben werden können, dieselbe Wirkung zuzuschreiben, wie einer dauernden Verkrümmung infolge defekter Ausbildung der einen Seite.

Ủbrigens will $H$.Wilhelmi der Verkrümmung nicht jede Wirkung abstreiten; S. 528: "Es ist ja möglich, wenn infolge Fehlens des richtenden Reizes der Zufall über die Richtung der Darmkrümmung entscheidet, daß zufällige Krümmungen des Körpers dieselben beeinflussen. " Dieses Zugeständnis ist jedoch mit dem sonst eingenommenen Standpunkt unverträglich; nach ihm muß die Verkrümmung ganz wirkungslos sein, denn sonst würde sie, da ihr (nach Wilhelmi) in dem symmetrisch gewordenen Keim keine Kräfte entgegen wirken, den Situs ausnahmslos invertieren, nicht nur in einem Teil der Fälle.

Hier, nicht in den Worten "Asymmetriefaktor " and "Krümmungstendenz " liegt der Kernpunkt unserer Differenz. Nach Wilhelmis Ansicht ist erstens der Asymmetriefaktor auf eine eng begrenzte Stelle der linken Seite lokalisiert, und zweitens kann eine Verkrümmung infolge von Defekt keinen Einfluß auf den Situs haben. Meine Hypothese sagt über don ersten dieser beiden Punkte nichts aus. Es könnte eine eng begrenzte Stelle auf der linken Seite der Darmanlage sein, von welcher im gegebenen Augenblick das zur Asymmetrie führende stärkere Wachstum dieser Seite ausgehen würde. Mit der Entfernung dieser Stelle würde aber nach meiner Auffassung nicht nur der Grund für dieses stärkere Wachstum fortfallen, sondern dieses würde in sein 
162 Gudrun Ruud und Hans Spemann: Die Entwicklung isolierter dorsaler

Gegenteil verkehrt. Daß trotzdem normaler Situs entstehen kann, käme dann daher, daß von der rechten Seite aus dieses stärkere Wachstum der linken neu induziert wird, gerade wie es das erstemal, wahrscheinlich auf Grund einer asymmetrischen Intimstruktur, induziert. worden ist. Immerhin ist diese Vorstellung nicht ohne Schwierigkeit; daher ist mir wahrscheinlicher, daß die Krümmungstendenz nicht in einem kleinen Punkt der linken Seite lokalisiert ist, sondern den ganzen Quersehnitt der Darmanlage umfaßt, so daß auch deren rechte Hälfte sie noch hätte, wenn man sie von der linken trennt.

Für meine Auffassung scheint mir auch ein älteres Experiment von mir und $R$. Meyer (1913, S. 92) zu sprechen, bei dem dasselbe Stück der Rückenplatte, welches sonst umgedreht wurde, ganz aus dem Keim entfernt blieb. In diesem Fall entstand immer ein normaler Situs. Der Asymmetriefaktor \& war bei diesem Experiment genau so gut entfernt worden, wie bei dem Defektversuch von $H$. Withelmi; es hätte also auch manchmal Inversion des Situs eintreten müssen. Dagegen war der Defekt nicht einseitig, sondern symmetrisch, also auch keine seitliche Verkrümmung die Folge; daher also wohl das Ausbleiben der Inversion. Das Experiment zeigt weiter, daß auch den übrigen Teilen der Darmanlage eigene Krümmungstendenzen innewohmen, die der Inversion entgegen arbeiten und aktiv überwunden werden müssen. Ich wïßte nicht, was bei dem Defektversuch von $H$. Wilhelmi zu dieser positiven Leistung befähigt sein sollte, wenn nicht eben die durch den Defekt an entscheidender Stelle hervorgerufene Verlsrümmung.

\section{Zusammenfassung der Ergebnisse.}

Keime von Triton taeniatus und alpestris lassen sich zu Beginn und im Verlauf der Gastrulation durch einen aufgelegten, mit Glasreiter beschwerten Glasfaden sehr exakt in jeder gewünschten Richtung fast ohne Zellverlust durchschneiden (S. 101).

Vor der Durchtrennung können kleine Stückchen fremden, dureh die Farbe abstechenden Gewebes an genau bestimmten Stellen zur Einheilung gebracht werden; diese Stückchen lassen sich zusammen mit dem Keim zerschneiden und dann als Marken verwenden (S. 121).

Durch Zerschneidung längs der Eiachse senkrecht zur Medianebene (frontale Durchschneidung) läßt sich die dorsale Keimhälfte von der ventralen abtrennen und auf ihre Regulationsfähigkeit hin prüfen. Es zeigt sich, daß diese zu Beginn der Gastrulation noch ganz oder jedenfalls naheau vollkommen ist (S. 107), daB sie im Lauf der Gastrulation abnimmt (S. 111) und mit ihrem Ende erlischt (S. 110). .Danach scheint die Indifferenz, bzw. die Fähigkeit zur Umdifferenzierung in etwas spätere Stadien hineinzureichen als die Regulationsfähigkeit (S. 112). 
und lateraler Gastrulahälften von Triton taeniatus und alpestris usw. 163

Nach medianer Durchtrennung zu Beginn der Gastrulation grenzen die zuerst verklebten, dann verschmolzenen Ränder der Keimhälften, der dunkeln animalen und der hellen vegetativen, in einer scharfen Linie aneinander. Diese Verwachsungsnaht bleibt noch lange sichtbar und ermöglicht eine Orientierung des Keimes (S. 115). Die zuerst deutlich halbe Urmundlippe dehnt sich allmählich nach beiden Seiten hin aus, nach außen in normaler Weise längs der Randzone, nach innen durch Übergreifen auf die Verwachsungsnaht. Sie rückt über die Dotterzellen vor und diese ihrerseits stülpen sich ein, wobei sie die Verwachsungsnaht mit sich ziehen und einbiegen (S. 116). Der Urmundschluß bleibt sehr häufig unvollkommen.

Wenn die Medullarplatte sichtbar geworden und von Wülsten umgeben ist, zeigt sich die Verkümmerung ihrer inneren Seite in einer Einkrümmung ihrer Medianlinie und einer schwächeren Ausbildung des inneren Medullarwulstes, beides hinten mehr als vorn (S. 119). Hat sich der Urmund nicht vollkommen geschlossen, so geht von dem inneren Medullarwulst, da, wo er auf den Dotter stößt, ein schwächerer Wulst ab, der den Dotter längs der Verwachsungsnaht umzieht (S. 120, 125) und später Medullarrohr und Urwirbel enthält (S. 133 und 134).

Dieses sekundäre Medullarrohr nebst den sekundären Urwirbeln entsteht somit aus Material, welches normalerweise etwas ganz anderes gebildet haben würde. Dagegen entwickelt sich die Hauptplatte im großen und ganzen aus demselben Material, welches sonst die halbe Platte geliefert hätte; im einzelnen aber haben die Teile der letzteren eine durchgreifend andere Verwendung gefunden. Man kann kurz sagen, daß die Medianebene der wirklichen Medullarplatte gegen diejenige der präsumptiven um einen spitzen Winkel nach außen gedreht ist (S. 121). Dieses Ergebnis wird durch die Versuche mit den Implantationsmarken bestätigt (S. 128). Im einzelnen bleibt hier noch manches genauer festzustellen.

Denkt man sich zwei solche Embryonen mit unvollkommen geschlossenem Urmund so zusammengefügt, daß Dotter, primäres und sekundäres Medullarrohr des einen mit denselben Teilen des anderen verschmelzen, so erhält man einen Janus mit defekter Ausbildung des einen (sekundären) Rückens, wie sie häufig durch mediane Einschnürung von TritonEiern entstehen. (S. $135 \mathrm{ff}$.).

Im weiteren Verlauf der Entwicklung wächst der primäre halbe Medullarwulst in eine Schwanzknospe aus, welche in weitgehendem Maße symmetrisch ergänzt ist; der sekundäre Wulst dagegen ist ein rudimentäres Schwänzchen, wohl immer ohne Chorda, mit Bindegewebe und Pigmentzellen (S. $143 \mathrm{ff}$.). Ist der Urmundschluß nur wenig verzögert gewesen, so kann die Anlage dieses sekundären Schwänzchens seitlichen Anschluß an die des primären gewinnen und mit ihm zusammen 
auswachsen; das sekundäre Schwänzchen erscheint dann als seitlicher Flossensaum (S. 149).

Der seitliche Defekt des Schwanzes läßt den dorsalen usu ventralen Flossensaum auf der inneren Schwanzfliche zusammenrücken, oft bis zur Versehmelzung (S. 15lff.). Dann kann sich gegen die Schwanzspitze hin gegenüber dem ventralen Flossensaum ein sekundärer dorsaler erheben (S. 153). Vielleicht hat sich das Material des dorsalen Flossensaums der Länge nach in zwei Hälften gespalten, von denen die eine auf die innere Seite des Schwanzes herabrückt, die andere sich dem ventralen Flossensaum gegenüberstellt. Vielleicht entsteht aber der sekundäre dorsale Flossensaum auch ohne Abspaltung einer besonderen Anlage, gewissermaßen als Gegenstück des ventralen (S. 153).

Bei unvollkommenem Schluß des Urmundes enthält der primäre Wulst, der seinen äußeren Rand bildet, ein Medullarrohr mit deutlichen Spuren der Ergänzung, eine Chorda von rundem Querschnitt, eine Reihe von Muskelsegmenten und einen Vornierengang; er ist also deutlich halb angelegt und erst nachträglich ergänzt worden. Vor und hinter dieser nittleren Strecke treten innere Muskelsegmente auf und ist auch sonst die Ergänzung viel vollkommener durchgeführt; Kopf und Schwanz können fast völlig symmetrisch sein. Da cinmal gebildete Ursegmente nicht auf die andere Seite der Chorda rücken können, wie ihr Fehlen im Gebiet des offenen Urmundes zeigt, so müssen sie im Rumpf und Schwanz gleich auf der inneren Seite entstanden sein; das mesodermale Material muß sich hier von Anfang an anders in Chorda und Urwirbel aufgeteilt haben (S. $155 \mathrm{ff}$ ).

Danach muB auch die Postgeneration in den drei Gebicten zu verschiedener Zeit begonnen und auf verschiedene Weise durchgeführt worden sein; nämlich vorn und hinten schon bei der Determination, in der mittleren Strecke erst nachher, durch stärkeres Wachstum der inneren Hälfte. Das läBt sich noch am verschiedenen Dottergehalt der beiden Hälften ablesen (S. 156).

Die mittlere Strecke des Körpers, im Bereich des verspätet geschlossenen Urmunds, ist deswegen am unvollkommensten ergänzt, weil sie im Augenblick der Durchtrennung schon am weitesten differenziert war; je weiter von dieser Stelle entfernt, wo zu Beginn der Gastrulation das Organisationszentrum lag, um so vollkommener im allgemeinen die Ergänzung. Es sind also diejenigen Teile an vollkommensten ausgeglichen, welche sich am spätesten differenzierten. Danach muß ein von der fortschreitenden Differenzierung unabhängiger Faktor auf Herstellung der bilateralen Symmetrie hinarbeiten, mit um so größerem Erfolge, je längere Zeit ihm zur Auswirkung gelassen ist (S. 157). 
An einer größeren Anzahl von rechten Zwillingen wurde wieder Situs inversus viscerum beobachtet, und zwar wie früher in etwa der Hälfte der Fälle (S. $159 \mathrm{ff}$ ).

\section{Literaturverzeichnis.}

D. Barfurth, 1892, Regeneration. Ergebn. d. Anat. u. Entwicklungsgesch. Bd. 2. - Th. Boveri, 1901. Über die Polarität des Secigeleies. Verb. Phys. Med. Ges. Würzburg, N. F. Bd. 34. - Ders,, 1902. Über mehrpolige Mitosen als Mittel zur Analyse des Zellkerns. Verh. d. Phys. Med. Ges. Würzburg. N. F. Bd. 35, S. 67-90. - Ders., 1907. Zellstudien VI. Die Entwicklung dispermer Seeigeleier. Ein Beitrag zur Befruchtungslehre und zur Theorie des Kerns. Jen. Zeitschr. Naturw. Bd. 43, S. 1-292, - A. Brachet, 1904. Recherches expérimentales sur l'oeuf de Rana fusca. Arch. de Biologie, T. 21, p. 103-160. Ders., 1910. Recherches sur l'influence de la polyspermie expérimentale dans Je developpement de l'oeuf de Rana fusca. Arch. de Zool. expérim., T. 6, p. 1-99. - H. Braus, 1920. Über Cytoarchitektonik des embryonalen Rückenmarkes. Verh. d. Anat. Ges. Jena. Anat. Anz. Bd.53. Ergänzungsband, - H. Driesch, 1905. Altes und Neues zur Entwicklungsphysiologie des jungen Asteridenkeimes. Arch. f. Entw.-Mech. Bd. 20, S. 1-20. - Ders., 1906. Studien zur Entwicklungsphysiologie der Bilateralität. Arch. f. Entw.-Mech. Bd. 2l, S. 756-791. - Ders., 1908. Zur Theorie der organischen Symmetrie. Arch. f. Entw,-Mech. Bd. 26, S. 130-145. - O. Hertwig, 1892. Urmund und Spina bifida. Eine vergleichend morphologiseh-teratologische Studie an mibgebildeten Eroscheiern. Arch. f. mikr. Anat. Bd. 39, $\mathrm{S}, 353 \mathrm{ff} .-A . H e y, 1911$. Uber künstlich erzeugte Janusbildungen von Triton taeniatus. Arch. f. Entw.-Mrech. Bd. 33, S. 117-196. - E. Laqueur, 1909. Über Teilbildungen aus dem Frosehei und ihre Postgeneration.' Arch. f. Entw.-Mech. Bd. 28, S. 327-367. - W. H. Lewis, 1907. Transplantation of the lips of the blastopore in Rana palustris. The Amer. Journ. of Anat. Vol. 7, p. 137-143. - J. F. Me Clendon, 1909. On the totipotence of the first two blastomeres of the frogs egg. The Amer. Naturalist. Vol. 43. - Ders., 1909. The development of isolated blastomeres of the frogs egg. The Amer. Journ. of Anat. Vol. 10, p. 425-430. - O. Mlangold, 1920. Fragen der Regulation und Determination an umgeordneten Furchungsstadien und verschmolzenen Keimen von Triton. Arch. f. Entw.-Mfech. Bd. 47, S. 250-301. - R. Meyer, 1913. Die ursächlichen Beziehungen zwischen dem Situs viscerum und Situs cordis. Arch. E. Entw.-Mech. Bd. 37, S. 85-107. - Moszkowski, 1902. Zur Analysis der Schwerkraftswirkung auf dio Tntwicklung des Froscheies. Arch. f. mikr. Anat. Bd. 61, S, 362. $-K$. Pressler. 1911. Beobachtungen und Versuche über den normalen und inversen situs viscerum et cordis bei Anurenlarven. Arch. f. Entw.-Mech. Bd. 32. - W. Roux, 1895. Gesammelte Abhandlungen über Entwicklungsmechanik der Organismen. Bd. 2. Leipzig bei Engelmann. - J. Runnström, 1914. Analytische Studien über die Seeigelentwicklung. Erste Mitteilung. Arch. f. Entw.-Mcch. Bd.40, S. 525-564. - O. Schultze, 1894. Die künstliche Erzeugung von Doppelbildungen bei Froschlarven mit Hilfe abnormer Gravitationswirkung. Arch. f. Entw.-Mech. Bd. 1, S. 269ff. - H. Spemann, 1901-1903. Entwicklungsphysiologisehe Studien am Triton-Ej, I-III. Arch. f. Entw.-Mech. Bd. 12, 15, 16. -Ders., 1906. Über eine neve Methode der embryonalen Transplantation. Verh. d. D. Zool. Ges. 1906. S. 200. - Ders., 1912. Zur Entwicklung des Wirbeltierauges. Zool. Jahrb., Abt. f. allg. Zool. u. Phys. Bd. 32, s. 1-98. - Ders., 1914. Über verzögerte Kernversorgung von Keimteilen. Verh. D. Zool. Ges. 
Freiburg. - Ders., 1918, Über die Determination der ersten Organanlagen des Amphibienembryos, I-VI. Arch. f. Entw.-Mech. Bd. 43, S. 448-555. Ders., 1919. Experimentelle Forschungen zum Determinations- und Individualitätsproblem. Naturwissenschaften 1919, Heft 32. - Ders, u. H. Falkenberg, 1919. Über asymmetrische Entwicklung und Situs inversus viscerum bei Zwillingen und Doppelbildungen. Arch. f. Entw.-Mech. Bd. 45, S. 371-422. - Ders., 1920. Mikrochirnrgisehe Operationstechnik. Abderhaldens Handbuch der biologischen Arbeitsmethoden. 2. Aufl. - Ders, 1921. Die Erzeugung tierischer Chimären durch heteroplastische embryonale Transplantátion zwischen Triton cristatus und taeniatus. Arch. f. Entw.-Mech. Bd. 48, S. 533-570. - St. Wa. rynski et Hermann Fol, 1884. Recherches expérimentales sur la cause de quelques monstruosités simples et de divers processus embryogéniques. Recueil Zoologi. ques Suisse. T. 1, p. 20-24. - G. Wetzel, 1895. Über die Bedeutung der circulären Furche in der Entwicklung der Schultzeschen Doppelbildungen von Rana fusca. Arch. f, mikr. Anat. Bd. 46. - Ders., 1896. Beitrag zum Studium der künstlichen DoppelmiBbildungen bei Rana fusca. Dissertation Berlin 1896. H. Wilhelmi, 1920. Ein Beitrag zur Theorie der organischen Symmetrie. Arch. f. Fntw.-Mech, Bd, 46, S. 210-258. - Dies., 1921. Experimentelle Untersuchungen über Situs inversus viscerum. Arch. f. Entw.-Mech. Bd, 48, S. 517 bis 532 . 